Portland State University

PDXScholar

Spring 7-23-2015

\title{
Steps Towards Deciphering the Post-Polyketide Synthase Tailoring Steps in the Phoslactomycin Biosynthesis Pathway
}

Patience Marimo

Portland State University

Follow this and additional works at: https://pdxscholar.library.pdx.edu/open_access_etds

Part of the Chemistry Commons

Let us know how access to this document benefits you.

Recommended Citation

Marimo, Patience, "Steps Towards Deciphering the Post-Polyketide Synthase Tailoring Steps in the Phoslactomycin Biosynthesis Pathway" (2015). Dissertations and Theses. Paper 2408.

https://doi.org/10.15760/etd.2405

This Thesis is brought to you for free and open access. It has been accepted for inclusion in Dissertations and Theses by an authorized administrator of PDXScholar. Please contact us if we can make this document more accessible: pdxscholar@pdx.edu. 
Steps Towards Deciphering the Post-Polyketide Synthase Tailoring Steps in the Phoslactomycin Biosynthesis Pathway

by

Patience Marimo

A thesis submitted in partial fulfillment of the requirements for the degree of

\author{
Master of Science \\ in \\ Chemistry
}

Thesis Committee:

Kevin Reynolds, Chair

David Peyton

Niles Lehman

Portland State University

2015 


\begin{abstract}
Phoslactomycins (PLMs) are a group of natural products belonging to a polyketides class. These polyketides are synthesized by sequential reaction catalyzed by a collection of enzymes activities called polyketide synthases. A polyketide is a large class of diverse compounds that are characterized by more than two carbonyl groups connected by single intervening carbon atoms. In other words, a polyketide is a polymer whose monomer is a ketide. The PLMs are also known as phosphazomycins or phospholines. These compounds were isolated based on antifungal and antitumor activities. This array of promising biological activities has stimulated research into the field of PLMs for treatment of various diseases such as aspergillosis. A significant success has been reported in understanding and manipulating PLM biosynthesis. However, its post-polyketide biosynthetic mechanism remains to be elucidated. In this study, we established steps needed to pave the way for the elucidation of the post-polyketide synthase tailoring steps in the phoslactomycin biosynthetic pathway. Various, biological activities of polyketide natural products are often linked with specific structural motifs, biosynthetically introduced after construction of the polyketide core. Therefore, investigation of such "post-polyketide synthase (PKS)" modifications is important, and the accumulated knowledge on these processes can be applied for combinatorial biosynthesis to generate new polyketide derivatives with enhanced biological activity.
\end{abstract}

In this study, the enzymes and genes responsible for the modification of the phoslactomycin moiety have been investigated to verify their functions and to study how 
they are coordinated to achieve the desired phoslactomycin. The proposed modification steps in the PLM biosynthesis pathway involves, $\mathrm{PlmT}_{4}$ a cytochrome P450 monooxygenase, $\mathrm{PlmT}_{5}$, a kinase, and $\mathrm{PlmT}_{8}$ an oxidoreductase. These enzymes were successfully cloned, overexpressed, and purified from an overexpression vector. Mutant strains for two genes plmT4 and plmT8 were either constructed or studied. The function of $\mathrm{PlmT}_{4}$ tailoring enzyme was characterized, by gene disruption and an in vitro enzyme activity assay. The isolation of PLM 1 an intermediate analog from plmT4 mutant strain and the observation of a malonylated PLMs, suggests that the malonyl side chain is introduced during polyketide chain formation These results, will pave the way to delineate the intermediary steps between the PLM PKS product(s) that is released from the PLM PKS and the formation of the final phoslactomycin. 


\section{DEDICATION}

I humbly offer my heartfelt thanks to my family, who taught me to value hard work, humility, and critical thinking, all of which were necessary to persevere through graduate school. Mom, Dad, Pauline, Primrose, Walter, you have been a constant source of love, concern, support and strength all these years and 1 love you all. Lastly, I wish to thank my son, Ariel McWilbes Mbiya for always believing in me, his presence in my life has brought joy and more than I could ever ask for. To him I dedicate this thesis. 


\section{ACKNOWLEDGEMENTS}

I would like to convey my sincere appreciation and gratitude to Dr. Kevin Reynolds for allowing me to work with him and his research, for his patience, and guidance. I thank my fellow labmates in the Karlab Group for the stimulating discussions. I am deeply grateful to the post docs (Dr Wanli Lu and Dr Reddy) for the insightful discussions. Dr. David Peyton and Dr. Niles Lehman deserve special thanks as my thesis committee members. I appreciated the insightful comments and constructive criticisms at various stages in my graduate studies. I thank my husband for his help. I also want to thank my mentors Moreblessing Mhini, Pastor Kadiwa and Mrs Kadiwa, Dr Grace Taruvinga and Lois Kandwe, without their continuous edification, prayers and guidance it would have been impossible for me to finish this work. Many friends helped me stay sane throughout the difficult years in graduate school with their support and care. I greatly value their friendship and I deeply appreciate their belief in me. To IW (PM, PC, MG, AMC, ) and the rest of the warriors, 1 believe you were positioned at the right time in my life, thank you for going an extra mile with me, you are awesome.

I would also like to acknowledge the Portland State University chemistry department for providing me with a truly unique and special place to learn and grow. 


\section{TABLE OF CONTENTS}

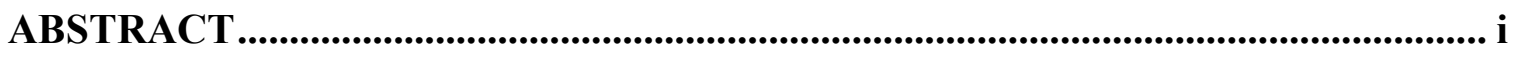

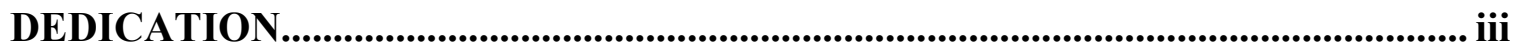

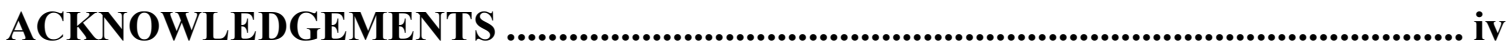

LIST OF TABLES ................................................................................................................... viii

LIST OF FIGURES ............................................................................................................... ix

LIST OF SCHEMES ........................................................................................................... xii

LIST OF ABBREVIATION...................................................................................ii

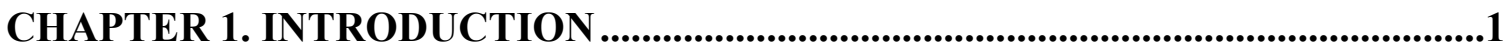

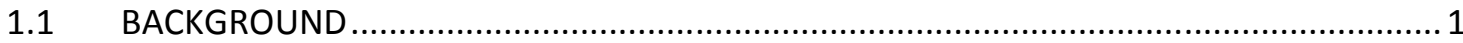

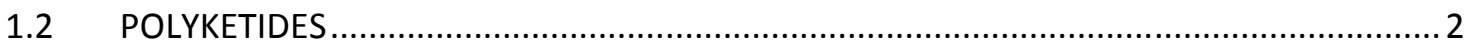

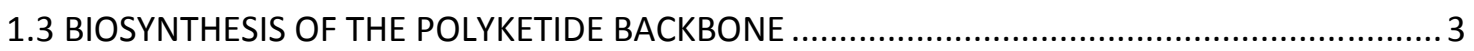

1.4 POST-PKS MODIFICATIONS AND SIGNIFICANCE OF POST-PKS MODIFICATIONS...................5

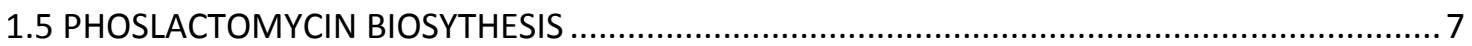

CHAPTER 2. ISOLATION AND PARTIAL CHARACTERIZATION OF PLM 113

2.0 INTRODUCTION ...................................................................................................................13

2.1 MATERIALS AND METHODS.................................................................................15

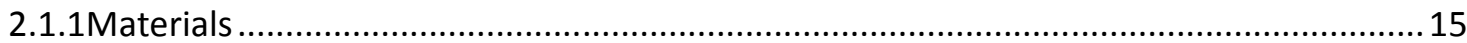

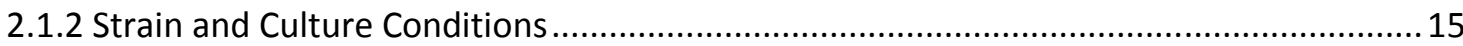

2.1.3 Equipment

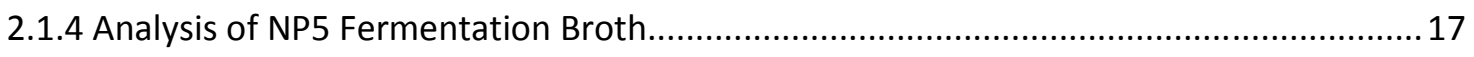

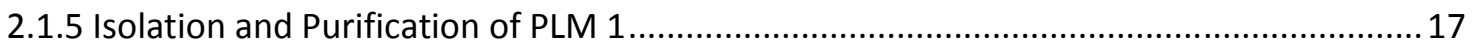

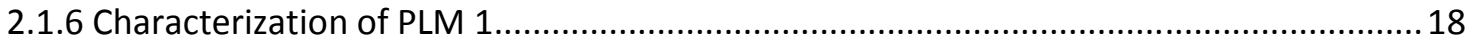

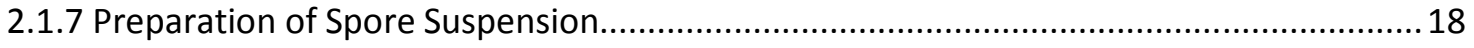

2.2 RESULTS AND DISCUSSION ............................................................................18 


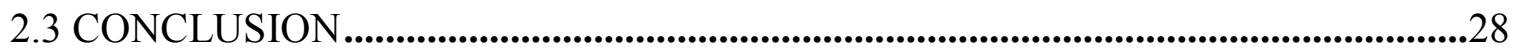

CHAPTER 3. GENERATION OF A BLOCKED PM 1 MUTANT .........................29

3.1 INTRODUCTION ..............................................................................................................29

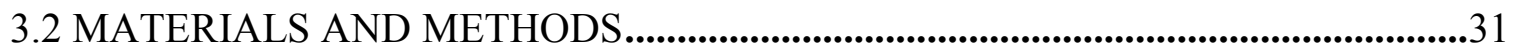

3.2.1 Bacterial Strain, Plasmids and Reagents..................................................................... 31

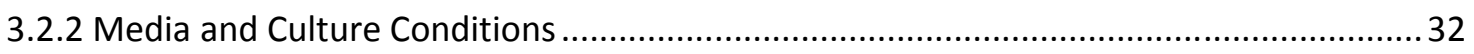

3.3 GENERATION AND ANALYSIS OF PM 1 MUTANT ..........................................32

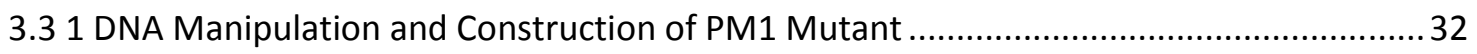

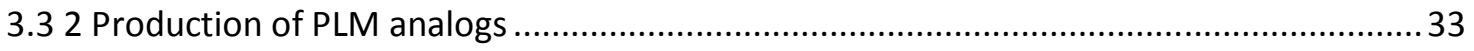

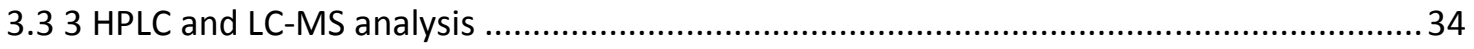

3.4 RESULTS AND DISCUSSION .......................................................................................35

CHAPTER 4. HETEROLOGOUS EXPRESSION OF TAILORING ENZYMES ..42

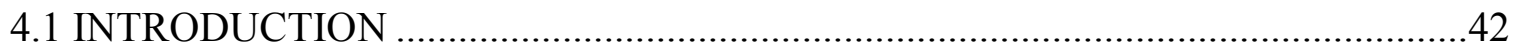

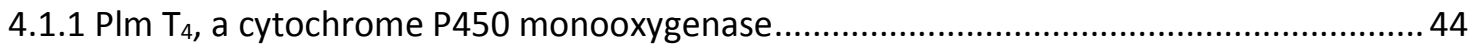

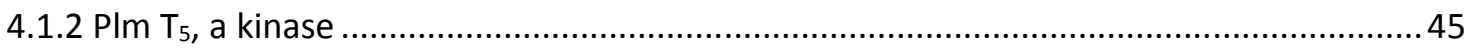

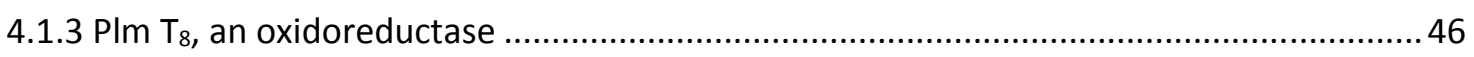

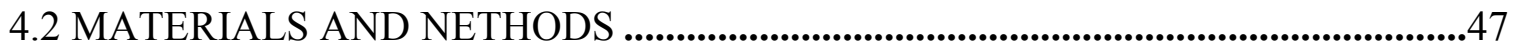

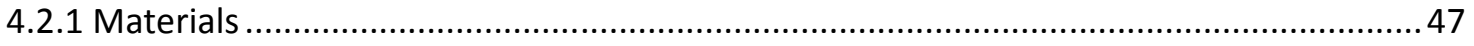

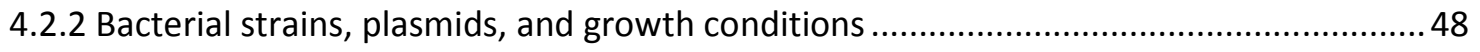

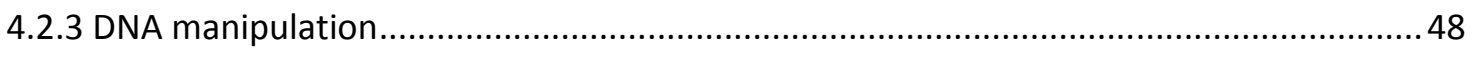

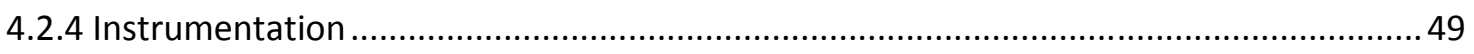

4.2.5 Cloning, Expression and Purification of $\mathrm{PlmT}_{4}$ Protein ................................................ 49

4.2.6 Cloning, Expression and Purification of $\mathrm{PImT}_{5}$ Protein................................................ 50

4.2.8 Cloning, Expression and Purification of $\mathrm{PlmT}_{8}$ Protein.................................................. 52

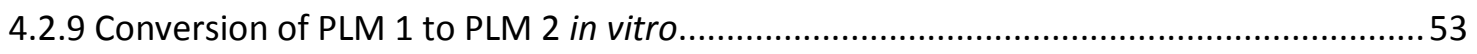


4.3 RESULTS AND DISCUSSION ..........................................................................53

4.3.1 Characterization of the CYP450 in vitro by heterologous expression in E.coli .................53

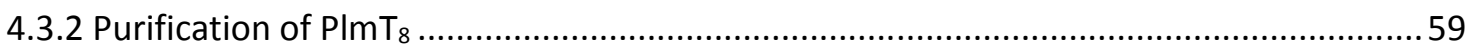

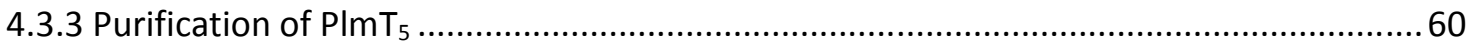

CHAPTER 5. CONCLUSION AND FUTURE DIRECTION ................................63

5.0 CONCLUSION AND RECOMMENDATION FOR FUTURE WORK ...................63

6.0 REFERENCES .....................................................................................67

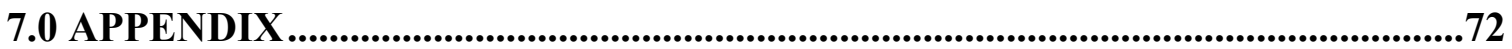




\section{LIST OF TABLES}

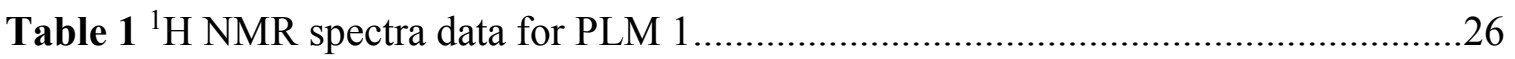

Table 2 Comparison of ${ }^{1}$ H-NMR chemical shifts for PLM 1and PLM B.....................27 


\section{LIST OF FIGURES}

Figure 1. Examples of some commonly used polyketide derived antibiotics

Figure 2. Structural organization of a bacterial type 1 PKS .5

Figure 3. Post-tailoring steps leading to formation of erythromycin .................................6

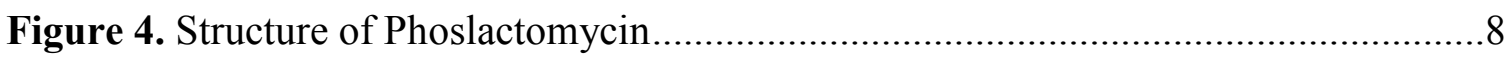

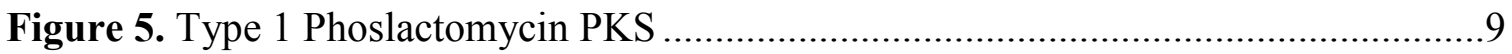

Figure 6. Possible role for $\mathrm{PlmT}_{2}$ in catalyzing a decarboxylative elimination..................9

Figure 7. The last two steps of the phoslactomycin biosynthetic pathway.......................11

Figure 8. The proposed post-polyketide tailoring steps in the phoslactomycin

biosynthetic pathway, studied for this project ……….....................................................12

Figure 9. Proposed ordering of the post PKS tailoring steps in the PLM pathway ..........14

Figure 10. HPLC analysis of fermentation broth of NP5 ...........................................20

Figure 11. Mechanism for decarboxylation of M-PLM 1 to PLM 1 ..............................20

Figure 12. HPLC analysis of purified PLM 1 from fermentation broth of NP5 ..............21

Figure 13. LC-MS analysis of purified PLM 1, m/z 420 and $425 \ldots \ldots \ldots \ldots \ldots \ldots \ldots \ldots \ldots \ldots \ldots \ldots . . .22$ 
Figure 14. Comparison between the acquired mass and predicted mass for PLM 1

Figure 15. $\mathrm{ES}^{+} \mathrm{MS}$ analysis of purified PLM 1, m/z 420

Figure 16. ${ }^{1} \mathrm{H}$ NMR of PLM 1 .25

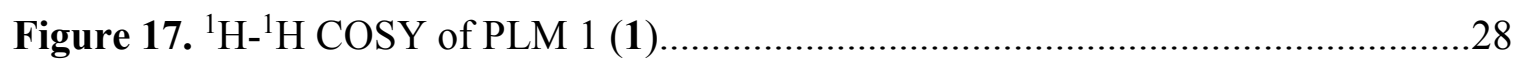

Figure 18. Proposed product of the plmT8 mutant .31

Figure 19. Growth of Streptomyces mutant strain PM1 on SY agar. Colonies appear slightly grayish in color .34

Figure 20. (A) Flow chart of gene disruption by PCR-targeting .36

Figure 21. (A) Apramycin gene aac(3)IV/oriT (red) cassette 37

Figure 22. PCR confirmation analysis .38

Figure 23. LC-MS analysis of purified PM1 broth, m/z 583 40

Figure 24. $\mathrm{ES}^{+} \mathrm{MS}$ analysis of filtered of PM1 fermentation broth, m/z 515, 532 and 537

Figure 25. $\mathrm{ES}^{+} \mathrm{MS}$ analysis of filtered of PM1 fermentation broth, $\mathrm{m} / \mathrm{z} 453$ and $475 \ldots . .41$

Figure 26. (A) SDS-PAGE of purified $\mathrm{PlmT}_{4}$ protein .54

Figure 27. UV-Visible absorption spectrum of purified $\mathrm{PlmT}_{4}$ .55

Figure 28. In vitro conversion of PLM 1 to PLM 2 .56 
Figure 29. $\mathrm{ES}^{+} \mathrm{MS}$ analysis of purified of PLM $1, \mathrm{~m} / \mathrm{z} 425$ and 441

Figure 30. $\mathrm{ES}^{+} \mathrm{MS}$ analysis of PLM 1 conversion reaction, $\mathrm{m} / \mathrm{z} 453$ and $475 \ldots$ .58

Figure 31. $\mathrm{ES}^{+} \mathrm{MS}$ analysis of the enzyme control reaction (without enzyme), m/z 44158

Figure 32. SDS-PAGE of purified Plm $\mathrm{T}_{8}$ protein. .60

Figure 33. SDS-PAGE of purified Plm $\mathrm{T}_{5}$ protein. .62

Figure 34A. Purified $\mathrm{PlmT}_{4}$ protein .72 


\section{LIST OF SCHEMES}

Scheme 1. Proposed ordering of the post-PKS tailoring steps in PLM pathway ..............44

Scheme 2. Proposed PlmT8 reaction...................................................................... 47 


\section{LIST OF ABBREVIATION}

$\begin{array}{ll}\text { Amp } & \text { Ampicillin } \\ \text { Apra } & \text { Apramycin } \\ \text { CoA } & \text { Coenzyme A } \\ \text { COSY } & \text { Correlation spectroscopy } \\ \text { Da } & \text { Dalton } \\ \text { DEBS } & \text { Deoxyerythronolide-B-synthase } \\ \text { IPTG } & \text { Dimethyl sulfoxide } \\ \text { HMSO } & \text { High resolution mass spectrometry } \\ \text { HPLC } & \text { Deoxyribonucleic acid } \\ \text { DNA } & \text { Electrospray ionization } \\ & \\ & \end{array}$




$\begin{array}{ll}\text { LB } & \text { Luria broth } \\ \text { LC-MS } & \text { Liquid chromatography - mass spectrometry } \\ \text { MeOH } & \text { Methanol } \\ \text { min } & \text { Minute } \\ \text { MS } & \text { Mass spectrometry } \\ \text { NMR } & \text { Nuclear magnetic resonance } \\ \text { O.D } & \text { Optical density } \\ \text { PCR } & \text { Polymerase chain reaction } \\ \text { PKS } & \text { Podium docecyl sulphate polyacrylamide gel electrophoresis } \\ & \\ & \end{array}$




\section{CHAPTER 1. INTRODUCTION}

\subsection{BACKGROUND}

The discovery of penicillin in the 1920s followed by its successful application to treat infectious diseases, brought a lot of interest in finding new antibiotics from natural products

1,2. Meaningful progress has been made in both academia and industry leading to the isolation of thousands of novel natural products from a variety of sources including plants, insects, bacteria, fungi, and marine organisms ${ }^{3,4}$. However, serious infections caused by bacteria that have become resistant to commonly used antibiotic have become one of the most serious healthcare problems in the 21 st century ${ }^{1}$. The emerging drug resistant pathogens demands novel antibiotics classes to be developed ${ }^{5}$. Among many natural products, polyketides are not only the most promising ones for developing new antibiotic leads, but also exhibit unusually high therapeutic value ranging from clinical use as anticancer, antiviral, and immunosuppressant drugs $s^{6,7}$. Figure 1 shows a representative of polyketide natural products that possess pharmacologically useful properties and have clinical uses. 


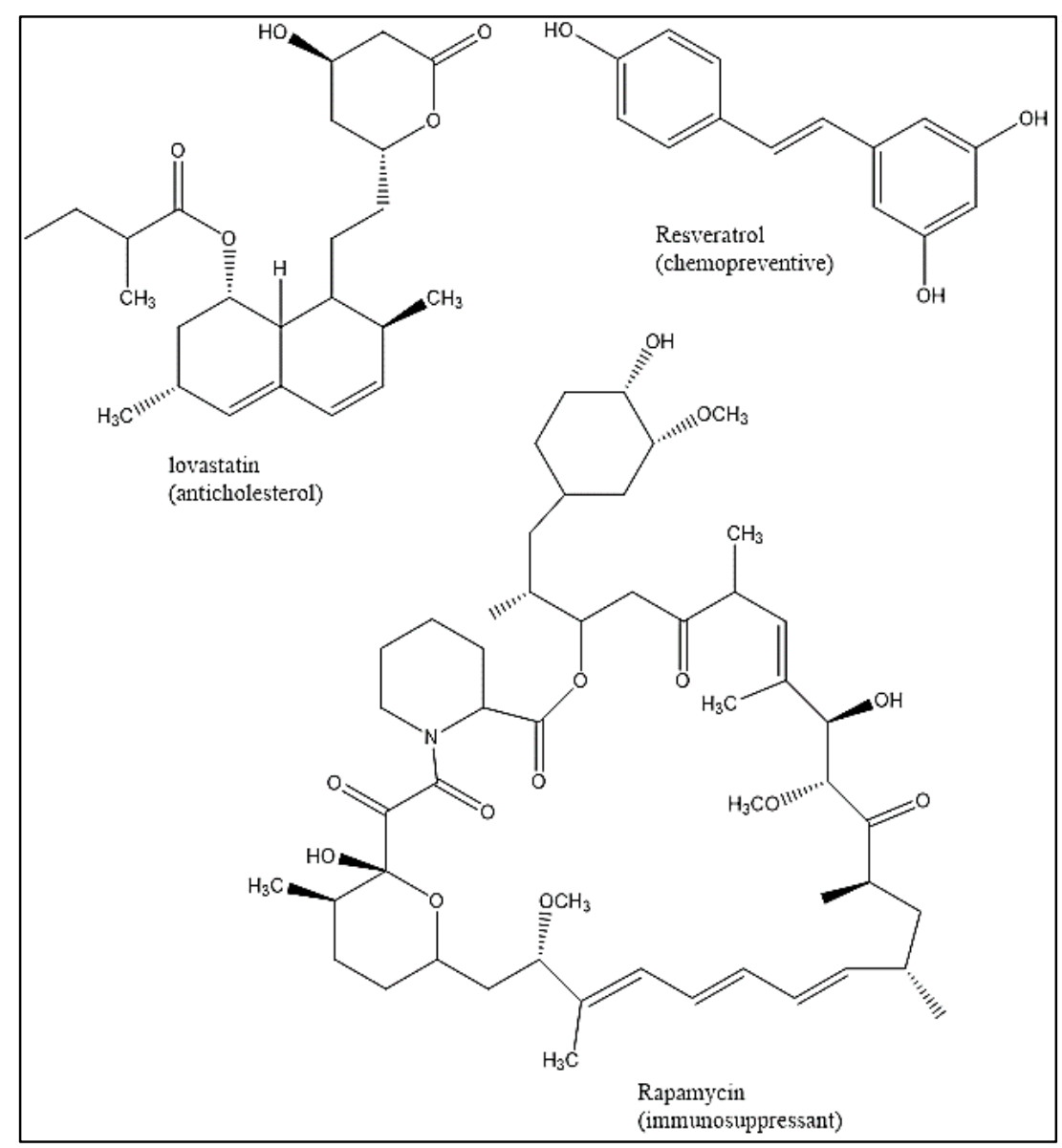

Figure 1. Examples of some commonly used polyketide derived antibiotics

\subsection{POLYKETIDES}

Polyketides, isolated mostly from bacterial and fungal species, comprises one of the most structurally diverse classes of natural products whose scaffolds include macrolides, polyethers, enediynes, polyphenols, and others ${ }^{8,9}$. Polyketides are produced as secondary metabolites and they display a wide range of pharmaceutical properties ${ }^{10}$. Figure 1 shows examples of polyketides that have therapeutic value such as rapamycin, an 
immunosuppressant, lovastatin, a cholesterol lowering agent and resveratrol, a chemopreventive. Since their discovery, a number of polyketides have been clinically approved as drugs, in fact polyketide-derived pharmaceuticals comprise $20 \%$ of the topselling drugs in the world ${ }^{11,12}$. There are 10,000 known natural polyketides, and about $1 \%$ has useful biological activities ${ }^{11}$. There is a tremendous interest in discovering new of polyketide with improved or novel pharmacological properties. Synthetic organic chemistry, molecular genetics and biochemistry are common routes utilized to access or obtain new analogues. However, synthesis of polyketides remains problematic, due to the structural complexity of polyketides with many functional group and stereo chemical centers ${ }^{6}$. Polyketides can also be difficult to isolate naturally since the producing organisms are often hard to culture and produce low yields ${ }^{6,12}$. However, significant advances in microbial genetics and biochemistry during the past decades has permitted a better understanding of the functions of genes involved in polyketide biosynthesis ${ }^{13}$. Understanding the pathway provides the necessary knowledge for manipulating these natural enzyme systems to produce novel metabolites.

\subsection{BIOSYNTHESIS OF THE POLYKETIDE BACKBONE}

Polyketides are assembled by enzymes known as polyketide synthases ${ }^{14}$. Polyketides synthases (PKSs) are currently classified into three broad types based on the protein architecture and biosynthetic schemes ${ }^{14}$. These are type 1 , type 11 and type $111^{15}$. The first reports of bacterial type I PKS was in 1990, for type II PKS was in 1984 and type III PKS in $1999^{16}$. Type I PKS are large multifunctional enzymes, which are organized into 
modules ${ }^{15}$. Modular PKS are demonstrated by 6-deoxyerythromycin B synthase (DEBS) 16 for the biosynthesis of reduced polyketides such as erythromycin as seen in Figure $2{ }^{17}$. Each separate module contains three domains to catalyze one cycle of chain extension, ketosynthase (KS), acyltransferase (AT), and acyl carrier protein (ACP). Some modules carry variable domains, such as ketoreductase (KR), dehydratase (DH) and enoylreductase (ER), which are responsible for keto group modification ${ }^{18}$. Type II PKS are discrete dissociable proteins which only own one enzymatic activity or domain, respectively ${ }^{14}$. The discrete proteins work synergistically and can be used iteratively, thus the final product cannot be predicted. Type III PKS are simple homodimers of ketosynthases which catalyze the condensation of one to several molecules of extender substrate onto a starter substrate iteratively ${ }^{13,18}$. Bacterial and fungal PKS genes have been found to exist as gene clusters ${ }^{19}$. The chemistry associated with PKSs is closely related to that of the well-studied fatty acid synthases (FASs) ${ }^{19}$. Polyketide biosynthesis overlaps with fatty acid synthesis not only in terms of mechanistic details involved in chain elongation process but also in that both the utilize common precursors such as acetyl coenzyme A (CoA), and malonyl CoA ${ }^{20}$. Products synthesized by various types of PKSs can undergo different sets of post-PKS modifications by decorative enzymes encoded in the biosynthetic pathway ${ }^{21,22}$. 


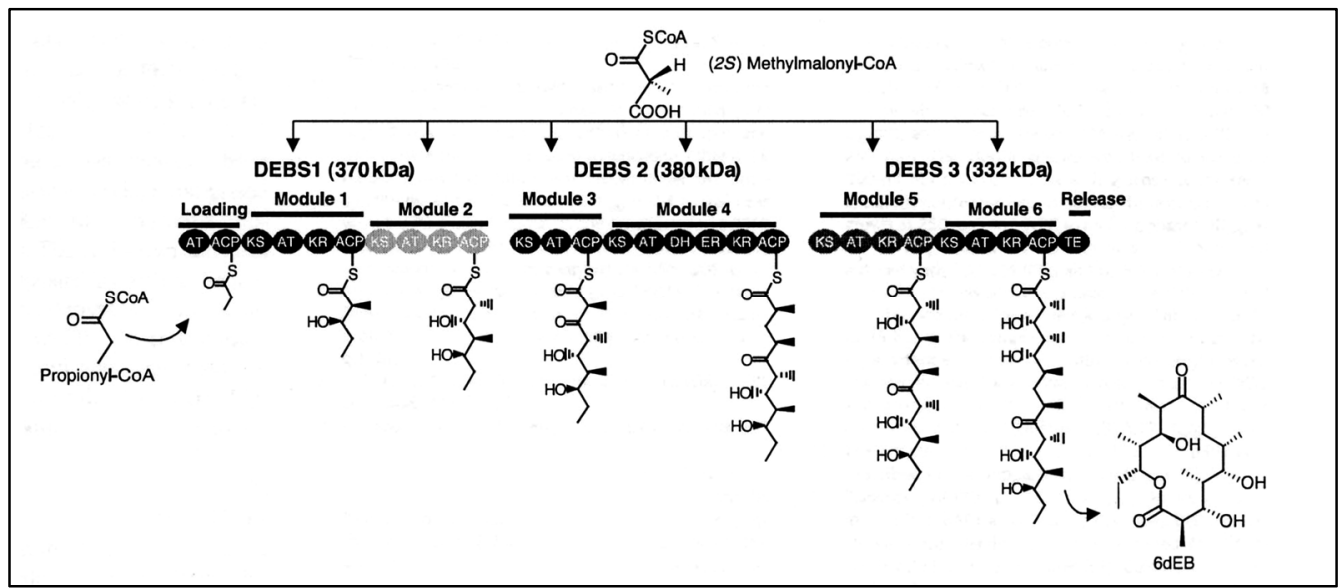

Figure 2. Structural organization of a bacterial type 1 PKS

\subsection{POST-PKS MODIFICATIONS AND SIGNIFICANCE OF POST-PKS MODIFICATIONS}

The formation of a biologically active polyketide requires that fully condensed products of PKS catalyzed reactions usually undergo a series of tailoring events known as post-PKS events such as glycosylation, methylation, oxidation, reduction, and halogenation ${ }^{23}$. Such tailoring can enormously change the pharmacological properties of the parent polyketides, impacting factors such as solubility or receptor binding ability of the modified parent compound $^{24}$. Post-PKS modification has been the subject of intense investigations over the past two decades and proved as a rich source of intriguing and unprecedented enzyme chemistries. As mentioned earlier, these post-PKS events usually result in the conversion of a biologically non-active polyketide into an active product ${ }^{25}$. For example, Figure 3 showing the conversion of inactive 6-deoxyerythronolide B, to potent antibacterial agent, erythromycin A. 
Erythromycin A is synthesized in two phases. ability to manipulate natural.The first phase involves the PKS portion of the molecule, and the second is post polyketide synthase "tailoring". The systems to produce novel metabolites rests largely on increased mechanistic understanding of how these molecules are generated in the first and second phase.

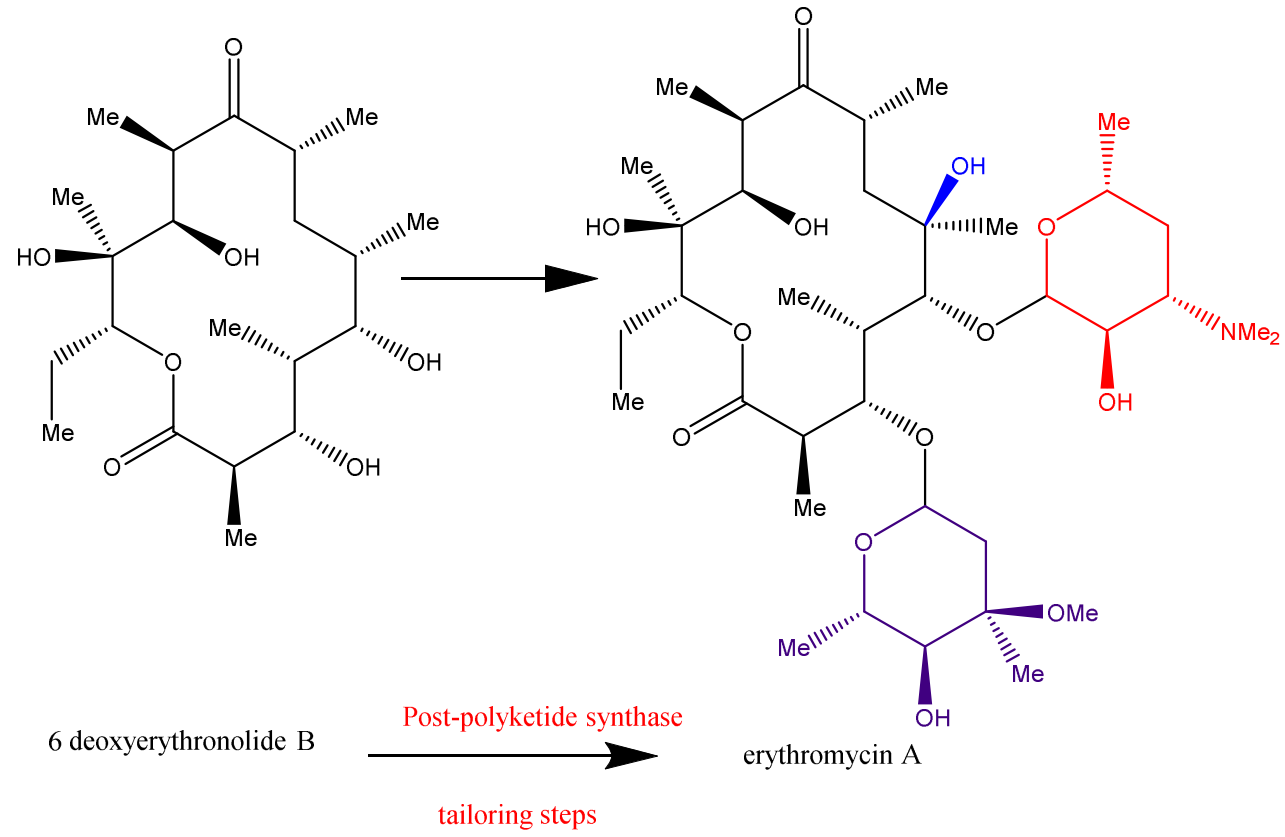

Figure 3. Post-tailoring steps leading to formation of erythromycin

Tailoring enzymes such as oxidoreductases, group transferases, halogenases, and deoxysugar biosynthetic enzymes have been largely used to generate modified polyketides, occasionally with improved pharmacological properties ${ }^{8}$. The overall objective of this work was to focus on initial post-PKS modifications involved in the biosynthesis of phoslactomycin polyketide. 


\subsection{PHOSLACTOMYCIN BIOSYTHESIS}

Phoslactomycins (PLMs) are polyketide natural products and are produced by several Streptomyces species. Streptomyces sp. HK803 is reported to produce six analogues of phoslactomycin (Plm A through F), shown in Figure $4{ }^{23}$. PLMs were isolated based on their potent antifungal activities. The protein phosphatase 2A (PP2A) inhibition is believed to be the mechanism of action and the basis for this antifungal activity ${ }^{26}$. A significant success has been reported in understanding and manipulating PLM biosynthesis. The biosynthesis of PLMs is catalyzed by modular polyketide synthase as shown in Figure 5. It has been reported and verified that it uses cyclohexanecarboxylic acid (CHC) as a starter unit $^{27}$. However, some of the biosynthesis steps of the post-polyketide synthase tailoring steps of PLMs remain to be elucidated.

The gene cluster for phoslactomycin has been cloned and characterized. The sequence analysis revealed a $75 \mathrm{~kb}$ region containing 29 open reading frames that appear to be associated with PLM biosynthesis ${ }^{28}$. Enzymes proposed to be involved in post polyketide modification studied so far are, $\mathrm{PlmT}_{2}, \mathrm{PlmS}_{3}$ and $\mathrm{PlmS}_{2}$. This work has led to the discoveries that the $\Delta^{2,3}$ double bond of the unsaturated lactone is established by a post tailoring enzyme $\operatorname{PlmT}_{2}{ }^{21}$. This is because the mutant strain named NP7 (plmT2 $\left.\Delta p \operatorname{lmS} 2\right)$ was shown to produce C-3 malonylated PLM B (M-PLM B) The enzyme PlmT 2 is thought to catalyze an unprecedented decarboxylative elimination reaction in the PLM intermediate with a malonylated group at $\mathrm{C}-3$ as shown in Figure 6 , even though up to this date it remains to be determined at which stage the decarboxylation occurs ${ }^{21}$. This observation 
demonstrates that all modification steps which occur to the PLM core structure can occur with a C-3 malonyl ester. Thus it is possible to observe malonylation as we study the post polyketide synthase -tailoring steps in the PLM biosynthetic pathway.

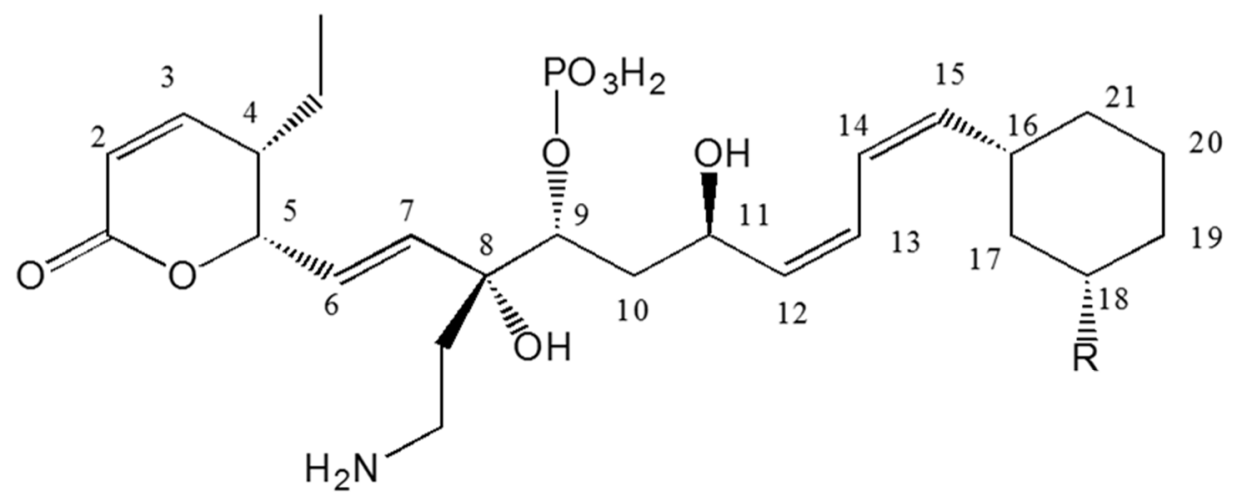

Phoslactomycins (PLMs)

PLM A R $=\mathrm{OCOCH}\left(\mathrm{CH}_{3}\right)_{2} \quad \mathrm{PLM} \mathrm{B} \mathrm{R}=\mathrm{H}$

PLM C R $=\mathrm{OCOCH}_{2} \mathrm{CH}\left(\mathrm{CH}_{3}\right)_{2}$

PLM D R $=\mathrm{OCOCH}_{2} \mathrm{CH}_{2} \mathrm{CH}_{2}\left(\mathrm{CH}_{3}\right)_{2}$

$\mathrm{PLM}$ E R $=\mathrm{OCOC}_{6} \mathrm{H}_{11}$ (cyclohexane)

PLM F R $=\mathrm{OCO}\left(\mathrm{CH}_{2}\right)_{2} \mathrm{CH}\left(\mathrm{CH}_{3}\right) \mathrm{CH}_{2} \mathrm{CH}_{3}$

Figure 4. Structure of Phoslactomycin 


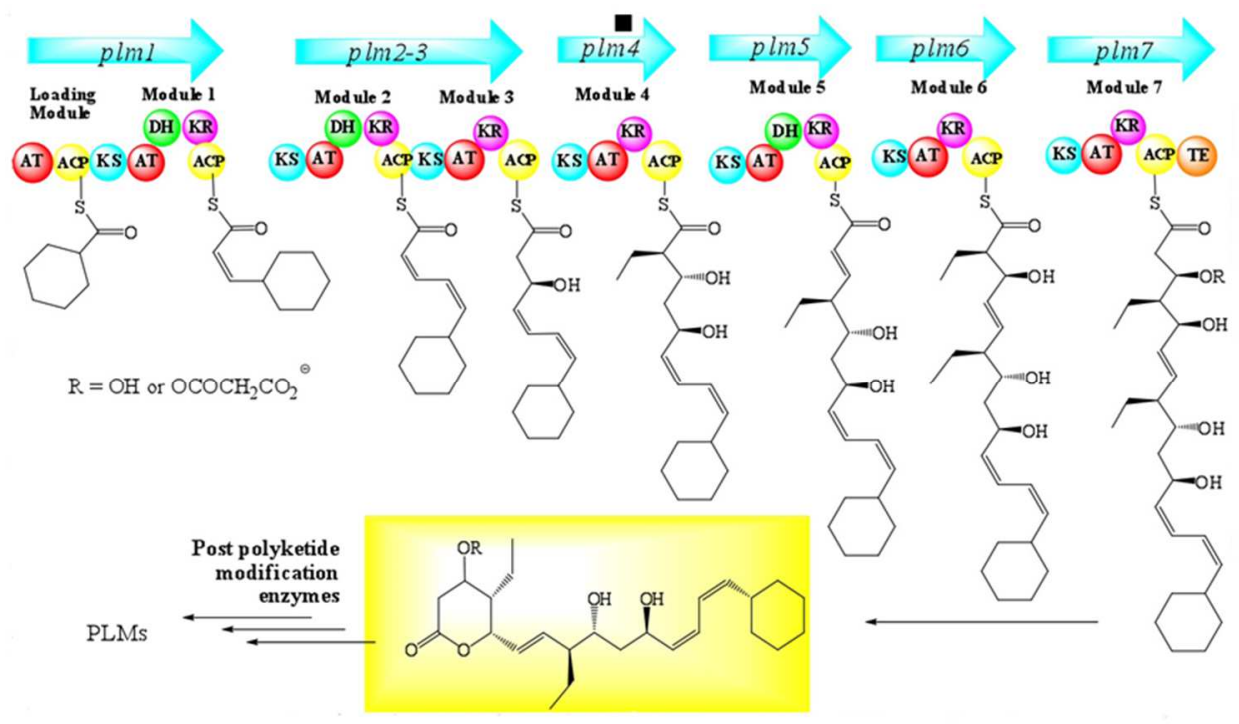

Figure 5. Type 1 Phoslactomycin PKS

M-PLM B

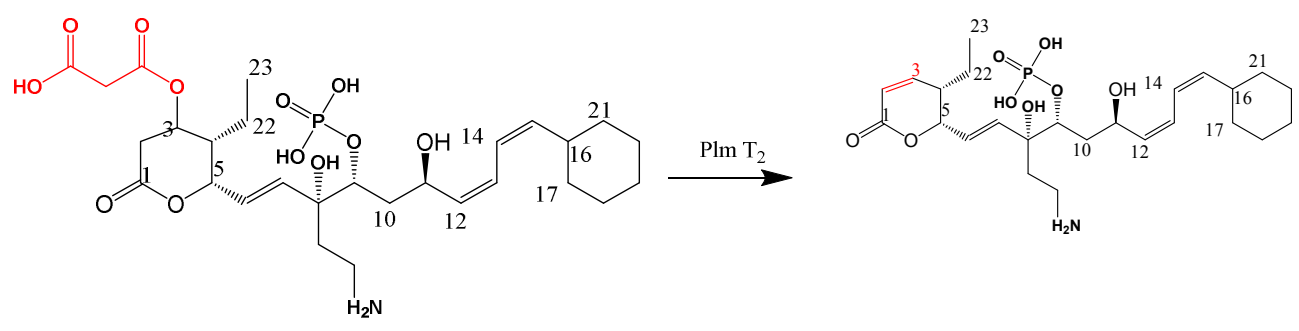

Figure 6. Possible role for $\mathrm{PlmT}_{2}$ in catalyzing a decarboxylative elimination

Studies on the biosynthetic pathway of Streptomyces pulveraceus which produces fostriecin antibiotics which are structurally related to PLMs also indicated that malonylated 
polyketide formation could be a normal biosynthetic process in the formation of unsaturated lactone in fostriecin ${ }^{25}$. Studies on other post-polyketide synthase tailoring enzymes involved in the PLM pathway, $\mathrm{PlmS}_{2}$ and $\mathrm{PlmS}_{3}$ also revealed some information regarding post polyketide synthase tailoring steps. A mutant strain of the gene, plmS2, resulted in a mutant (NP2) that only produced PLM B ${ }^{29}$. Additionally, the plmS2 open reading frame (ORF) was expressed as an N-terminally polyhistidine-tagged protein in Streptomyces coelicolor and the purified protein has been shown to catalyze conversion of PLM B to PLM G as shown in Figure $7^{29}$. Data obtained demonstrated that PlmS 2 , a cytochrome P-450 monooxygenase (CYPs), is responsible for catalyzing hydroxylation at C-18 of the PLM B as shown in Figure 7. F). The plmS3 gene was identified as the acyltransferase responsible for C-18 acylation of PLM $\mathrm{G}^{13}$. This was confirmed by generation of a plmS3 deletion mutant that resulted in selective production of PLM G, supporting the proposed role of this gene product. The 921-bp plmS3 ORF was cloned and expressed as an N-terminally polyhistidine-tagged protein in E.coli, and the recombinant purified protein was shown to catalyze acylation of PLM G with isobutyryl-CoA, 3methylbutyryl-CoA and cyclohexyl-carbonyl-CoA to give PLM A, PLM C and PLM E respectively, also confirming the role of $p \operatorname{lmS} 3$ gene product ${ }^{13}$.

This work will focus on studying other post-polyketide synthase tailoring genes, plmT4 (cytochrome P450 monooxygenase), plmT5 (a kinase), and $\operatorname{plm} T 8$ (oxidoreductase). Figure 9 shows the focus for this work, it is noteworthy that the introduction of amine precedes a reaction by an oxidoreductase, to form an aldehyde that will then be converted to an amine 
by a proposed aminotransferase PlmT1. This project will pave the way towards deciphering the post polyketide synthase tailoring steps in the phoslactomycin biosynthesis pathway.

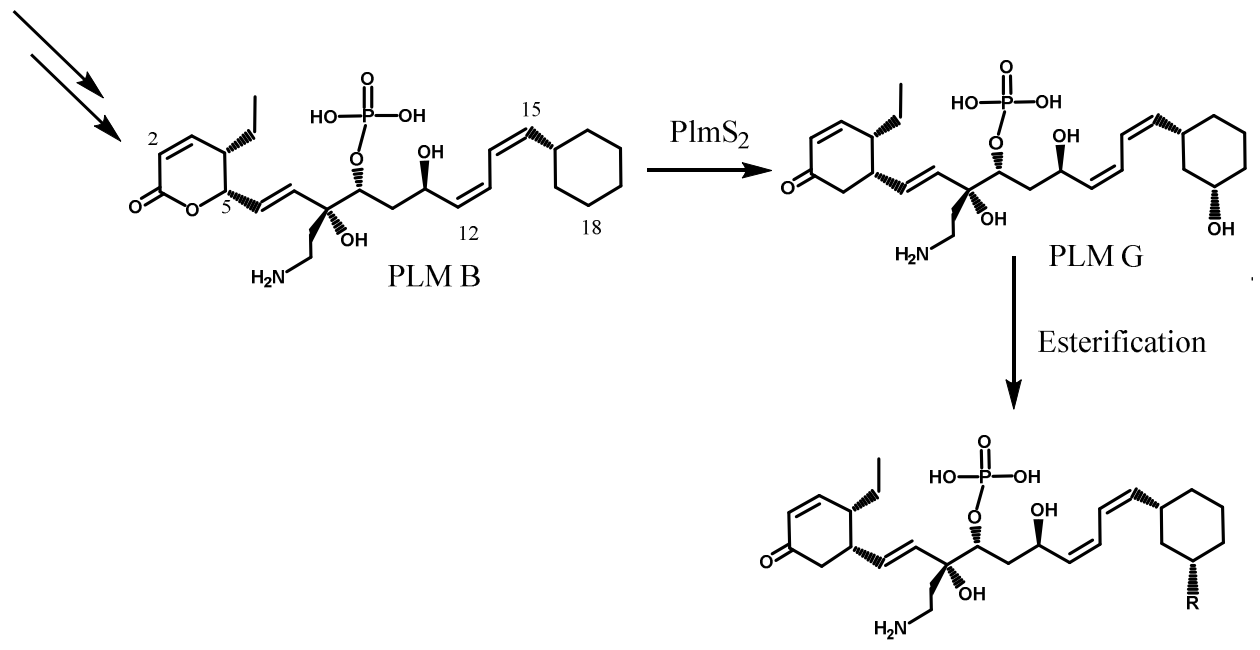

Figure 7. The last two steps of the phoslactomycin biosynthetic pathway 


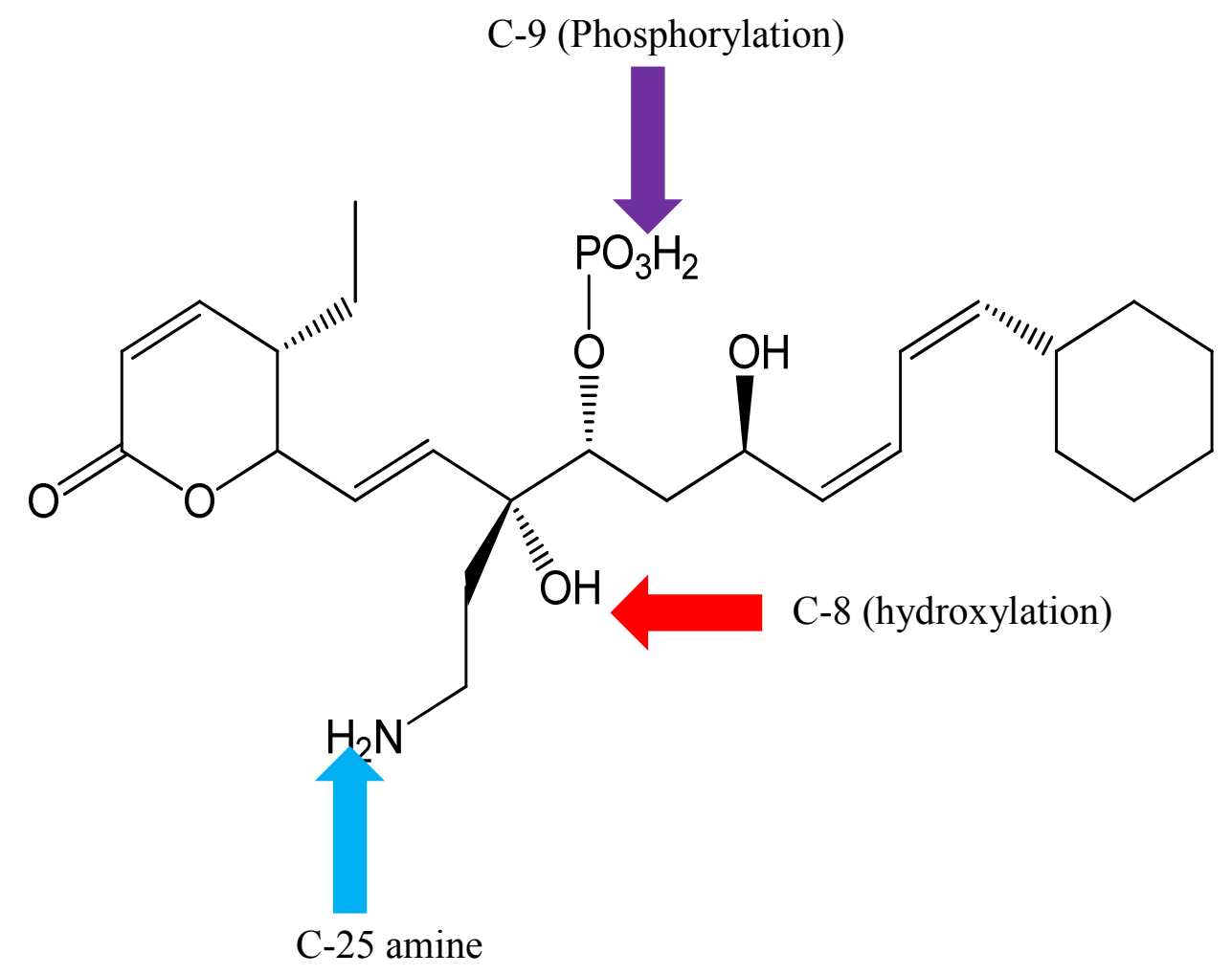

Figure 8. The proposed post-polyketide tailoring steps in the phoslactomycin biosynthetic pathway, studied for this project 


\section{CHAPTER 2. ISOLATION AND PARTIAL CHARACTERIZATION OF PLM 1}

\subsection{INTRODUCTION}

In nature phoslactomycins are synthesized by modular PLM polyketide synthases and then modified by post-PKS enzymes ${ }^{28,29}$. As mentioned earlier, the PLM gene cluster has been cloned and on the basis of predicted functions for each post-PKS gene inferred from sequence similarities, it was proposed that the post tailoring steps of the phoslactomycin biosynthesis pathway follow the pathway shown in Figure 9, but confirmation of the proposed pathway is unknown ${ }^{28}$. In order to pave the way for the elucidation of the ordering steps of the post-polyketide synthase tailoring steps in the phoslactomycins pathway, we decided to study the functional role of the first proposed gene involved in the postpolyketide synthase tailoring steps in vivo.

Targeted gene replacement of post-PKS genes, provides a very useful tool for elucidation of the biosynthetic pathway, by analysis of accumulated intermediates or shunt products. Acquired knowledge from isolating and characterizing pathway intermediates can also be used in context of combinatorial biosynthesis to generate new unnatural natural products with potentially higher or altered biological activities ${ }^{30}$. A good example is the CYP450 monooxygenase EpoK that catalyzes the final epoxidation step in epothilone A and B biosynthesis. Upon deletion of epoK, the resulting mutant stain accumulates epothilones $\mathrm{C}$ and D with epothilone D being most valuable antitumor due to increased therapeutic index ${ }^{31}$. It is possible that the opposite phenomenon can be observed, for example 
biosynthesis gene inactivation in mithramycin, where gene inactivation led to the production of biologically inactive precursor premithramycin ${ }^{32}$.

This chapter describes the isolation and partial structural elucidation of a new phoslactomycin intermediate (PLM 1) isolated from the culture broth of a plmT4 gene replacement mutant strain (named NP5) made from a mutant strain named NP2 (plmS2 gene replacement mutant) a PLM B producing $\operatorname{strain}^{29}$. We report that in vivo plmT4 gene replacement leads to the accumulation of PLM 1, the earliest intermediate released from the phoslactomycin biosynthesis assembly line, supporting the proposed pathway in Figure 9. PLM 1 was purified from various fractions by reverse phase HPLC to yield $0.12 \mathrm{mg}$ $1 \mathrm{mg}$ and was partially characterized using a combination of spectroscopic analyses (MS, LC-MS and NMR) and the data obtained was consisted with the formation of the predicted PLM 1 compound.

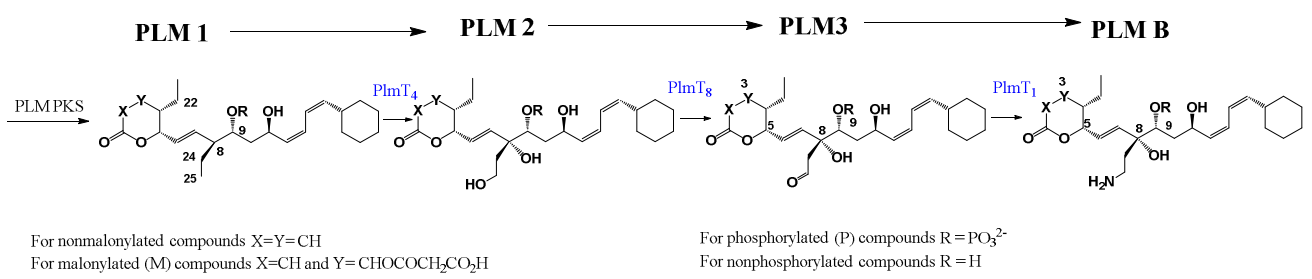

Figure 9. Proposed ordering of the post PKS tailoring steps in the PLM pathway 


\subsection{MATERIALS AND METHODS}

\subsubsection{Materials}

All chemicals and solvents were purchased from Sigma or Fisher and were of highest grade. Yeast extract, $\mathrm{N}-\mathrm{Z}$ amine type A and beef extract were obtained from Difco. Yeast was generously given as a gift from Eli Lilly Scientific. Luria-Bertani (LB) capsules were purchased from Research Products International.

\subsubsection{Strain and Culture Conditions}

The NP2 mutant ( $\Delta$ plmS2, the control used as wild type) and the NP5 ( $\Delta$ plmT4 $\Delta p \operatorname{lmS} 2)$ mutants were generated by Nadaraj Palaniappan using a gene deletion method. The strain was maintained on SY agar (1.0\% soluble starch, $0.1 \%$ yeast extract, $0.1 \% \mathrm{~N}, \mathrm{Z}$ Amine type A, ( $\mathrm{pH} 7.0)$ for 7-14 days until the colonies appeared grayish in color. A seed culture was then prepared by inoculating $50 \mathrm{~mL}$ of seed medium $(3.0 \%$ soluble starch, $1.0 \%$ dried yeast, $0.3 \% \mathrm{NaCl}, 0.3 \% \mathrm{CaCO}, \mathrm{pH} 7.0$ ) in a $500 \mathrm{~mL}$ baffled flask with a loopful of spores. This culture was incubated at $28^{\circ} \mathrm{C}$ in the dark with shaking at $170 \mathrm{rpm}$ for $48 \mathrm{hrs}$. A second culture was then started using $1-1.5 \mathrm{~mL}$ of the seed culture in $70 \mathrm{~mL}$ of production medium (3.0\% soluble starch, $1.0 \%$ dried yeast, $0.3 \% \mathrm{NaCl}, 0.1 \%$ meat extract, $0.3 \% \mathrm{CaCO} 3, \mathrm{pH}$ 7.0) in a $500 \mathrm{~mL}$ baffled flask and was incubated for 96 hours at $28^{\circ} \mathrm{C}$ in the dark with shaking at $170 \mathrm{rpm}$. To enhance production of naturally occurring PLMs or promote the production of novel compounds, the carboxylic acid form of the corresponding starter units 
(cyclohexanecarboxylic acid 8-10mg per day )was dissolved in ethanol and were added to the production medium in four equal portions at $0,24,48$ and 72 hours. At the end of the fermentation period, the mycelia were removed by centrifugation and the supernatant was subjected to further analysis and purification.

\subsubsection{Equipment}

Analytical and semi-preparative HPLC were performed using an Agilent 1100 HPLC system connected to a diode array detector. Samples were injected onto a $5 \mu \mathrm{m}$ Discovery HS C18 reverse phase column $(4.6$ x $250 \mathrm{~mm}$, Supelco, Belefonte, PA) using a linear gradient from $0 \%$ to $60 \%$ between solvent A (acetonitrile: water; $20: 80$ with $0.05 \%$ formic acid) and solvent B (acetonitrile: water; 80:20 with $0.05 \%$ formic acid) over 40 minutes at a flow rate of $1.0 \mathrm{ml} / \mathrm{min}$ and detected at $235 \mathrm{~nm}$. Semi-preparative HPLC was performed using a $5 \mu \mathrm{m}$ Phenomenex C18 column $(10.0 \times 250 \mathrm{~mm})$ under the same conditions except with a flow rate of $3.0 \mathrm{ml} / \mathrm{min}$. Preparative HPLC was conducted with an Ascentis C18 preparative column (Supelco, Belefonte, PA). Mass spectrometric analysis was carried out with a mass spectrometer (Bruker, Billerica, MA) utilizing electrospray ionization (ESI). 4.0. LC-MS analysis was carried out using a linear gradient between solvent A (100\% water, $0.1 \%$ formic acid) and solvent B (acetonitrile, $0.1 \%$ formic acid) from 20 to $60 \%$ over 30 minutes at a flow rate of $0.3 \mathrm{ml} / \mathrm{min}$ using an Agilent 1200 series HPLC equipped with an autosampler. The column used was a $5 \mu \mathrm{m}$ Discovery HS C18 reverse phase column $(2.1 \times 250 \mathrm{~mm})$. All constant temperature incubations were done using an Innova 44 incubator $\left( \pm 0.5^{\circ} \mathrm{C}\right.$, New Brunswick Scientific, Edison, NJ). 


\subsubsection{Analysis of NP5 Fermentation Broth}

To verify the presence of PLM products in the supernatant after fermentation, the fermentation broth was centrifuged and filtered ( $0.2 \mu \mathrm{L}$ PTFE filter, Millipore Corp, MA). $500 \mu \mathrm{L}$ of filtered broth was analyzed by analytical HPLC and PLM products were identified based on known retention times. The broth was injected onto a $5 \mu \mathrm{M}$ Discovery HS C18 reverse phase column (4.6 x $250 \mathrm{~mm}$, Supelco, Belefonte, PA) using a linear gradient described above and UV detection at $235 \mathrm{~nm}$.

\subsubsection{Isolation and Purification of PLM 1}

Once production was confirmed, PLM products were extracted using XAD4 hydrophobic resin. The resin was first prepared by soaking in methanol overnight followed by a series of rinses with DI water. Approximately $300 \mathrm{~mL}$ of broth was applied to $100 \mathrm{~mL}$ of resin slurry and incubated with stirring at room temperature for 1 hour. The mixture was applied to a $250 \mathrm{~mL}$ column and the run through was discarded. After washing the column with $1 \mathrm{~L}$ of DI water, the PLM products were eluted using $300 \mathrm{~mL}$ of methanol. The eluent, containing the active component was concentrated to dryness to give a brown residue. The residue was suspended in 10mL of methanol: water; 40:60 and filtered. This crude extract was purified by preparative or semi-preparative HPLC. Peaks corresponding to the various PLMs were collected and evaporated to dryness. 


\subsubsection{Characterization of PLM 1}

The identity and purity of the isolated compound was confirmed by HPLC, LC-MS, MS.

${ }^{1} \mathrm{H}$ NMR was obtained for the isolated compound, to aid in the identification of the compound isolated proposed to be PLM 1. MS $m / z 420\left[\mathrm{M}+\mathrm{NH}_{4}\right]^{+}$and $425[\mathrm{M}+\mathrm{Na}]^{+}$. The data for ${ }^{1} \mathrm{H}$ NMR (chemical shifts and peaks) and for ${ }^{1} \mathrm{H}-{ }^{1} \mathrm{HCOSY}$ is shown in Figure 9 and Figure 10 respectively.

\subsubsection{Preparation of Spore Suspension}

Spore suspension were prepared in $20 \%$ glycerol or 2 YT media to maintain the NP5 strain . The bacteria was allowed to grow and sporulate on SY agar for 14 days . $5 \mathrm{~mL}$ of water or 2 YT media was added to each plate. Using an inoculating loop, the spores were scraped off the plate and into suspension. The spore suspension was transferred using a biosterile pipette into a sterile tube with glycerol and stored at $-80^{\circ} \mathrm{C}$

\subsection{RESULTS AND DISCUSSION}

Analysis of the PLM biosynthetic gene cluster indicated that there are three steps of hydroxylation ( at C-8,C-18 and C-25) after the polyketide chain is released that likely involve the plmT4 and plmS2 genes, which encode proteins highly homologous to the cytochrome $\mathrm{P} 450$ monooxygenase. $\mathrm{PlmS}_{2}$ is responsible for catalyzing hydroxylation at C18 and hydroxylation at C-8 and C-25 are most likely catalyzed by $\mathrm{PlmT}_{4}$. To better understand the role of plmT4 gene in the PLM biosynthesis, the plmT4 gene was disrupted 
(by a previous member of the group, Nadaraj Palaniappan) to block hydroxylation in the biosynthesis pathway. Using the fermentation and isolation method, the mutant strain, NP5 $(\Delta p \operatorname{lm} T 4 \Delta p \operatorname{lm} S 2)$ was fermented along with the control NP2 ( $\Delta p \operatorname{lm} S 2)$, a PLM B producing strain. Gene disruption of one of the tailoring enzymes, plmT4, not only results in the abolishment of the biosynthesis of PLM B, but also allows the accumulation of two intermediates, M-PLM1 and PLM 1 as shown in Figure 10. HPLC analyses of the fermentation broth of this mutant reveled that as days increased, the M-PLM 1 disappeared and after four days only PLM-1 was observed as shown in Figure 10 (A, B and C). The malonylated lactone M-PLM 1 is unstable and undergoes decarboxylative elimination to give the corresponding PLM 1 as shown in Figure 11. PLM 1 was purified and identified using HPLC, MS and LC-MS spectroscopic analysis. HPLC and LC-MS analysis of the purified compound revealed a peak eluting 25.7 min (Figure 12 and Figure 13 ) also consistent with the correct mass of PLM $1\left(\left[\mathrm{M}+\mathrm{NH}_{4}\right]^{+}\right)=420$ and $\left.\left([\mathrm{M}+\mathrm{Na}]^{+}\right)=425\right)$. Comparison between the acquired mass and predicted mass for PLM 1 is as shown in Figure 14. The difference between the mass acquired for PLM 1, and the mass of the predicted molecular formula is only $\mathrm{m} / z$ 0.1505. A high resolution MS measurement for the compound was also consistent with a formula $\mathrm{C}_{25} \mathrm{H}_{38} \mathrm{O}_{4}$ for $\mathrm{m} / \mathrm{z} 420\left(\left[\mathrm{M}+\mathrm{NH}_{4}\right]^{+}\right)$as shown in Figure 15. The results suggests that hydroxylation at C-8 and C-25 are the first steps in the process and catalyzed by the cytochrome P450 monooxygenase, encoded by plmT4. The formation of M-PLM1 from the mutant suggest that malonylation process must be occurring at an early stage, most likely preceding the release of the full length polyketide intermediate from PLM-PKS 


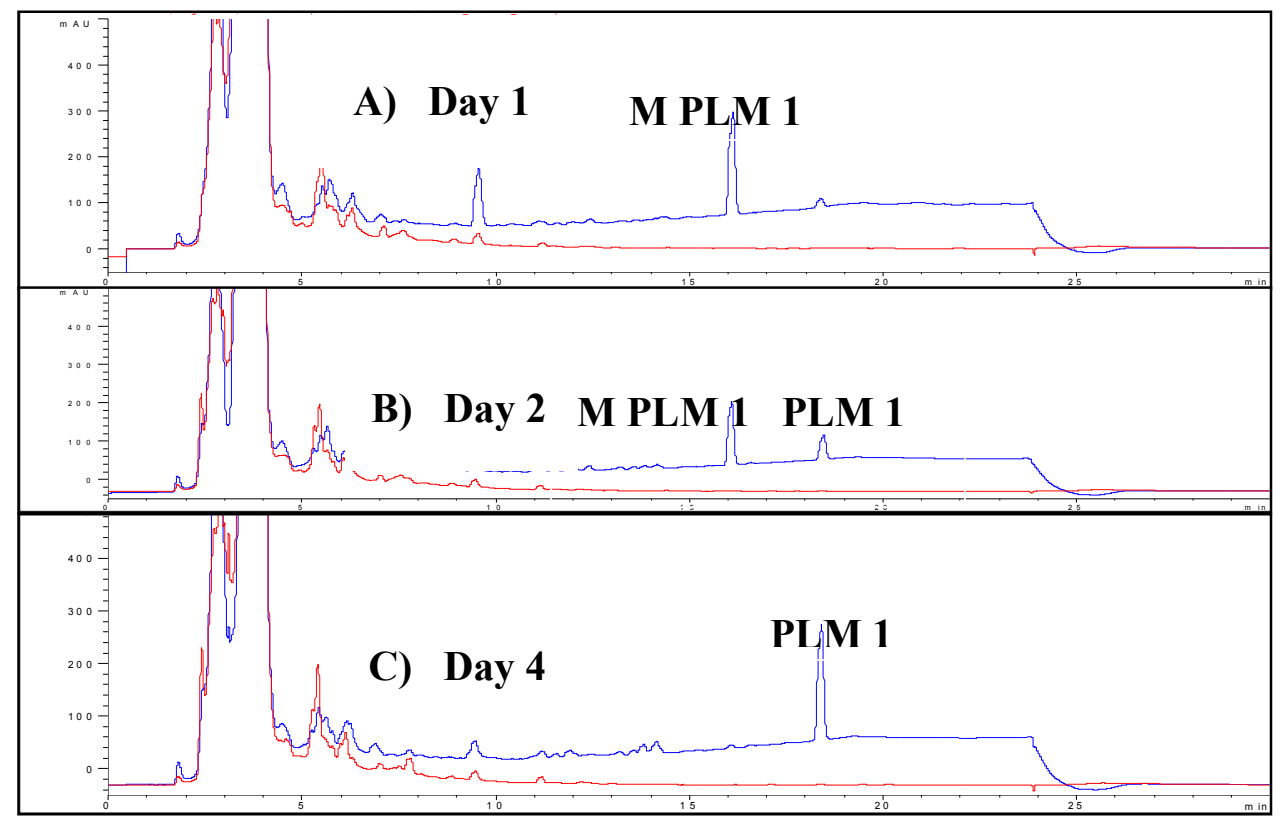

Figure 10. HPLC analysis of fermentation broth of NP5

Figure 10. HPLC Analyses of fermentation broth of NP5
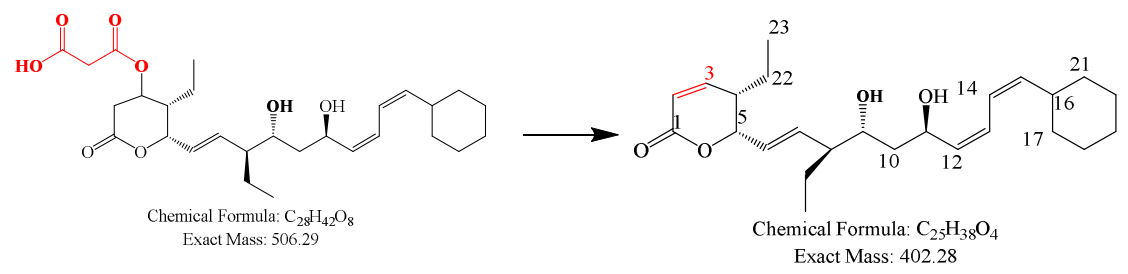

Figure 11. Mechanism for decarboxylation of M-PLM 1 to PLM 1 


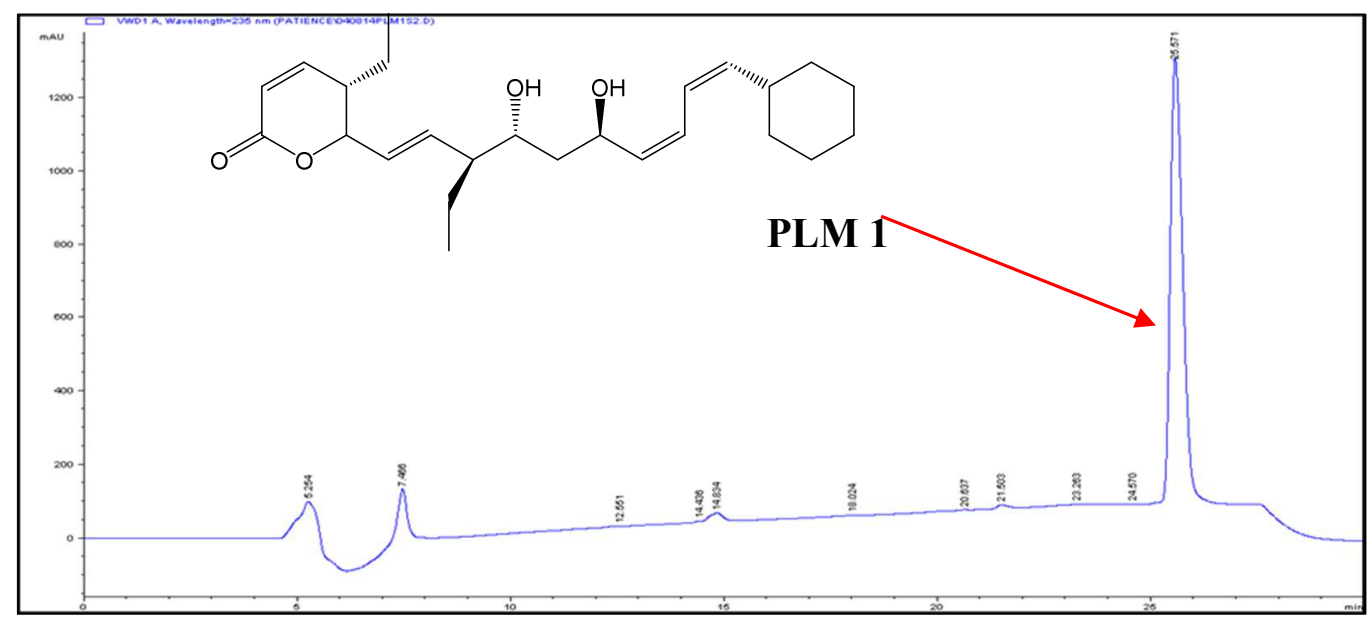

Figure 12. HPLC analysis of purified PLM 1 from fermentation broth of NP5 


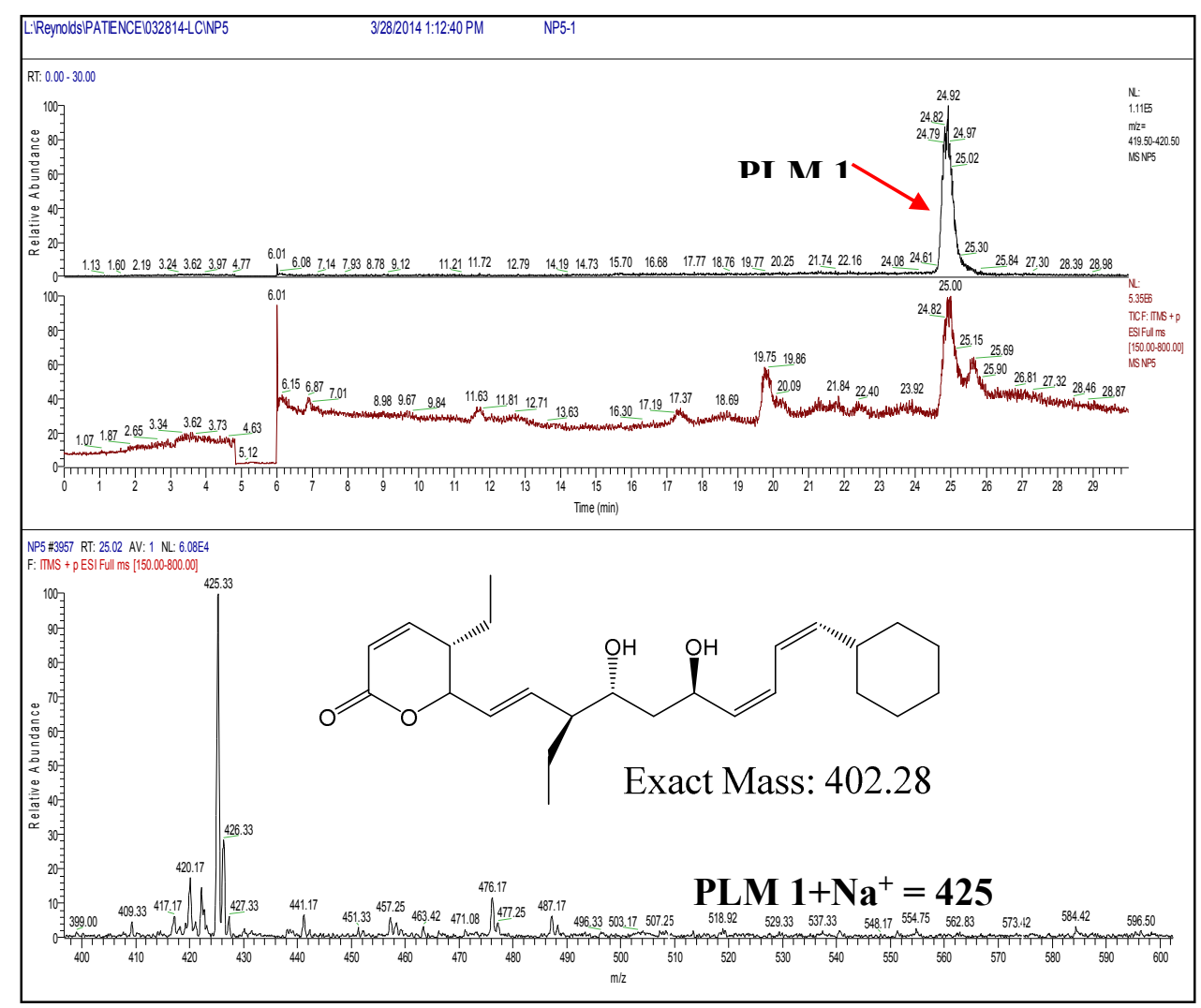

Figure 13. LC-MS analysis of purified PLM 1, m/z 420 and 425 


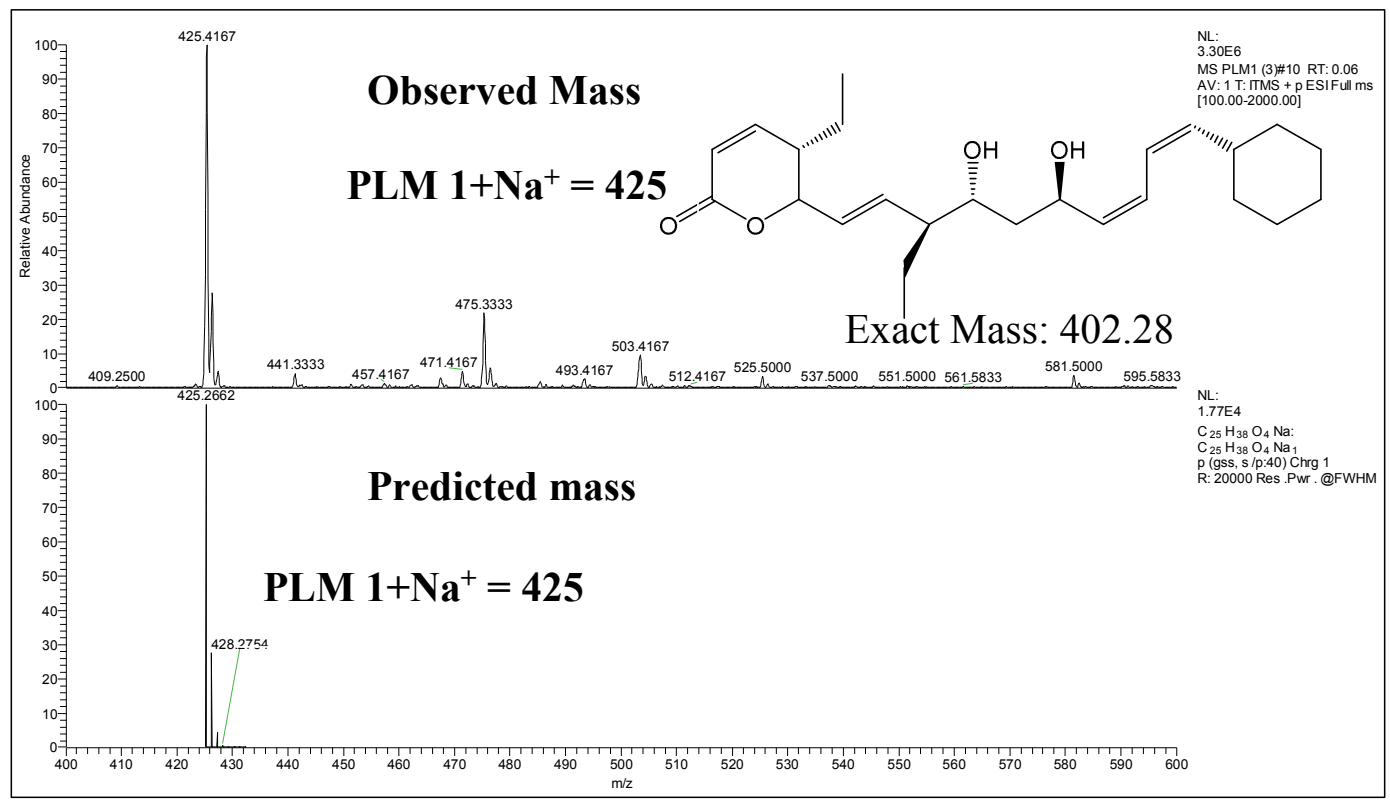

Figure 14. Comparison between the acquired mass and predicted mass for PLM 1

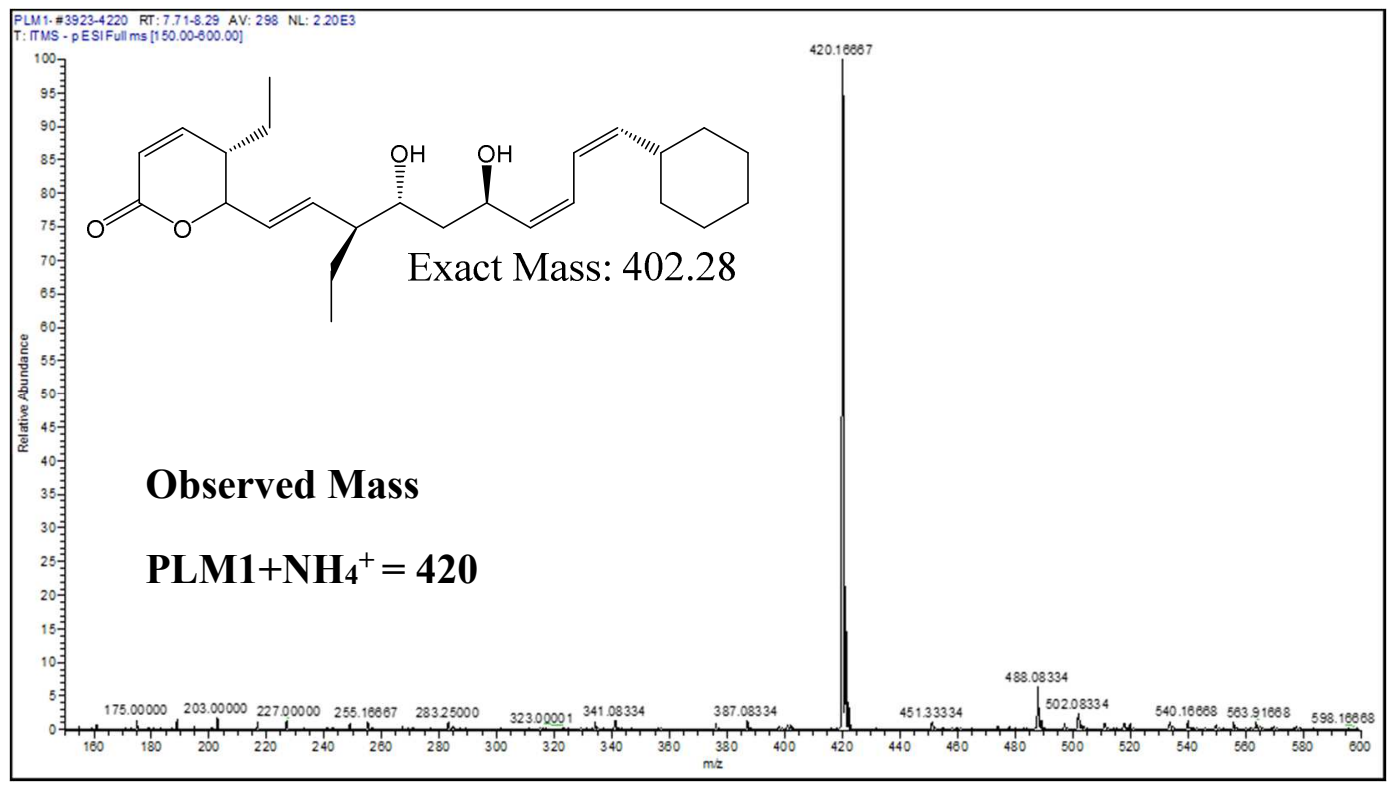

Figure 15. $\mathrm{ES}^{+} \mathrm{MS}$ analysis of purified PLM 1, m/z 420 
To further verify the structure of PLM, ${ }^{1} \mathrm{H}$ NMR of PLM 1 shown Figure 16 and ${ }^{1} \mathrm{H}-{ }^{1} \mathrm{H}$ COSY shown in Figure 17, were carried out. PLM B ${ }^{1} \mathrm{H}$ NMR has been previously reported and was used in comparison with the isolated intermediate PLM 1. All of the typical peaks of the phoslactomycin polyketide were present, which suggesting some similarity with the isolated product. The difference between PLM 1 and PLM B is the functional group at C$8\left(\mathrm{OH}\right.$ in PLM B and $\mathrm{H}$ in PLM 1) and $\mathrm{C} 25\left(\mathrm{NH}_{2}\right.$ in PLM B and $\mathrm{CH}_{3}$ in PLM 1). Most peaks were assigned by comparison with the spectra of the ${ }^{1} \mathrm{H}$ NMR of PLMB. PLM 1 spectrum was very similar to PLM-B except for the absorbance associated with a methyl proton at position $\mathrm{C}-25$ and the proton at $\mathrm{C}-8$. The new peak ( a triplet) appearing at 0.87 ppm is assigned to the $\mathrm{C}-25$ methyl protons. The proton absorbance were assigned using the ${ }^{1} \mathrm{H}-\mathrm{NMR}$ and the ${ }^{1} \mathrm{H}-{ }^{1} \mathrm{H}$ COSY with the most significant shift listed in Table 2. The assignment of vinyl protons at $\mathrm{H}-2$ and $\mathrm{H}-3$ indicates that the double bond alpha to the C1 is present in PLM 1. Detailed analyses of the ${ }^{1} \mathrm{H}-{ }^{1} \mathrm{H}$ COSY NMR spectra data shown in Figure 17 also verified the polyketide structure by confirming the proton-proton correlations. The data shows key proton to proton coupling, linking $\mathrm{C}_{4}, \mathrm{C}_{5}, \mathrm{C}_{6}, \mathrm{C}_{7}, \mathrm{C}_{8}, \mathrm{C}_{9}$ $\mathrm{C}_{10}, \mathrm{C}_{11} \mathrm{C}_{12}$ and $\mathrm{C}_{13}$. The data also shows that protons on $\mathrm{C}_{8}$ are coupled to the protons at $\mathrm{C}_{24}$. Closer examination of the spectrun also reveals that the protons at $\mathrm{C}_{15}$ are coupled to the protons at $\mathrm{C}_{16}$. This data is consistent with the predicted PLM 1 intermediate. 


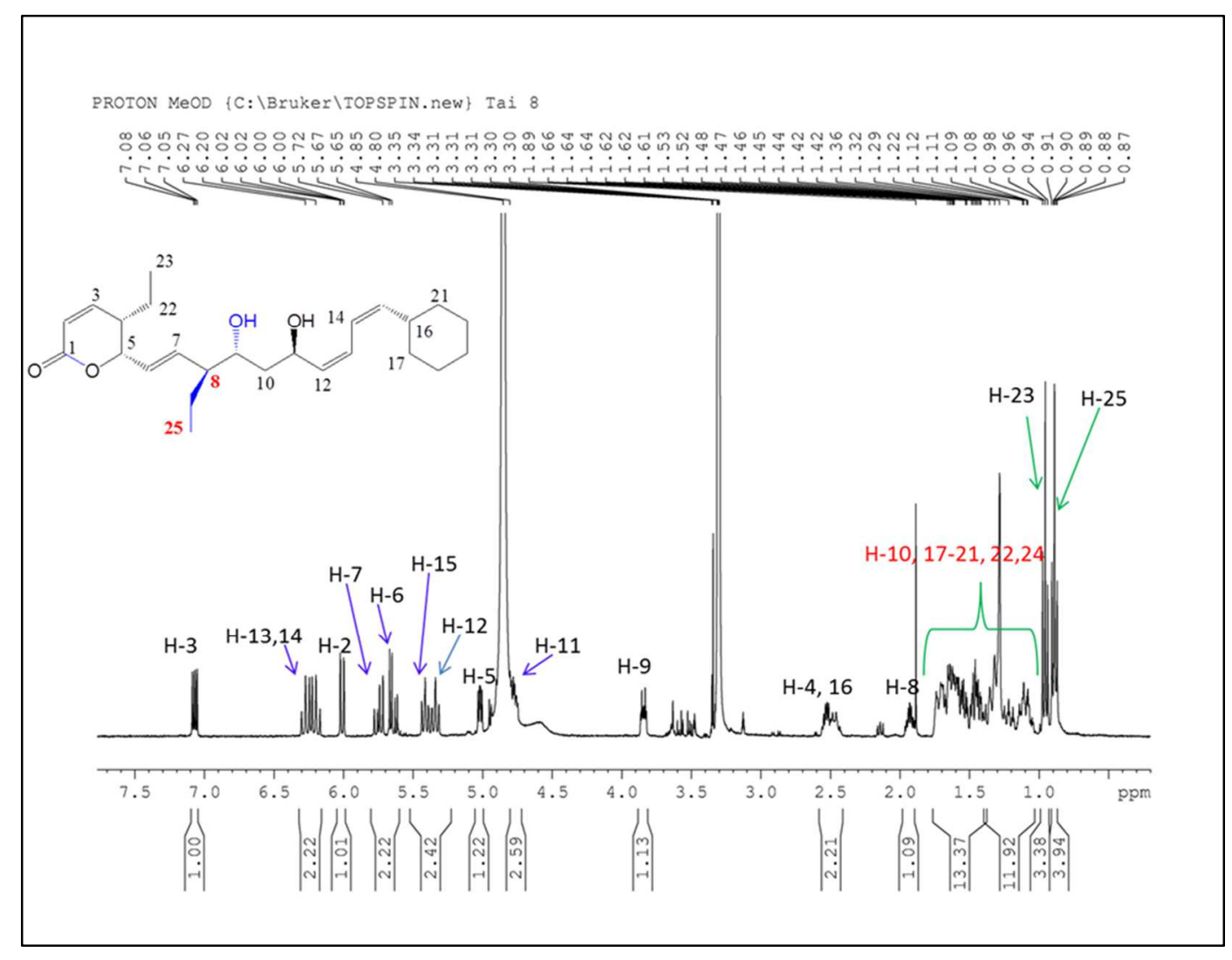

Figure 16. ${ }^{1} \mathrm{H}$ NMR of PLM 1 
Table $1{ }^{1} \mathrm{H}$ NMR spectra data for PLM 1

\begin{tabular}{|c|c|}
\hline ppm & Assignment \\
\hline 7.09 & $3-\mathrm{H}$ \\
\hline $6.2 \sim 6.4$ & $13,14-\mathrm{H}$ \\
\hline 6.00 & $2-\mathrm{H}$ \\
\hline 5.72 & $7-\mathrm{H}$ \\
\hline 5.67 & $6-\mathrm{H}$ \\
\hline 5.33 & $15-\mathrm{H}$ \\
\hline 5.41 & $12-\mathrm{H}$ \\
\hline 5.11 & $23-\mathrm{H}, 19-\mathrm{H}$ \\
\hline 4.95 & $5-\mathrm{H}, 21-\mathrm{H}$ \\
\hline 3.90 & $11-\mathrm{H}$ \\
\hline $2.48 \sim 2.55$ & $9-\mathrm{H}, 16-\mathrm{H}$ \\
\hline $1.9 \sim 1.8$ & \\
\hline
\end{tabular}


Table 2 Comparison of ${ }^{1} \mathrm{H}-\mathrm{NMR}$ chemical shifts for PLM 1and PLM B

\begin{tabular}{|c|c|c|}
\hline Assignment & ppm PLM 1 & ppm PLM B \\
\hline $2-\mathrm{H}$ & 6.00 & 6.09 \\
\hline $3-\mathrm{H}$ & 7.09 & 7.09 \\
\hline 4-H & 2.55 & 2.55 \\
\hline $5-\mathrm{H}$ & 5.11 & 5.11 \\
\hline $6-\mathrm{H}$ & 5.67 & 6.04 \\
\hline 7-H & 5.72 & 5.97 \\
\hline $8-\mathrm{H}$ & 1.9 & (OH group) \\
\hline $9-\mathrm{H}$ & 3.90 & 4.28 \\
\hline $11-\mathrm{H}$ & 4.95 & 4.95 \\
\hline $12-\mathrm{H}$ & 5.41 & 5.41 \\
\hline $15-\mathrm{H}$ & 5.33 & 5.33 \\
\hline $13-\mathrm{H}, 14-\mathrm{H}$ & $6.2 \sim 6.4$ & $6.32 \sim 6.20$ \\
\hline $16 \mathrm{H}$ & 2.55 & 2.48 \\
\hline $23 \mathrm{H}$ & 0.90 & 3.04 \\
\hline $25-\mathrm{H}$ & 0.87 & 3.00 \\
\hline
\end{tabular}




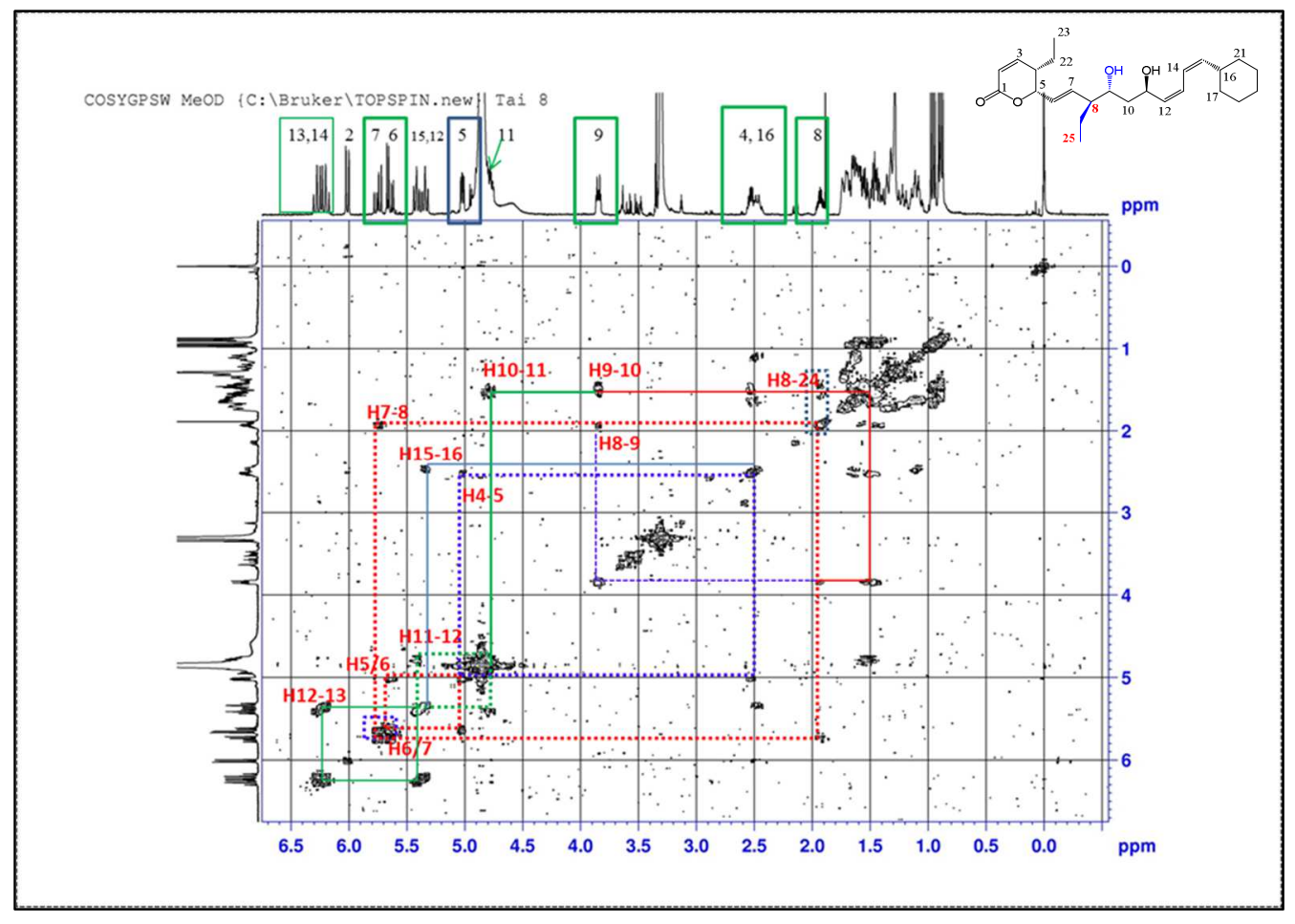

Figure 17. ${ }^{1} \mathrm{H}-{ }^{1} \mathrm{H}$ COSY of PLM 1 (1)

\subsection{CONCLUSION}

Gene disruption of the tailoring enzyme encoded by plmT4 resulted in accumulation of compounds lacking C-8 and C-25 hydroxyl groups. Partial characterization of the isolated intermediate suggested that the plmT4 is likely to be responsible for C-8 and C-25 oxidation in the phoslactomycin biosynthesis. Further characterization is required using 2D-NMR techniques, to reveal carbon-carbon correlations and carbon-proton correlations. Together these results will support the proposed role of the plmT4 gene in the PLM biosynthesis. 


\section{CHAPTER 3. GENERATION OF A BLOCKED PM 1 MUTANT}

\subsection{INTRODUCTION}

The biosynthetic gene cluster of phoslactomycin has been analyzed in detail by genetic and biochemical investigations and genes responsible for the synthesis of the phoslactomycin polyketide synthase have been cloned and sequenced Studies showed that all PLM compounds were originating from a common $\mathrm{CHC}$ starter unit ${ }^{26}$. The sequence analysis of PLM biosynthetic gene cluster revealed the existence of a complete set of highly conserved genes responsible for the formation of $\mathrm{CHC}-\mathrm{CoA}$ starter unit. Genes responsible for assembling the PLM carbon skeleton were identified and genes proposed to be involved in post-polyketide synthase tailoring steps were proposed for example, an oxidoreductase $(p \operatorname{lm} T 8)$ and aminotransferase $(p \operatorname{lm} T 1)^{28}$. The gene cluster also contains numerous other genes involved in regulation and resistance. The role of plmT8 has been proposed, but not experimentally determined. This chapter reports a genetic investigation of $p \operatorname{lm} T 8$, and partial characterization of the mutant strain lacking a plmT8 gene, in order to confirm its role in the phoslactomycin biosynthetic pathway.

The deletion or replacement of individual genes along a biosynthetic pathway can be used to probe the role of the genes in the biosynthesis in vivo ${ }^{33,34}$. In this process, a particular gene can be completely deleted or replaced with another gene that confers resistance to a certain antibiotic such as ampicillin via PCR-targeted recombination or Red/ET-mediated recombination ${ }^{7,35}$. In this study, a plmT8 gene was replaced with an ampicillin resistance 
marker. The cosmid 10B4 containing the partial phoslactomycin biosynthetic cluster was replaced in $E$ coli by $\lambda$ RED-mediated recombination, creating a gene replacement. Gene replacement is an effective technique that takes advantage of the natural ability of an organism to recombine homologous regions of $\mathrm{DNA}^{34}$. A gene replacement generates a mutant inefficient or totally incapable of producing the natural product in question. The role of a gene in the biosynthesis of the natural product is found by analyzing and comparing the metabolite pool (intermediates or shunt metabolites) of the resultant mutant with the wild type $\mathrm{e}^{35}$. The order of steps is then determined by ordering of mutants blocked at different steps within the pathway This study paves the way for the elucidation of ordering steps of the phoslactomycin biosynthesis pathway by creating a plmT8 mutant strain (PM1) and partial characterization of generated compounds using mass spectroscopy. The $\operatorname{plm} T 8$ is proposed to be an oxidoreductase. The group of oxidoreductases comprises different types of enzymes such as oxygenases, oxidases, peroxidases, reductases and dehydrogenases ${ }^{23}$. To date various kinds of oxidoreductases are known, which are involved in post polyketide synthase tailoring steps ${ }^{23}$. These enzymes introduce oxygen-containing functionalities, such as hydroxyl, epoxide, aldehyde and keto groups, or modify these functionalities by adding or removing hydrogen atoms ${ }^{36}$. PlmT8 is proposed to catalyze oxidation of the C-25 OH group of PLM 1, a first step in introduction of amine function. Therefore the plmT8 mutant strain is expected to generate or accumulate PLM 2 intermediate and other possible analogues as shown in Figure 18. The proposed post-PKS tailoring steps in phoslactomycin biosynthesis suggests that PLM 1 is the earliest intermediate, followed by PLM 2. 


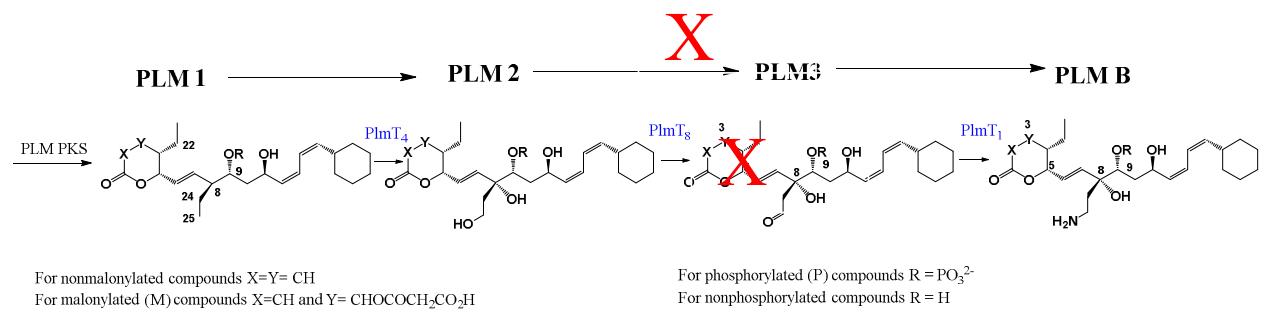

Figure 18. Proposed product of the plmT8 mutant

\subsection{MATERIALS AND METHODS}

\subsubsection{Bacterial Strain, Plasmids and Reagents}

All chemicals and solvents were purchased from Sigma or Fisher and were of a highest grade. Yeast extract, N-Z amine type A and beef extract were obtained from Difco. Primers for PCR were purchased from Integrated DNA Technologies (Coralville, IA). Cosmid 10B4 containing partial Streptomyces HK 803 genomic DNA and NP2 mutant strain were kindly provided by the previous member of the group. NP2 was the wild type PLM B producer used for generation of the PM1 mutant strain. DH5a was used as the host for standard cloning experiments. E. coli ET12567/pUZ8002 was used as cosmid donor host for E. coli-Streptomyces conjugation. E. coli BW25113/pIJ773 was provided by John Innes Center (Norwich, UK) as part of the REDIRECT Technology kit SuperCos1 (Stratagene). Platinum High Fidelity polymerase supermix was purchased from Invitrogen. All other 
required reagents, including media, restriction enzymes, and other molecular biological reagents were acquired from standard commercial sources.

\subsubsection{Media and Culture Conditions}

E. coli strains were grown in Luria broth (LB) supplemented with antibiotics apramycin (50 $\mu \mathrm{g} / \mathrm{ml})$, chloramphenicol $(25 \mu \mathrm{g} / \mathrm{ml})$, and kanamycin $(50 \mu \mathrm{g} / \mathrm{ml})$ were added to the growth media as required. Soybean mannitol agar was used for maintaining NP2 and PM1 mutant. Soybean mannitol agar supplemented with $50 \mu \mathrm{g} / \mathrm{ml}$ apramycin was used to maintain the exconjugants. All growth media for Streptomyces and E. coli were prepared according to standard protocols.

\subsection{GENERATION AND ANALYSIS OF PM 1 MUTANT}

\subsection{DNA Manipulation and Construction of PM1 Mutant}

The NP2 ( $\triangle p l m S 2)$ mutant (that produces only PLM B) from Streptomyces sp. HK 803 strain was previously generated in our lab using a PCR-targeting based gene replacement method. The $\Delta p \operatorname{lm} T 8 \Delta p \operatorname{lm} S 2$ (PM1 mutant) was created from the NP2 (wild type strain), by replacing $p \operatorname{lm} T 8$ with an aac(3)IV resistance marker and oriT cassette (which allows for efficient transfer to Streptomyces by RP4-mediated intergeneric conjugation). The replacement was first accomplished in cosmid 10B4 and subsequently in the chromosome of the NP2 mutant. Cosmid 1OB4 DNA was isolated from E. coli cells using QIAprep Spin Miniprep kit. In order to allow the integration of the 10B4 cosmid carrying the 
phoslactomycin cluster into the genome of NP2 mutant, cosmid 10B4 was first transformed into E. coli BW25113/pIJ790 (recombination strain expressing $\lambda$-Red recombination functions)) via electroporation according to standard protocol. A gene replacement cassette containing aac (3)IV, oriT of RK2 and two FRT sites was amplified by using primers containing $39 \mathrm{nt} 5^{\prime}$ homology extension corresponding to regions flanking the target gene and 20 nt-3' homology to the unique priming sites of the disruption cassette. Primer design and analysis was performed using MacVector (MacVector Inc., Cary, NC) and the forward

primer: $\quad 5^{\prime}-$ CGGCCGCCCATGAAACGACTCGAAGGACGCAACGGCATGATTCCGGGATCCG $\begin{array}{llll}\text { TCGACC-3, } & \text { and } & \text { reverse }\end{array}$ AGTGGYGTCGCCAACGGACGCGAACCGGCTCATGTAGGCTGGAGCTGCTTC3'were used (sequence homologous to the pIJ773 disruption cassette is shown in the bold, italicized text). The allelic replacement of the $\operatorname{plm} T 8$ gene in the NP2 was confirmed by PCR amplification.

\subsection{Production of PLM analogs}

The NP2 and PM1 mutants were maintained and grown in SY agar medium as shown in Figure 19. The production of phoslactomycin was carried out as previously described, were a loopful of spores was inoculated in $70 \mathrm{ml}$ fermentation medium and incubated for $96 \mathrm{~h}$ at $28{ }^{\circ} \mathrm{C}$ with shaking at $170 \mathrm{rpm}$ in the dark and at the end of the fermentation period, the cultures where harvested, the mycelia were removed by centrifugation, and the resulting supernatant was analyzed directly by HPLC, MS and LC-MS. 


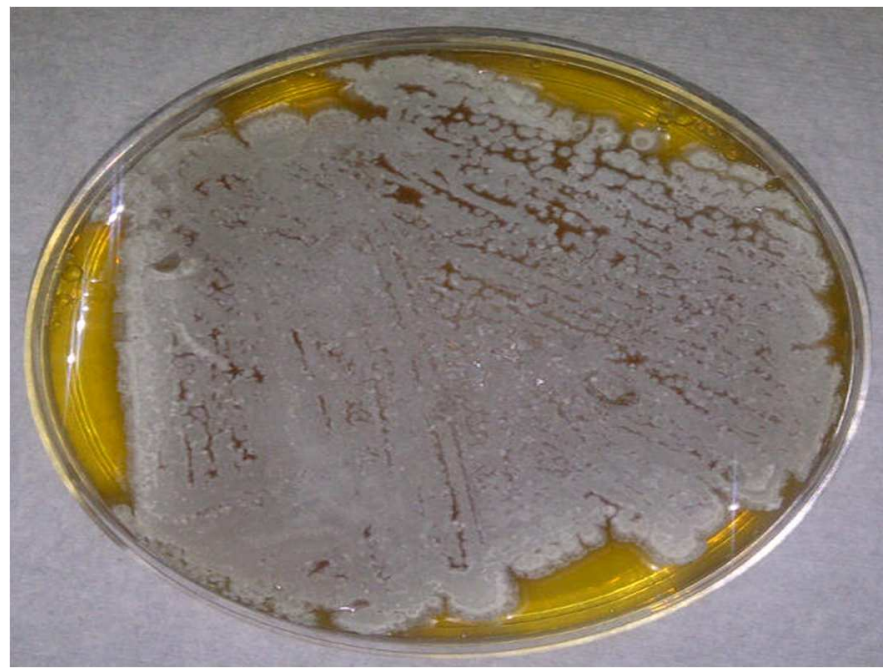

Figure 19. Growth of Streptomyces mutant strain PM1 on SY agar. Colonies appear slightly grayish in color

\subsection{HPLC and LC-MS analysis}

A $500 \mu \mathrm{L}$ sample of the filtered supernatant of the fermentation broth was analyzed by using an Agilent 1100 HPLC system connected to a diode array detector. The PM broth was analyzed with $5 \mu \mathrm{m}$ Discovery HS C18 reverse phase column (4.6x $250 \mathrm{~mm}$, Supelco, Belefonte, PA) using a linear gradient between solvent A (acetonitrile: water; 20:80 with $0.05 \%$ formic acid) and solvent B (acetonitrile: water; $80: 20$ with $0.05 \%$ formic acid) from $0 \%$ to $60 \%$ over 40 minutes at a flow rate of $1.0 \mathrm{ml} / \mathrm{min}$ and detected at $235 \mathrm{~nm}$. The LCMS analysis was carried out using 100 of the supernatant under the same solvent and gradient conditions, with a flow rate of $0.3 \mathrm{ml} / \mathrm{min}$ using a Surveyor HPLC system (ThermoFinnigan) connected to a diode array detector equipped with a $2.1 \mu \mathrm{m}$ Discovery 
HS C18 reverse phase column ( 4.6 x $250 \mathrm{~mm}$, Supelco). Mass spectra was collected on an LCQ quadrupole ion trap (ThermoFinnigan) mass spectrometer equipped with an electrospray ion source operating in positive mode.

\subsection{RESULTS AND DISCUSSION}

The replacement of the plmT8 gene was achieved through double crossover using REDIRECT technology. The target gene, which was identified on the 10B4 cosmid, was replaced by the aac(3)IV/oriT (red) cassette using PCR targeting strategies, yielding a mutated cosmid as shown in Figure 20. Figure 21, shows the PCR product of the amplified apramycin gene aac(3)IV oriT (red) cassette used to replace the targeted gene in the cosmid. The mutated cosmid was introduced into E.coli ET12567/pUZ8002 by electroporation and subsequently transferred into the target strain (NP2) by conjugation. The desired double crossover mutants, which were selected by their apramycin-resistant and kanamycinsensitive phenotype were isolated as PM1 $(\Delta$ plmT8 4 plmS2) and confirmed by PCR analysis as shown in Figure 22 (Lane 1and 2) and Lane 3-5 shows the control PCR (wild type NP2). 

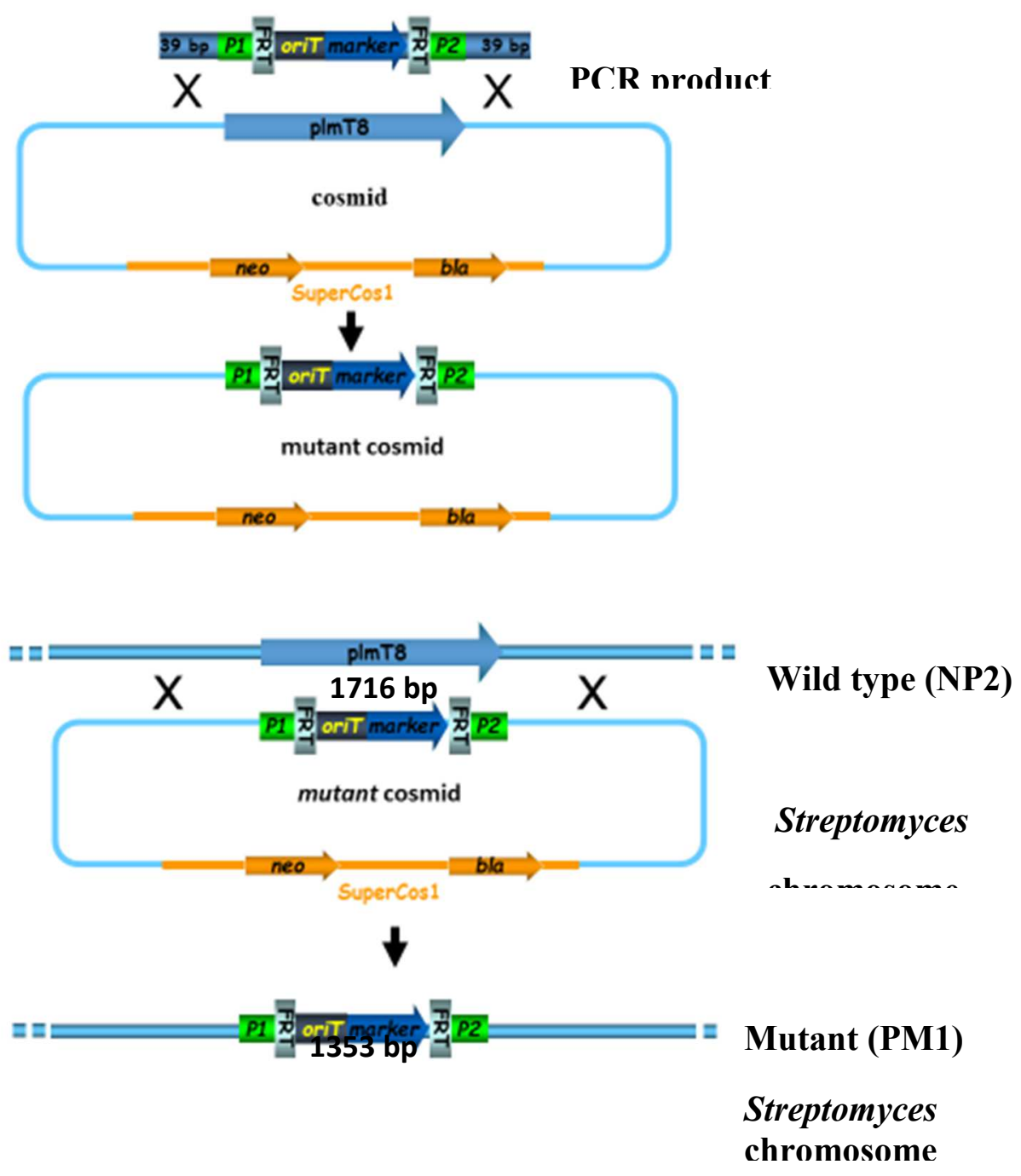

Figure 20. (A) Flow chart of gene disruption by PCR-targeting 


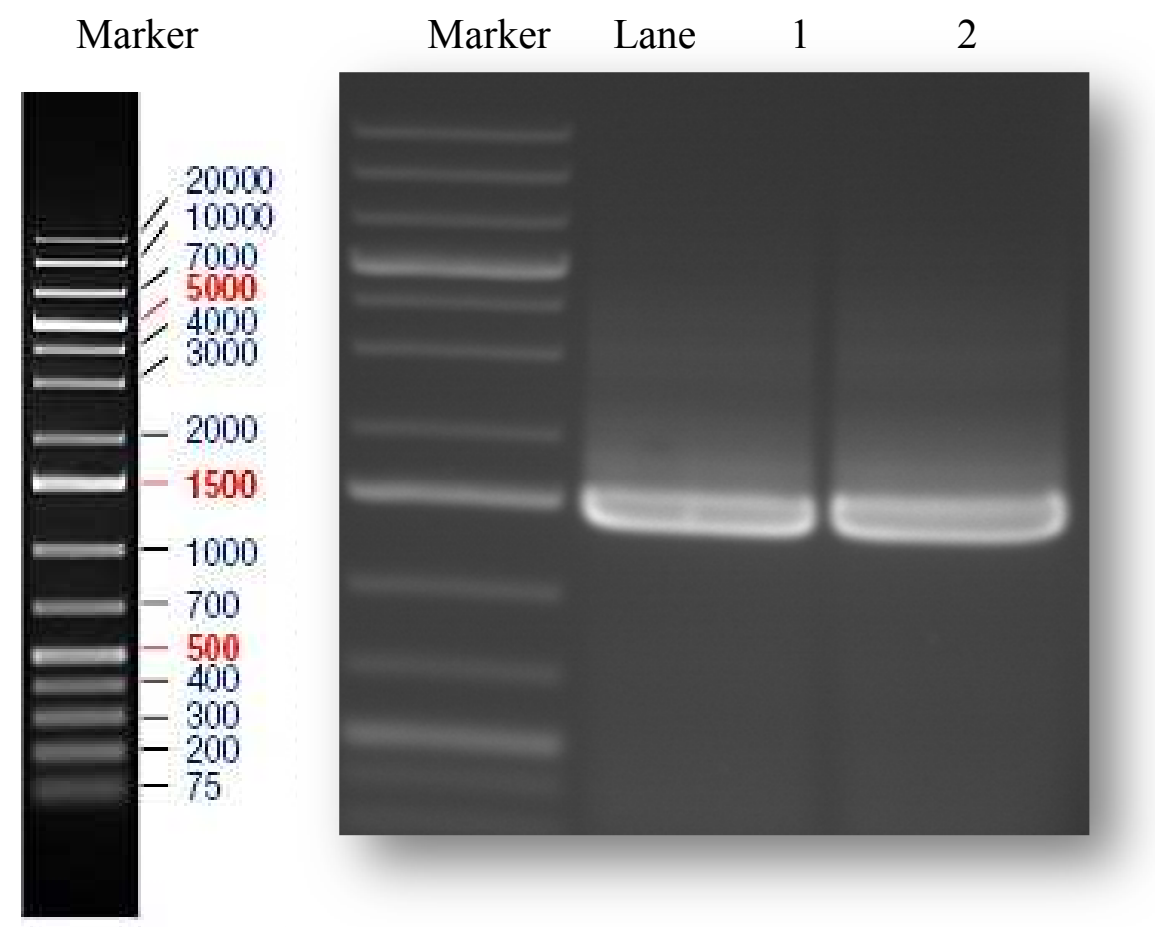

Figure 21. (A) Apramycin gene aac(3)IV/oriT (red) cassette 

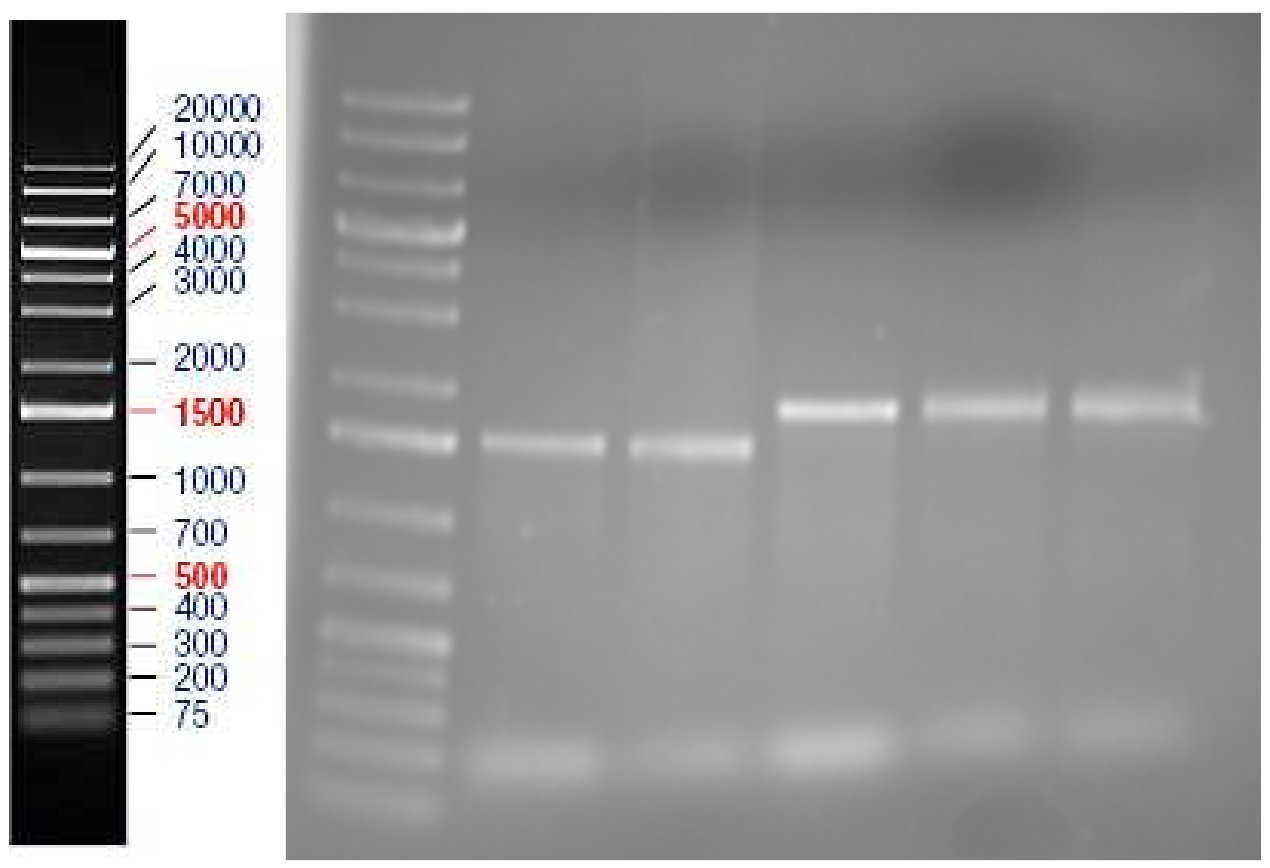

Figure 22. PCR confirmation analysis

The PM1 ( $\Delta p \operatorname{lm} T 8 \Delta p \operatorname{lm} S 2)$ mutant was fermented and processed along the wild. Analysis of fermentation broth revealed a peak eluting $\sim 20.7 \mathrm{~min}$ in the total ion chromatogram (TIC) that had a $m / z$ of 583 as shown in Figure 23, consistent with the formation of M-PLM 2 $\left([\mathrm{M}-\mathrm{H}+2 \mathrm{Na}]^{+}\right)$. The addition of mild base to the PM1 fermentation broth resulted in the disappearance of this peak, consistent with our prediction of a malonylated product. Addition of a base will cause deprotonation of the malonyl group facilitating decarboxylative elimination reaction and the formation of corresponding product without 
a malonyl group. Analysis of the purified broth also revealed peaks with m/z $515([\mathrm{M}+\mathrm{H}]$ $\left.{ }^{+}\right), 532\left(\left[\mathrm{M}+\mathrm{NH}_{4}\right]+\right)$ and $\mathrm{m} / \mathrm{z} 537\left([\mathrm{M}+\mathrm{Na}]^{+}\right)$as shown in Figure 24, consistent with the mass of the PLM 2 P compound. Analysis of the PM1 mutant also revealed a peak eluting at $6.2 \mathrm{~min}$ in the total ion chromatogram (TIC) that had a $\mathrm{m} / \mathrm{z}$ of 453 and 475 , consistent with the formation of PLM 2 with hydrolyzed lactone, $\left([\mathrm{M}+\mathrm{H}]^{+}\right)$and $\left([\mathrm{M}+\mathrm{Na}]^{+}\right)$ respectively. A high resolution MS analysis of the filtered broth was consistent with formation of PLM 2 with a hydrolyzed lactone as shown in Figure 25.

The observation of mass consistent with the formation of M-PLM 2, PLM 2 and PLM 2 P products in PM1 mutant suggests the proposed role of plmT8 as an oxidoreductase. The observation M-PLM 2 in the plmT8 deletion mutant strain suggest that malonylation is likely to occurs in the early stage, indicating that modification steps can occur on an intermediate with a C-3 malonyl group attached. Decarboxylation elimination by $\mathrm{PlmT}_{2}$ is likely to occur later in the post-PKS modification steps of phoslactomycin. The observation of phosphorylated products in the plmT8 mutant strain suggests that the proposed phosphorylation catalyzed by $\mathrm{PlmT}_{5}$ kinase can occur early in the step in the phoslactomycin pathway. The accumulation of PLM 2 products also supports that plmT4 is responsible for addition of the C-8 and C-25 hydroxyl groups, since the mass obtained are consistent with oxidation at C-8 and C-25 (PLM 1). 


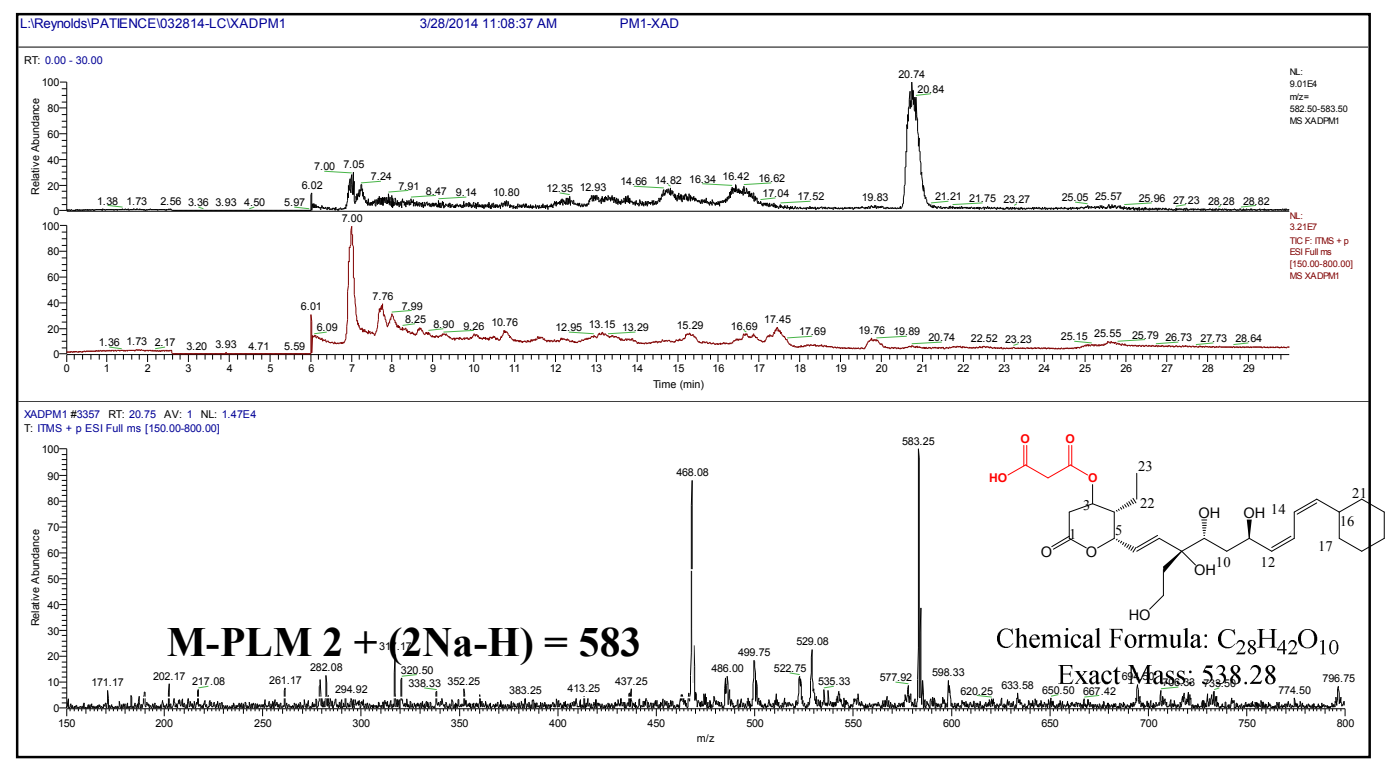

Figure 23. LC-MS analysis of purified PM1 broth, m/z 583

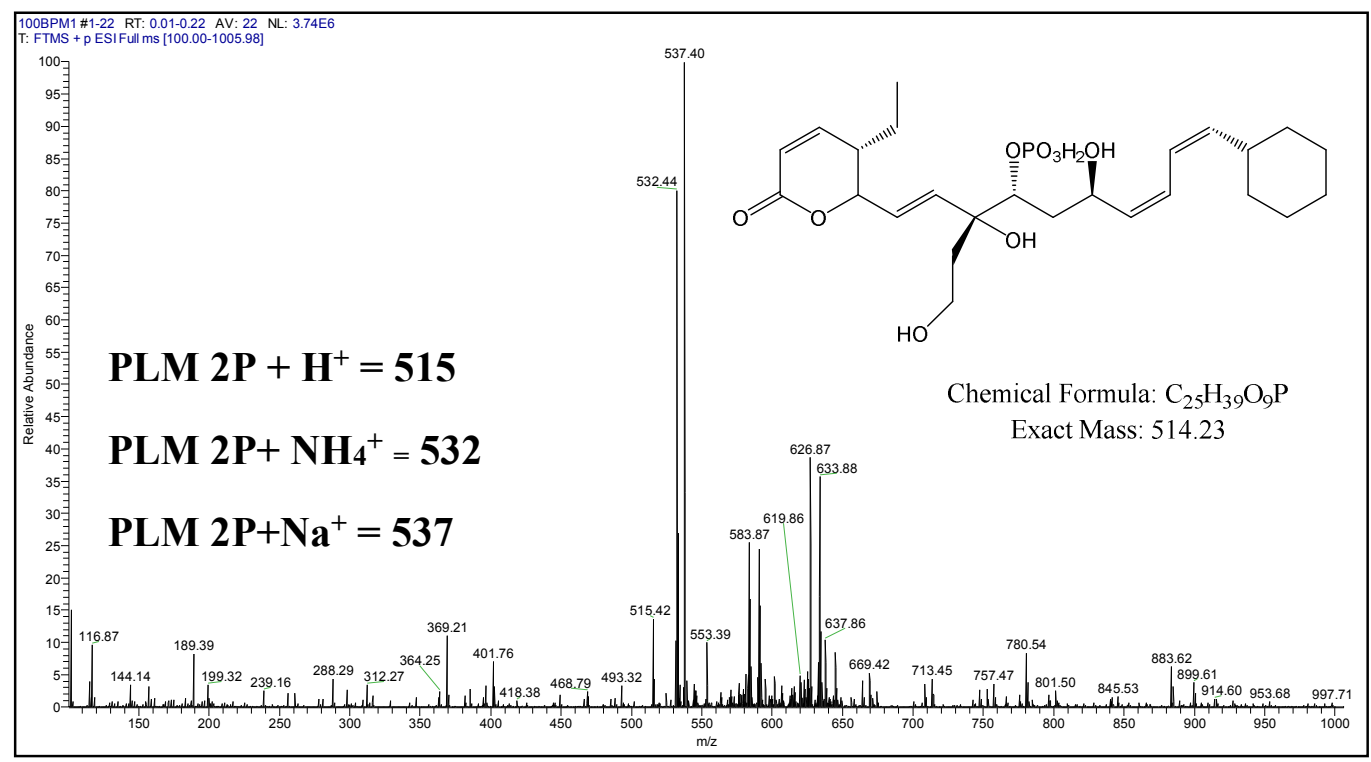

Figure 24. $\mathrm{ES}^{+} \mathrm{MS}$ analysis of filtered of PM1 fermentation broth, $\mathrm{m} / \mathrm{z} 515,532$ and 537 


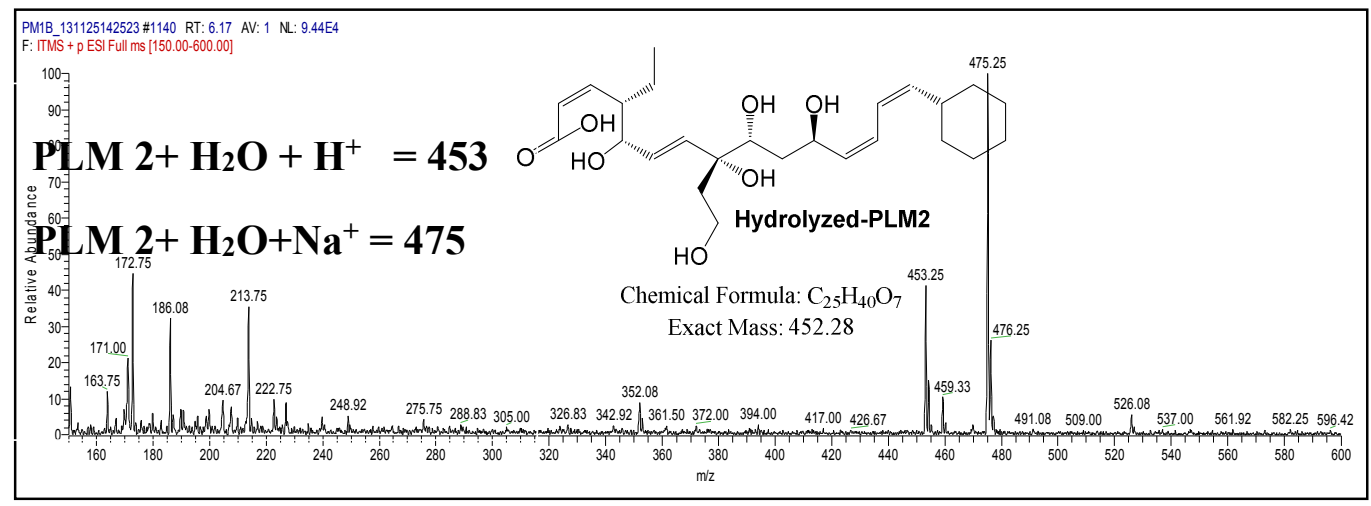

Figure 25. $\mathrm{ES}^{+} \mathrm{MS}$ analysis of filtered of PM1 fermentation broth, m/z 453 and 475

Some of the key drawbacks to continued partial analysis include low fermentation titers and various analogues produced in the fermentation. Cloning of the PLM biosynthetic gene cluster and creation of a PM1 mutant sets the stage for isolation of the more gene product of the PM1 mutant and then NMR characterization will be possible. 


\section{CHAPTER 4. HETEROLOGOUS EXPRESSION OF TAILORING ENZYMES}

\subsection{INTRODUCTION}

The enzymological phase of polyketide biosynthesis research started in the 1990's when the first crude cell extracts fractionations and in vitro characterizations were carried out. Amongst the first post-PKS tailoring enzymes to be isolated and studied was carminomycin 4-O-methyltransferas ${ }^{37}$. It was partially purified from the wild type producer Streptomyces sp. strain $^{37}$. In order to study and characterize individual enzymes participating in the biosynthesis of a polyketides, for example studying substrate specificity in vitro and a detailed kinetic analysis, their respective genes needs to be expressed in a heterologous host such as E.coli, followed by enzyme purification ${ }^{38}$. Successful production of proteins requires the success of three individual factors: expression, solubility and purification ${ }^{39} . E$. coli remains the most used host for recombinant protein expression because it is easy to manipulate and cheap ${ }^{40}$. A variety of high-level expression vectors are now available to allow gene expression under the influence of the bacteriophage $\mathrm{T} 7$ polymerase promoter ${ }^{41}$. The development of the His-Tag technology allows the fusion of six histidine amino acid residues to either the $\mathrm{N}$ - or $\mathrm{C}$-terminal end of the expressed protein which facilitates the purification of the recombinant protein by affinity chromatography using metal chelation resins $^{42}$. Additional residues or tags can be engineered on either $\mathrm{N}$-terminal or C-terminal end of the protein of interest during cloning, tags can confer the advantage of increased yield, by providing a reliable context for efficient translation initiation, enhancing 
solubility of expressed proteins ${ }^{42}$. A common limitation of recombinant protein production in bacteria is the formation of insoluble protein aggregates known as inclusion bodies. One possibility to avoid inclusion bodies is to use large affinity tags ${ }^{43}$. The biochemical features of different tags influence the stability, solubility and expression of proteins to which they are attached. In other words, using expression vectors that include a fusion tag facilitates recombinant protein solubility ${ }^{44}$. A disadvantage is, however, that proteins with these tags cannot be purified with a specific affinity matrix. The fusion construct must be used in combination with a small affinity tag for purification ${ }^{45}$. Elution of the bound enzyme is readily achieved by changing parameters such as salt concentration or $\mathrm{pH}^{46}$ After purification, the proteins can be used in a number of assays depending on the reactions they catalyze to monitor the substrate specificity as well as the rate by which they catalyze their reactions. The in vitro assays using expressed enzymes provide greater and more valuable insight into the mechanistic role of the individual enzyme in the biosynthetic process as a whole.

The final enzymes involved in phoslactomycin post-polyketide synthase tailoring steps have already been characterized. The enzymes studied are $\mathrm{PlmT}_{2}, \mathrm{PlmS}_{2}$ and $\mathrm{PlmS}_{3}$ as described in the introduction chapter and the enzymes were characterized by carrying out detailed in vitro enzyme assay.

This chapter we describe the cloning, expression and purification of the initial post-PKS tailoring enzymes in the phoslactomycin biosynthesis. The proposed tailoring enzymes for this work in are, $\mathrm{PlmT}_{4}$ a cytochrome $\mathrm{P} 450$ monooxygenase, $\mathrm{PlmT}_{5}$ a kinase and $\mathrm{PlmT}_{8}$, 
an oxidoreductase ${ }^{10}$. Expression and purification of these enzymes will pave the way for in vitro enzyme characterization methods and protein crystal structure determination (if needed) leading to analysis of the role of each proposed enzyme. This will lead the way for elucidation of the ordering steps of the post-polyketide synthase tailoring steps in the phoslactomycin pathway.

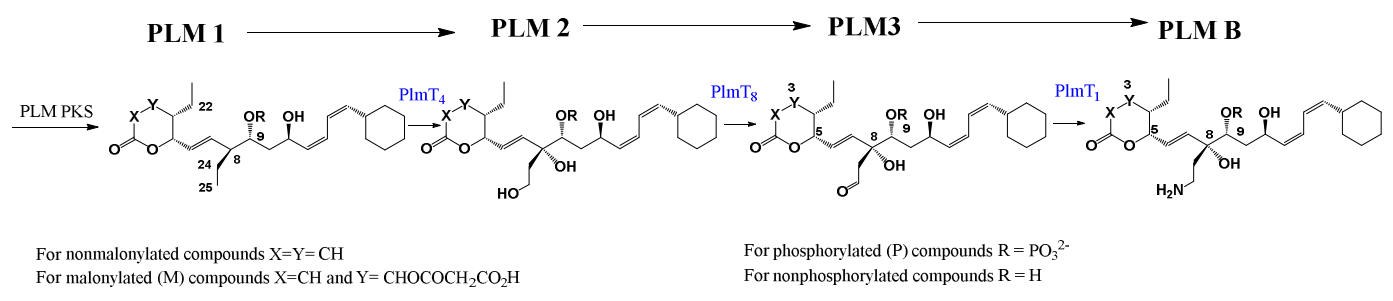

Scheme 1. Proposed ordering of the post-PKS tailoring steps in PLM pathway

The enzymes studied in this work, also commonly found occurring in post-PKS tailoring reactions are briefly discussed in the following section.

\subsubsection{PIm T4, a cytochrome P450 monooxygenase}

The plmT4 gene is proposed to be a cytochrome P450 monooxygenase. CYP450s belong to a very large and diverse family containing heme as a cofactor (hemeproteins) Cytochrome P450 (CYP450) proteins, named for the absorption band at $450 \mathrm{~nm}$ of their carbon monoxide bound form, are one of the largest superfamilies of enzyme proteins ${ }^{47}$. There is also a broad versatility of reactions catalyzed by cytochromes P450 such as carbon hydroxylation, heteroatom oxygenation, dealkylation, epoxidation, aromatic hydroxylation, 
reduction, and dehalogenation ${ }^{48}$. In several instances, monooxygenases activity, arises from induction of CYP450 and associated ferredoxin or of a CYP450 only. CYP450 plays two main roles in living organisms namely catalyzing oxidation steps in the biosynthesis of compounds like steroids and detoxification of xenobiotics compounds, facilitating their elimination from living organisms ${ }^{49}$. CYPs have been proposed to be involved in the biosynthesis of phoslactomycin ${ }^{29}$. To date various kinds of CYPs, are known, which are involved in post-PKS modifications and understanding of CYP450 is essential for efficient engineering of Streptomyces strains capable of generating novel antibiotics. For example, approaches that utilize substrate promiscuity of CYP450s have been applied to generate novel analogues of erythromycin and pikromycin ${ }^{50}$. The proposed CYP-dependent hydroxylation (C-8, C-18 and C25) in the post-PKS tailoring steps of PLM, are proposed to be carried out by $\mathrm{PlmS}_{2}$ and $\mathrm{PlmT}_{4}$. The work on $\mathrm{PlmS}_{2}$ has already been completed and published by the previous member of the group, this work focus on cloning, expression, purification of $\mathrm{PlmT}_{4}$, and partial characterization of the enzyme (in vitro enzyme assay).

\subsubsection{Plm $\mathrm{T}_{5}$, a kinase}

A kinase is an enzyme that adds phosphate group to other molecules and these enzymes are key regulators of cell function ${ }^{51}$. Kinases which are involved in post-PKS modification have been studied, for example, a kinase involved in the biosynthesis of a polyketide known as fostriecin ${ }^{25,22}$. Fostriecin is a unique phosphate monoester antibiotic that was isolated from Streptomyces pulveraceus and is structurally related to phoslactomycin ${ }^{52}$. 
Homology analysis showed that $f_{0 s} H$ shares $43 \%$ sequence identity with $\mathrm{PlmT}_{5}$ and was a kinase, based on an enzyme activity assay performed in vitro. A FosH heterologous expression system was constructed on $\mathrm{pET} 28 \mathrm{~b}$ and introduced into E. coli BL21 to produce the target protein. The results obtained supported the hypothesis that FosH is responsible for the phosphorylation of fostriecin ${ }^{22}$. In this study we focused on cloning, expressing and purifying $\mathrm{PlmT}_{5}$, a putative kinase. This work will pave the way for in vitro enzyme assays so that the $\mathrm{PlmT}_{5}$ role in phoslactomycin biosynthetic pathway is confirmed.

\subsubsection{PIm T8, an oxidoreductase}

Several types of enzymes have been reported to be involved in post-PKS modifications catalyzing different chemical reactions ${ }^{28,53}$. The group of oxidoreductases comprises different types of enzymes such as oxygenases, oxidases, peroxidases, reductases and dehydrogenases ${ }^{36}$. These enzymes introduce oxygen-containing functionalities, such as epoxide, aldehyde and keto groups, or modify these functionalities by adding or removing hydrogen atoms, for example, transforming a ketone into a secondary alcohol or an aldehyde into a carboxylic acid ${ }^{36}$. All of these reactions have an impact on the stereoelectronic and physico-chemical properties of the substrates, by creating or removing chiral centers, introducing highly reactive functional groups, such as aldehydes or epoxides, changing the solubility of a molecule or converting hydrogen bond donors. $\mathrm{PlmT}_{8}$ is proposed to transform the $\mathrm{C}-25 \mathrm{OH}$ group into an aldehyde as shown in scheme 2 below. 


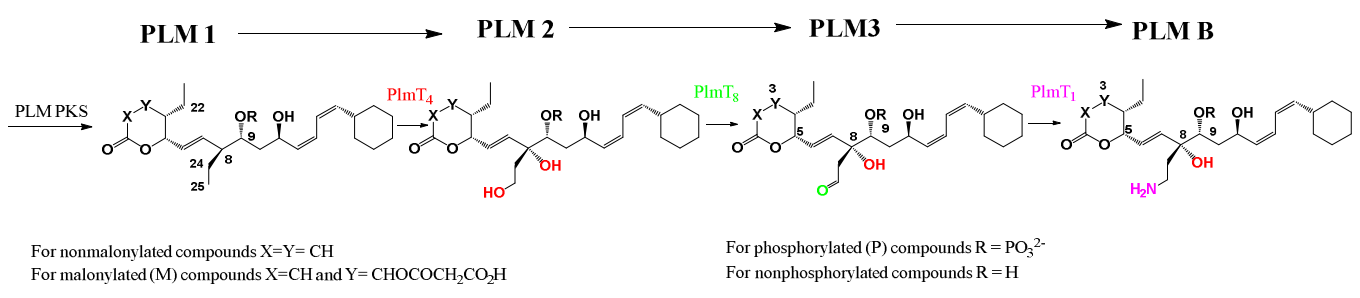

Scheme 2. Proposed PlmT8 reaction

\subsection{MATERIALS AND NETHODS}

\subsubsection{Materials}

Buffers, salts and reagents were of highest quality grade and were purchased from Sigma (St. Louis, MO) unless otherwise noted. Dithiothreitol (DTT), isopropyl- $\beta$-D-thiogalactopyranoside (IPTG), kanamycin sulfate, $\beta$-NADPH ( $\beta$ - Nicotinamide adenine dinucleotide phosphate), $\beta-\mathrm{NADP}^{+}$and ampicillin were purchased from RPI Corporation (Chicago, IL). Nickel-nitrilotriacetic acid agarose $\left(\mathrm{Ni}^{2+-} \mathrm{NTA}\right.$ agarose) was purchased from Qiagen (Valencia, CA). Plasmid Mini-Kits were from Fermentas (Glen Burnie, MD). All reagents for sodium dodecyl sulfate polyacrylamide gel electrophoresis (SDS-PAGE) and 10\% acrylamide/Tris- $\mathrm{HCl}$ precast gels were purchased from BioRad. SDS-PAGE analysis was carried out using $12 \%$ gels and visualized with Coomassie Brilliant Blue. DNA sequencing was carried out at the DNA sequencing core facility at Oregon Health and Sciences University (OHSU), Portland, OR. The LIC cloning kits containing the pET44a plasmid was from Novagen. Restriction endonucleases and T4 DNA ligase was purchased from 
New England Biolabs (Ipswich, MA). PCR primers were custom synthesized from Integrated DNA Technologies (Coralville, IA). PCR reactions were carried out with the GC Rich PCR System from Roche (Basel, Switzerland).

\subsubsection{Bacterial strains, plasmids, and growth conditions}

Luria-Bertani (LB) medium was used for growth of bacteria. The following antibiotics were added to the media when necessary: kanamycin $(50 \mathrm{~g} / \mathrm{ml})$, carbenicillin $(100 \mathrm{~g} / \mathrm{ml})$, chloramphenicol $(20 \mathrm{~g} / \mathrm{ml})$, streptomycin $(25 \mathrm{~g} / \mathrm{ml})$, and phleomycin $(50 \mathrm{~g} / \mathrm{ml})$.

\subsubsection{DNA manipulation}

DNA restriction and modifying enzymes were used as recommended by the manufacturer (New England Biolabs). Standard protocols were used for recombinant DNA techniques (Sambrook). DNA fragments were purified from agarose gels with the QIAquick purification kit (QIAGEN). Plasmids were prepared using a QIAprep spin miniprep kit (QIAGEN). Deep Vent DNA polymerase was used in all PCRs according to the supplier's instructions (New England Biolabs).

DNA sequencing was performed at the MMI core facility and at Primate Center, Oregon Health and Sciences University (Portland, OR). Primer design and analysis of DNA sequences was performed using MacVector (MacVector Inc., Cary, NC) and Accelrys DS gene (Accelrys Inc., San Diego, CA) software. 


\subsubsection{Instrumentation}

PCR was carried out on a Gene Amp PCR system 2400 from PerkinElmer Life Sciences. UV-Vis spectroscopy was performed with UV Shimadzu 1600. Centrifugation was carried out on an Avanti J- 20 centrifuge, an LE-80K Ultra centrifuge using a Ti-60 rotor, and a Model TJ 6 swinging bucket centrifuge, all from Beckman Coulter, Inc. SDS-PAGE was carried out on a mini Protean III from BioRad.

\subsubsection{Cloning, Expression and Purification of $\mathrm{PImT}_{4}$ Protein}

The plmT4 gene was amplified from genomic DNA via PCR and cloned with either N- or C-terminal His6-fusions using the following primers forward primer 5'CATATGTCACAGCTCTCGTCC-3 and reverse primer, 5'AAGCTTTCACCACGTGACGGG-3'. The primers contained the restriction sites (underlined) for NdeI and HindIII to allow directional cloning into a pET28a vector. Amplification of the gene for construction of the N-terminal fusion was followed by restriction digestion of the PCR product with NdeI/HindIII, gel purification (1\% agarose), and ligation into NdeI/HindIII digested pET28a using T4 DNA ligase to give pET28a-

plmT 4 . Plasmid DNA was isolated from all the constructs and the primary structure of the genes confirmed by sequencing. The plasmids containing plmT4 were transformed into $E$. coli BL21 (DE3) for expression of recombinant proteins. Cultures of transformed cells were 
grown at $37{ }^{\circ} \mathrm{C}$ in LB/kan with shaking (250 rpm) until an OD600 of 0.9 was obtained, IPTG was added to a final concentration of $0.25 \mathrm{mM}$, and the cells were grown for an additional $4 \frac{1}{2}$ hours. The cells were collected by centrifugation at 7,500g for 15 minutes at $4{ }^{\circ} \mathrm{C}$. The cells were stored at $-80{ }^{\circ} \mathrm{C}$ until needed. Frozen cell paste was suspended to 250 $\mathrm{mg} / \mathrm{mL}$ in $50 \mathrm{mM}$ HEPES (pH 7.0), $0.75 \mathrm{M} \mathrm{NaCl}, 2 \mathrm{mM} \beta \mathrm{ME}$, and $1 \mathrm{mM}$ PMSF. Lysozyme was added to a final concentration of $250 \mu \mathrm{g} / \mathrm{mL}$ and the cells incubated at 37 ${ }^{\circ} \mathrm{C}$ for 30 minutes, followed by 3 intervals of freeze thaw cycles. The cell lysate was centrifuged at $26,000 \mathrm{~g}$ for 30 minutes at $4{ }^{\circ} \mathrm{C}$, and the cell-free extract recovered and filtered $(0.45 \mu \mathrm{m} \mathrm{MCE})$. The CFE was loaded onto a column containing $\mathrm{Ni}^{2+-} \mathrm{NTA}$ agarose equilibrated in lysis buffer, and washed with 10 volumes of lysis buffer containing $25 \mathrm{mM}$ imidazole. The protein was eluted with $250 \mathrm{mM}$ imidazole in lysis buffer without. The eluant was concentrated to $2 \mathrm{~mL}$ using the Amicon Ultra YM-10. The fractions containing pure protein were pooled, exchanged with $50 \mathrm{mM}$ sodium phosphate buffer $\mathrm{pH} 7.2$ and stored in $20 \%$ glycerol at $-80{ }^{\circ} \mathrm{C}$.

\subsubsection{Cloning, Expression and Purification of PImT 5 Protein}

The plmT5 gene corresponding to a kinase was amplified from genomic DNA via PCR and cloned with $\mathrm{N}$-terminal using the following primer, forward primer 5'CATATGTATGTCGCCAAGTGC-3' (NdeI restriction site) and reverse primer, 5'AAGCTTTCACTCGTACTGGCG-3' (HindIII restriction site), Amplification of the gene for construction of the N-terminal fusion was followed by restriction digestion of the PCR 
product with NdeI/HindIII, gel purification (1\% agarose), and ligation into NdeI/HindIII digested pET28a using T4 DNA ligase to give pET28a-plmT 5 . The coding region of $\mathrm{plm} T_{5}$, was also amplified by primers were, 5'-GACGACGACAAGATGTATGTCGCCAA-3', 5'GAGGAGAAGCCCGGTCACTCGTACTG-3'. The 5' end of the primer incorporated ligation-independent cloning (LIC) sequences. The amplified product was ligated into the vector $\mathrm{pET}-44 \mathrm{Ek} / \mathrm{LIC}$ after being treated with LIC-qualified T4 DNA polymerase. Primers for amplification of plmT5 were designed for subsequent LIC cloning in pET44a with an N-terminal NusA Tag. Amplification of the gene was followed by the insertion of the PCR products into pET44a following the manufacturer's instructions to give $\mathrm{pET} 44-\mathrm{plmT}_{5}$. To analyze expression of the plmT5 genes cloned in pET28a and pET44a, cultures of transformed BL21 (DE3) were grown overnight in tubes containing LB medium and appropriate antibiotics. Cultures were diluted 1:50 and grown at $37^{\circ} \mathrm{C}$ to mid-log phase (0.4 to 0.6 OD600 unit $/ \mathrm{ml}$ ). Gene expression was induced with $0.5 \mathrm{mM} \mathrm{IPTG} \mathrm{(isopropyl-}$ D-thiogalactopyranoside), and cultures were grown for $6 \mathrm{~h}$ at the same temperature. Cells were harvested by centrifugation at $12,000 \mathrm{~g}$ for $20 \mathrm{~min}$, at $4{ }^{\circ} \mathrm{C}$. The $E$. coli cell pellets were suspended in lysis buffer $(50 \mathrm{mM}$ sodium phosphate buffer $\mathrm{pH} 7.2,300 \mathrm{mM} \mathrm{NaCl}$, 5mM 2-mercaptoethanol, 10\% glycerol, 0.05\% (v/v) Tween-20) with $10 \mathrm{mM}$ imidazole and lysozyme $\left(1 \mathrm{mg} \mathrm{mL}^{-1}\right)$. The resulting cell suspension was incubated on ice for $30 \mathrm{~min}$ and cell lysate was cleared by centrifugation at $16,000 \mathrm{~g}$ for $20 \mathrm{~min}$. For the protein cloned in pET28a, the crude cell extract was loaded onto a Ni-NTA resin column. His-tagged protein was eluted by using buffer-A with $300 \mathrm{mM}$ imidazole. The purified protein was 
analyzed by sodium dodecyl sulfate-polyacrylamide gel electrophoresis (SDS-PAGE) and visualized by staining with Coomassie blue

\subsubsection{Cloning, Expression and Purification of PImT8 Protein}

The gene plmT8 was amplified from 10B4 cosmid. To amplify plmT8, the following primers 5'-CATATGGCTAAGCGCTTCTCCACCATC-3' (NdeI restriction site) and reverse primer, 5'-AAGCTTTCAGAGCTCGTGGTTCCGGAG-3' (HindIII restriction site were used. The $p l m$ genes were cloned into expression vector pET28a to construct the plasmid pET28-plmT8. The $\operatorname{plmT8}$ gene was also cloned into pET44 a vector using the same procedure described previously. The generated plasmids named pET-8a-plmT 8 and pET-44-plmT 8 were then transformed into E.coli strain BL21 (D3) cells and the positive clones were confirmed by DNA sequencing. All plasmids were used to transform E. coli BL21 (DE3) cells. The resulting transformants were grown at $37{ }^{\circ} \mathrm{C}$ in $\mathrm{LB}$ medium containing either $50 \mu \mathrm{g} \mathrm{mL}^{-1}$ kanamycin (for pET28a transformants) or $100 \mu \mathrm{g} \mathrm{mL} \mathrm{m}^{-1}$ ampicillin (for pet44) to an $\mathrm{A}_{600}=0.6$, induced with $0.1 \mathrm{mM}$ isopropyl- $\beta$-Dthiogalactopyranoside, and incubated overnight. Cells were harvested by centrifugation at $12,000 \mathrm{~g}$ for $20 \mathrm{~min}$, at $4{ }^{\circ} \mathrm{C}$. The appropriate $E$. coli cell pellets were suspended in lysis buffer. A (50mM sodium phosphate buffer $\mathrm{pH} 7.2,300 \mathrm{mM} \mathrm{NaCl}, 5 \mathrm{mM} 2$ mercaptoethanol, $10 \%$ glycerol, $0.05 \%(\mathrm{v} / \mathrm{v})$ Tween-20) with $10 \mathrm{mM}$ imidazole and lysozyme $\left(1 \mathrm{mg} \mathrm{mL}^{-1}\right)$. The resulting cell suspension was incubated on ice for $30 \mathrm{~min}$ and cell lysate was cleared by centrifugation at $16,000 \mathrm{~g}$ for $20 \mathrm{~min}$. The crude cell extract was loaded onto a Ni-NTA resin column. The PlmT8 protein was eluted by using buffer-A with 
$300 \mathrm{mM}$ imidazole. Fractions containing pure protein were pooled, exchanged with $50 \mathrm{mM}$ sodium phosphate buffer $\mathrm{pH} 7.2$ and stored in $20 \%$ glycerol at $-80{ }^{\circ} \mathrm{C}$.

\subsubsection{Conversion of PLM 1 to PLM 2 in vitro}

The gene plmT4 encodes a cytochrome P450 monooxygenase (CYP450). The enzyme is likely to be responsible for C-8 and C-25 hydroxylation of the PLM PKS product. We believe that PLM 1, is one the first intermediates and a substrate for PlmT 4 . Enzymatic conversion of PLM 1 to PLM 2 was be monitored by HPLC assy. The purified $\mathrm{plmT}_{4}(0.3$ $\mu \mathrm{M})$ was incubated in a conversion buffer with PLM $1(100 \mu \mathrm{M})$, spinach ferredoxin (50 $\mu \mathrm{g})$, ferredoxin NADP reductase $(0.1 \mathrm{U})$, NADP $(1 \mu \mathrm{mol})$, NADPH+ $(1 \mu \mathrm{mol})$, glucose-6phosphate $(10 \mu \mathrm{mol})$ and glucose-6-phosphate dehydrogenase $(1 \mathrm{U})$ in a reaction volume

of one $\mathrm{ml}$ at $30^{\circ} \mathrm{C}$ for 30 minutes. NADP+, glucose-6-phosphate and glucose-6-phosphate dehydrogenase will be added as an "NADPH regenerating system. Simultaneous enzyme and substrate controls were run. An aliquot of reaction was be injected on HPLC to detect PLM 2 formation. The identity of PLM 2 was assayed by mass spectrometry.

\subsection{RESULTS AND DISCUSSION}

\subsubsection{Characterization of the CYP450 in vitro by heterologous expression in E.coli}

To investigate the function of $\mathrm{PlmT}_{4}$ in the PLM biosynthesis pathway, an enzyme activity assay was performed in vitro. First, a $\mathrm{PlmT}_{4}$ heterologous expression system was constructed on pET28a and introduced into E.coli BL 21 to produce target protein .The 
expression plasmid was confirmed by sequencing and the target protein was purified as descried in the experimental procedures and analyzed by SDS-PAGE analysis. The SDSPAGE analysis revealed the presence of a significant quantity of a soluble protein of 46 $\mathrm{kDa}$ (Figure 26 lane 7-9), which was consistent with the predicted molecular mass of $\mathrm{plmT}_{4}$ (44 kDa) and the hexahistidine tag $(2 \mathrm{kDa})$. This band was absent in the control culture. $\mathrm{PlmT}_{4}$ was purified as a His-tagged protein by affinity chromatography on a Ni-NTA agarose column. The typical yields of purified $\mathrm{PlmT}_{4}$ were $408-600 \mu \mathrm{g} / \mathrm{mL}$.

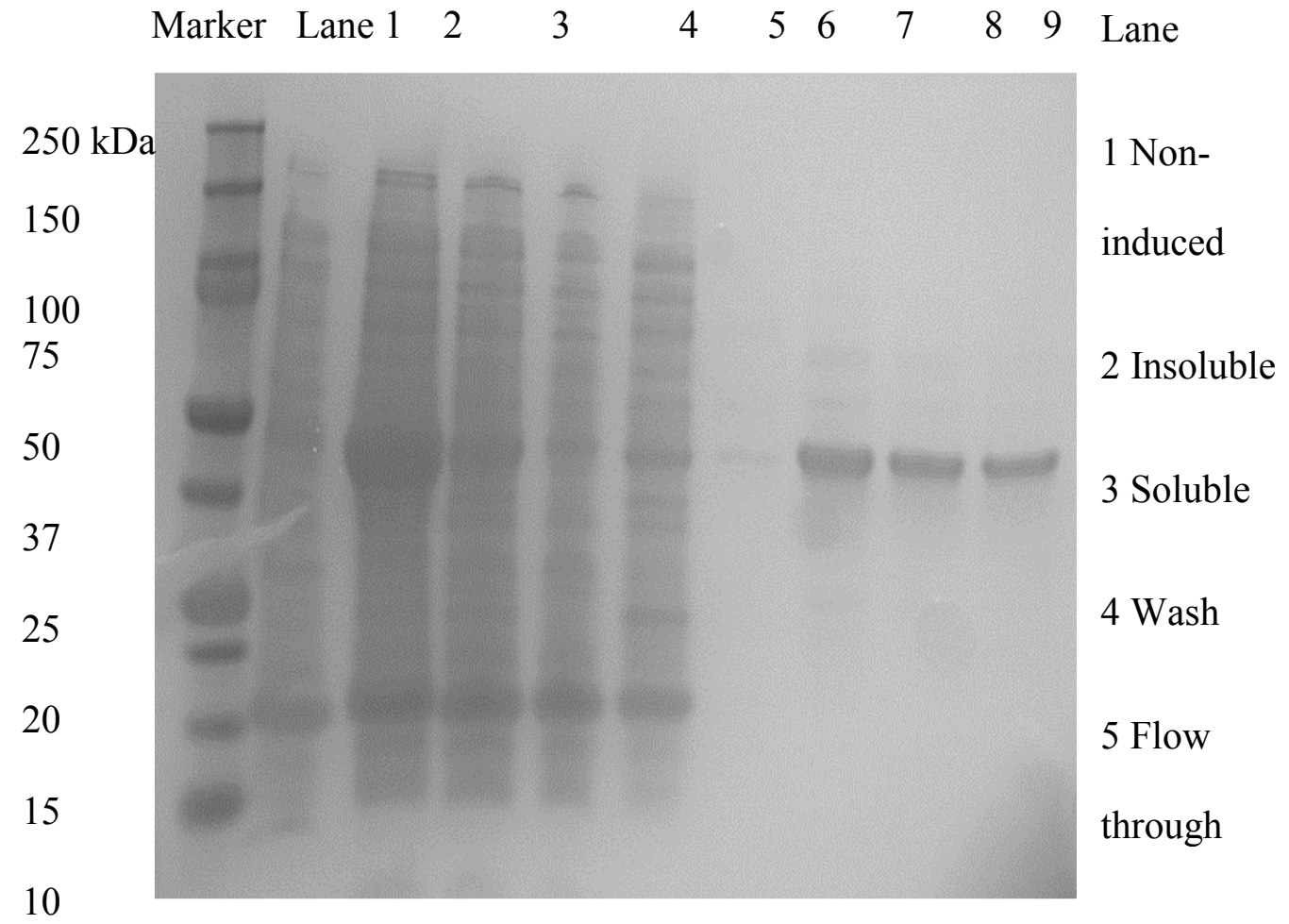

Figure 26. (A) SDS-PAGE of purified $\mathrm{PlmT}_{4}$ protein 
The eluted $\mathrm{PlmT}_{4}$ protein was brick red in color (Appendix Figure 34A). The term P450 is derived from the spectrophotometric peak at the wavelength of the absorption maximum of the enzyme $(450 \mathrm{~nm})$ when it is in the reduced state and complexes with CO. The UVvisible absorption spectrum of the spectrum of the purified protein shows a characteristic 390 to 450nm CYP spectrum (Figure 27). The absorbance increased as the concentration of increased, as shown in Figure 27

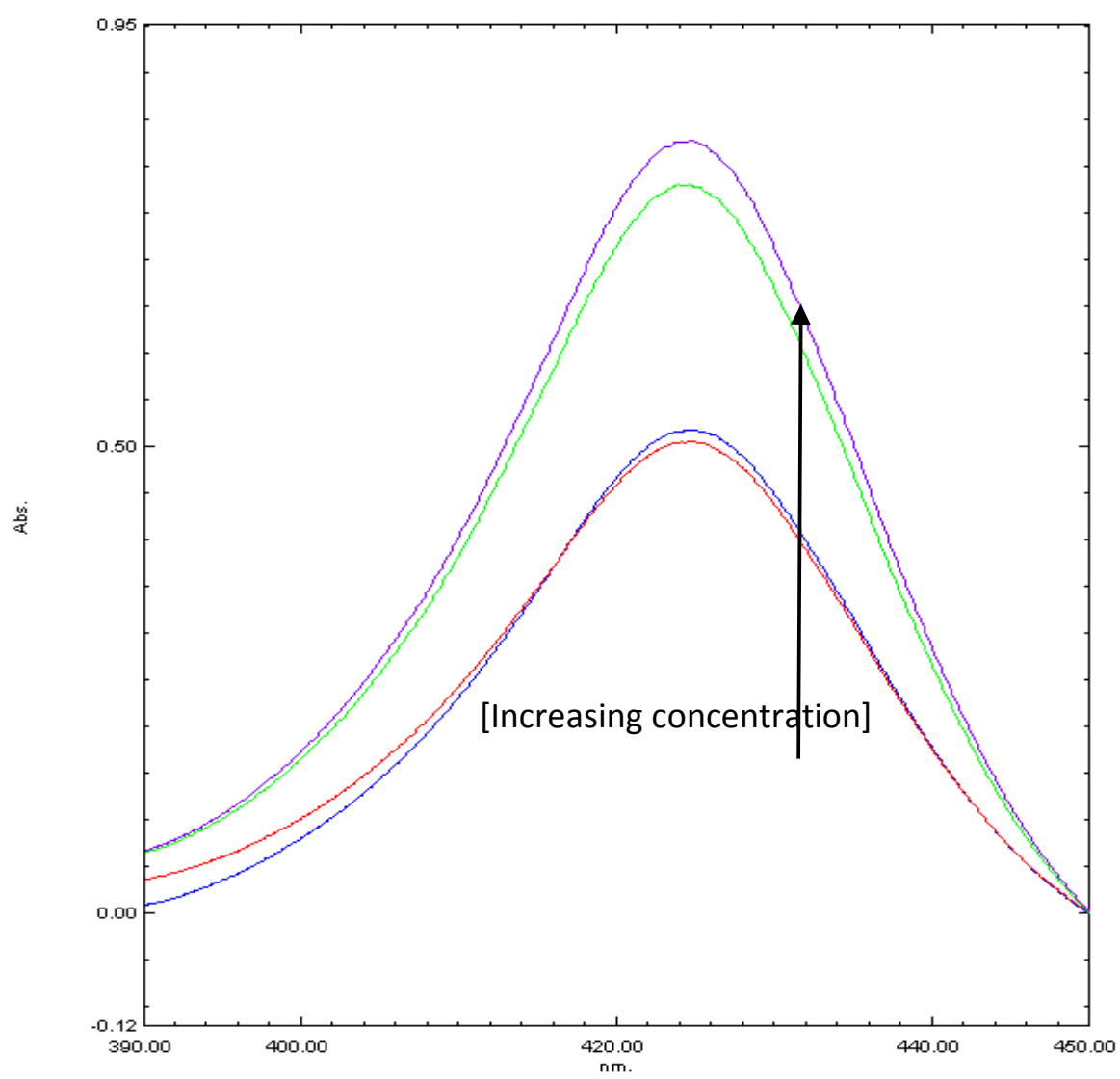

Figure 27. UV-Visible absorption spectrum of purified $\mathrm{PlmT}_{4}$ 
The recombinant PlmT4 was shown to catalyze a complete conversion of PLM 1 to PLM 2 as shown in Figure 28. It is noteworthy that the hydrolyzed-PLM 2 product was observed under these reaction conditions, this lactone likely opens under basic conditions. The MS for PLM 1 only is shown in Figure 29. The likely identity of PLM 2 was assessed by MS and the analysis revealed that the new product, m/z of 453 and 475 as shown in Figure 30, consistent with the addition of two oxygen atoms to PLM 1. Control reaction is shown in Figure 31. This result supports the hypothesis that $\mathrm{PlmT}_{4}$ is likely to be responsible for the hydroxylation of C-8 and C-25.

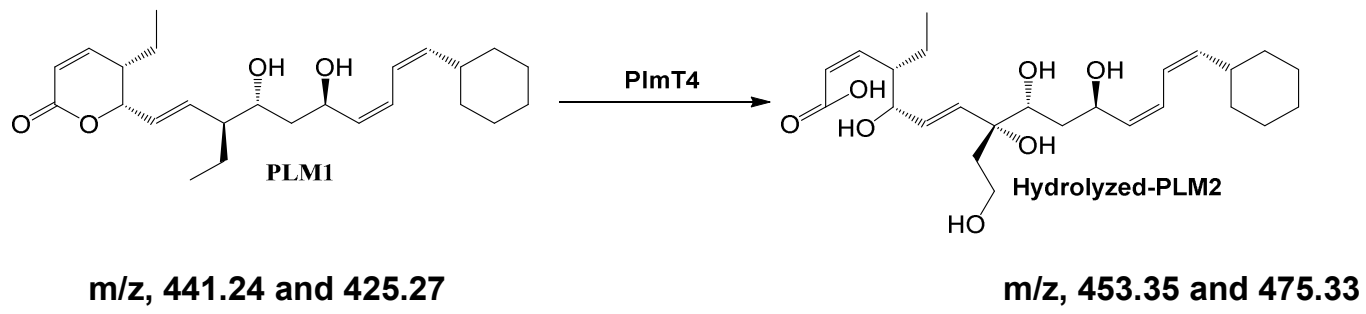

Figure 28. In vitro conversion of PLM 1 to PLM 2 


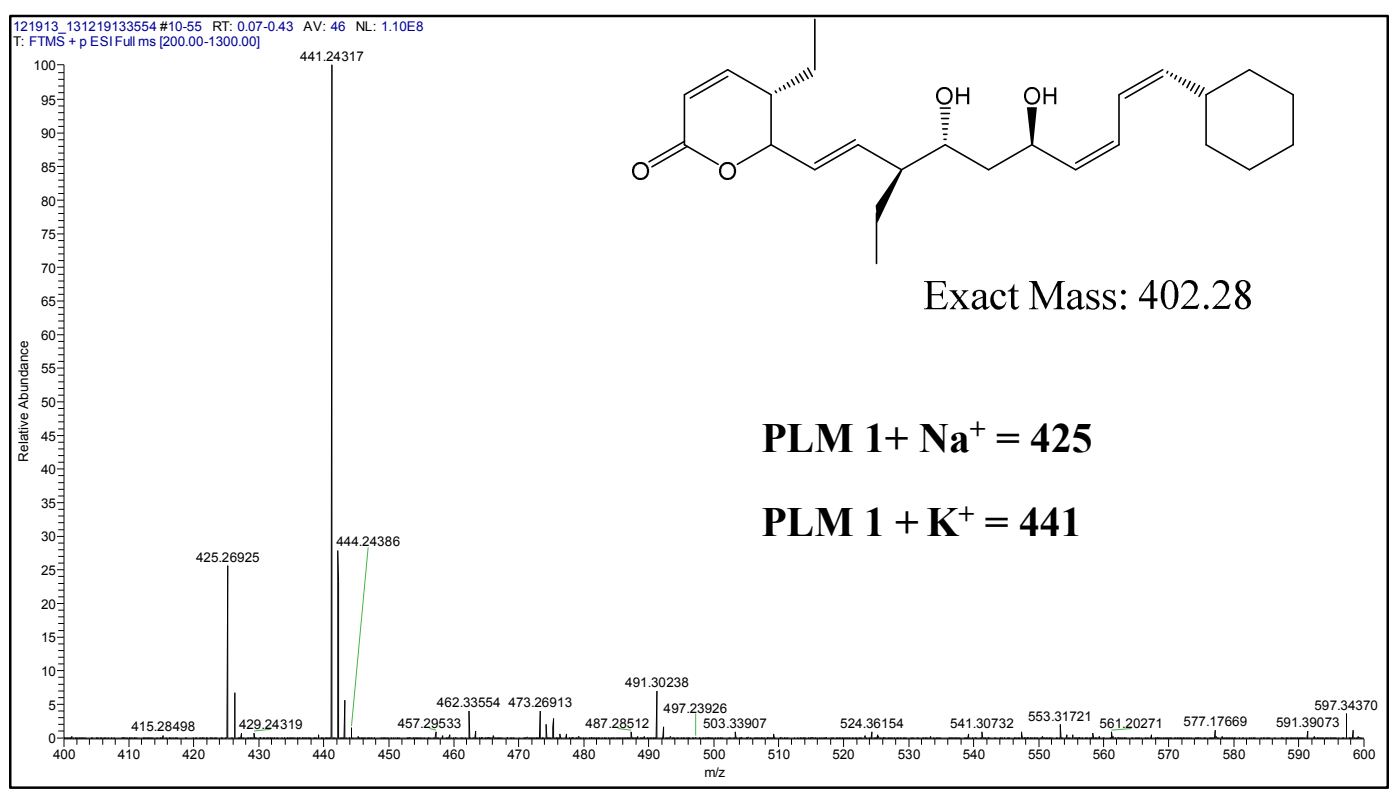

Figure 29. $\mathrm{ES}^{+} \mathrm{MS}$ analysis of purified of PLM 1, m/z 425 and 441 


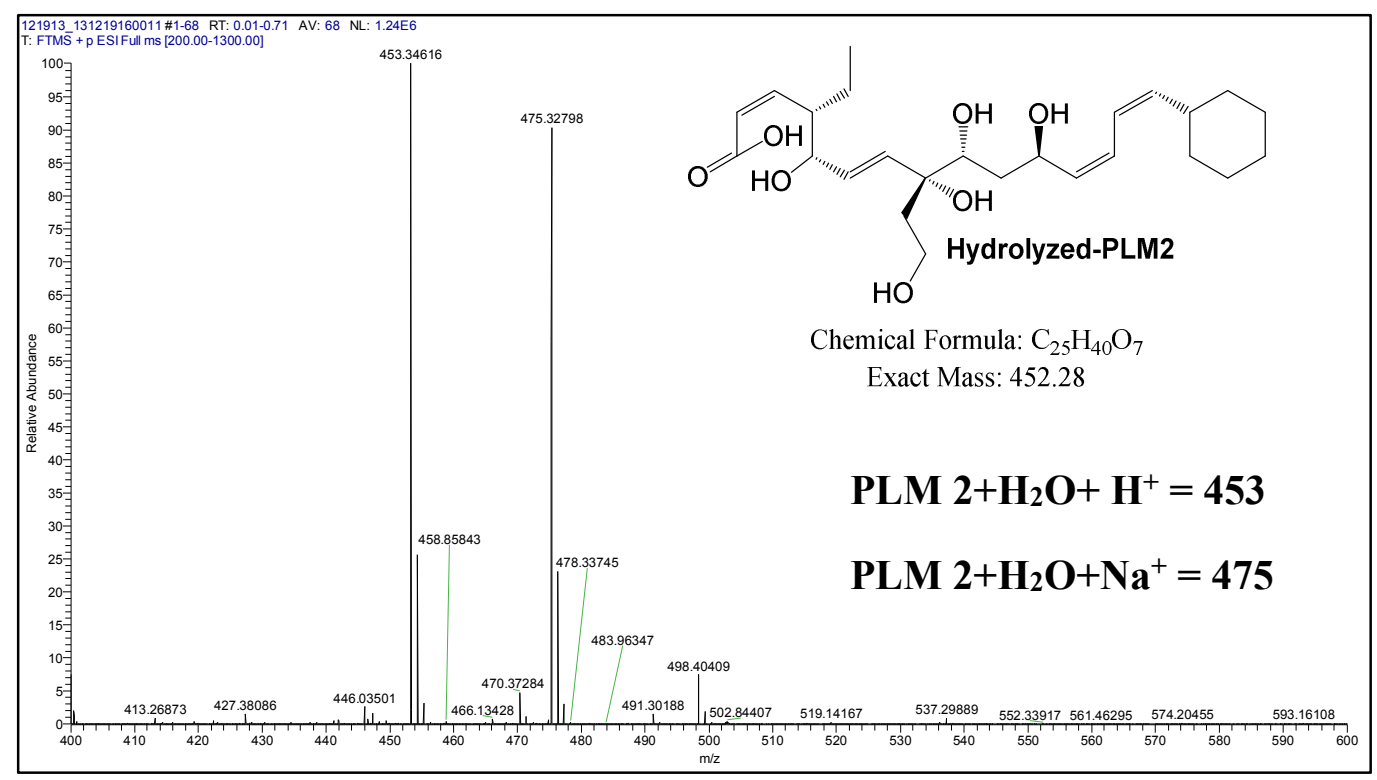

Figure 30. $\mathrm{ES}^{+} \mathrm{MS}$ analysis of PLM 1 conversion reaction,m/z 453 and 475

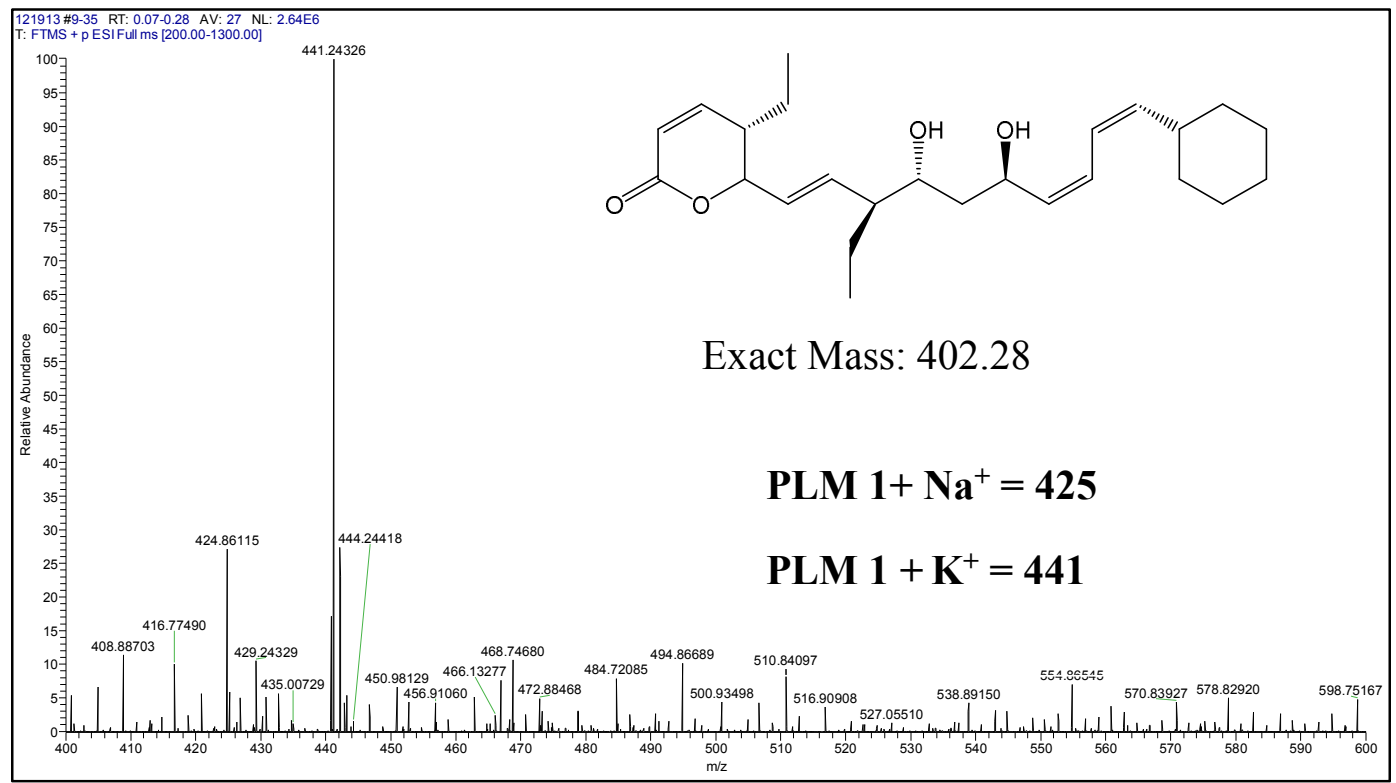

Figure 31. $\mathrm{ES}^{+} \mathrm{MS}$ analysis of the enzyme control reaction (without enzyme), $\mathrm{m} / \mathrm{z} 441$ 


\subsubsection{Purification of PImTs}

The $1716 \mathrm{bp}$ plmT8 ORF was cloned into prokaryotic expression vector $\mathrm{pET} 28 \mathrm{a}$ and $\mathrm{PlmT}_{8}$ was expressed as a soluble N-terminal polyhistidine tagged protein in E. coli ArcticExpressTM (DE3) cells. ArcticExpressTM competent cells are engineered to address the common bacterial gene expression hurdle of protein insolubility and competent cells have been engineered for improved protein processing at low temperatures. SDS-PAGE analysis of cell extracts grown under IPTG induction conditions revealed the presence of a significant quantity of a soluble protein of $62 \mathrm{kDa}$, which was consistent with the predicted molecular mass $61 \mathrm{kDa}$ of $\mathrm{PlmT}_{8}$ (Figure 32 lane 7). This band was absent in the control culture. 


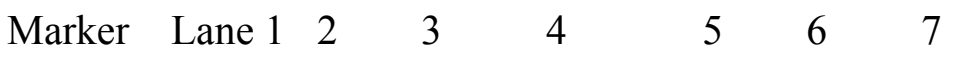

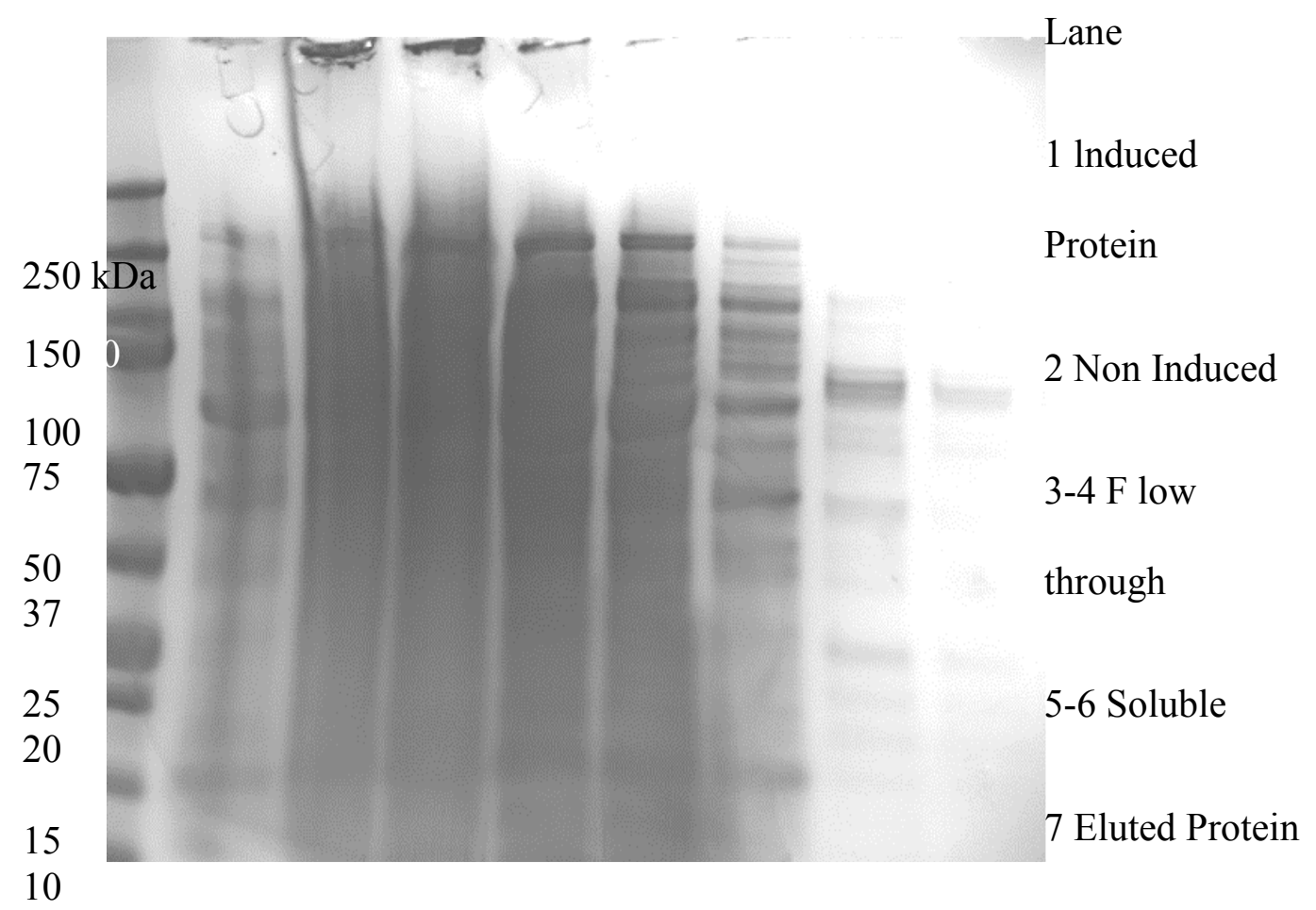

Figure 32. SDS-PAGE of purified $\mathrm{Plm} \mathrm{T}_{8}$ protein

\subsubsection{Purification of PlmT5}

$\mathrm{PlmT}_{5}$ was expressed as a fusion protein. The final $\mathrm{pET}-44-\mathrm{plmT}_{5}$ construct was able to express the recombinant protein as fusion protein with fusion tag consisting of the NusA protein, polyhistidine and S-peptide. The Nus-A protein increases the proportion of the soluble protein when expressed as a fusion partner. After induction of IPTG E.coli BL21 (D3) transformed with pET44-plmT 5 produces a fusion protein of approximately which 
contained a Nus-His-Tag of $57.8 \mathrm{kDa}$. With the fusion tag, the expressed $\mathrm{plmT}_{5}$ protein can be purified by either $\mathrm{Ni}^{2}+$ or S-protein affinity chromatography. Both Ni-NTA and Sprotein affinity chromatography were applied for the purification of pET44-plmTs. The size of the fusion matched well with its theoretical weight which is $88 \mathrm{kDa}$ (Lane 1). Meanwhile the pET-44-plmT 5 was also engineered to express an enterokinase and a thrombin cleavage site so that the encoded fusion sequence can be removed from the purified $\mathrm{PlmT}_{5}$ protein The target protein $\mathrm{PlmT}_{5}$ was easily released from S-protein agarose following digestion with a substantial quantity of thrombin, which appeared as a single band on SDS-PAGE with a mass consistent with the theoretical weight of $25 \mathrm{kDa}$ as shown in Figure 33 (lane 4- 6) 


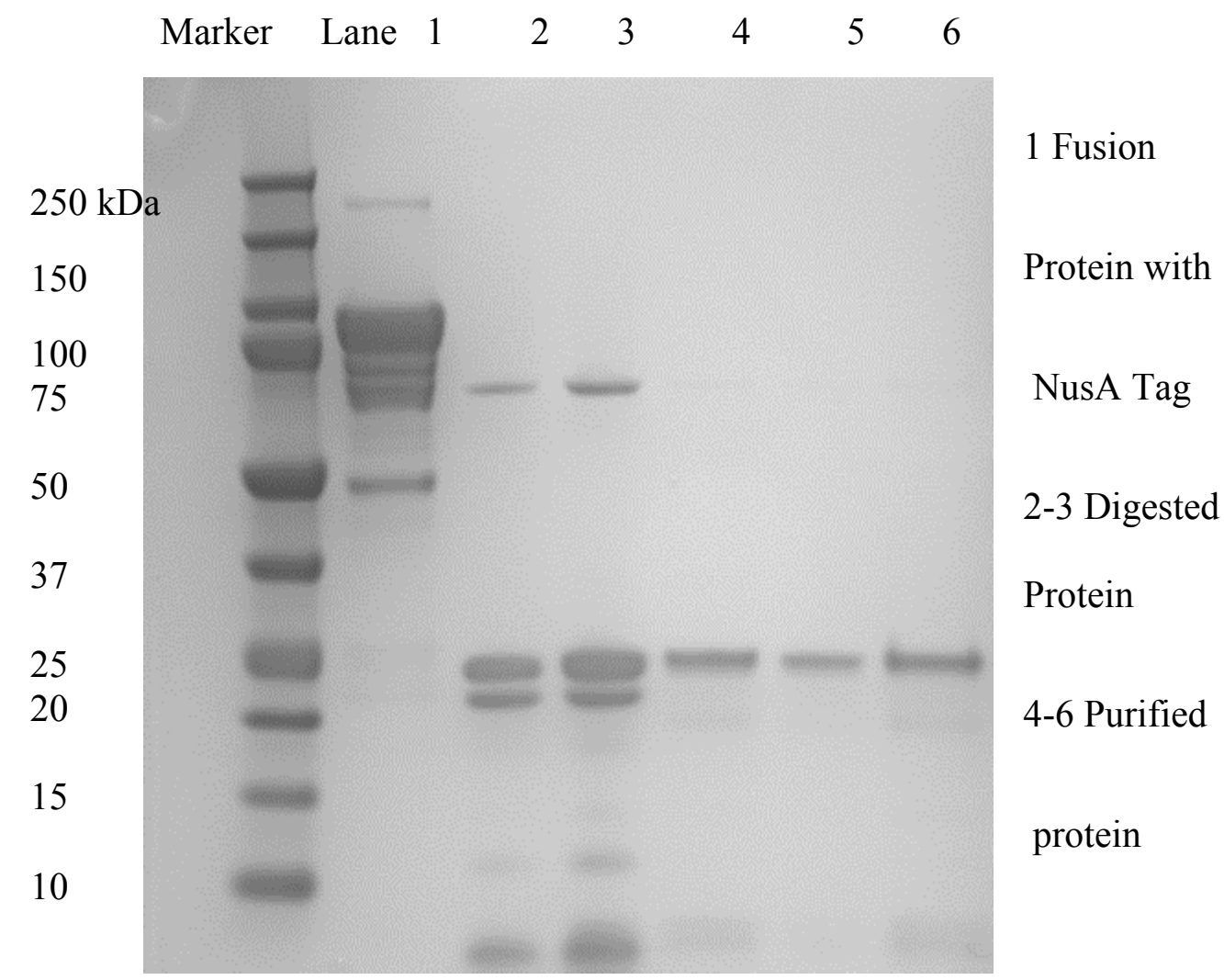

Figure 33. SDS-PAGE of purified $\mathrm{Plm} \mathrm{T}_{5}$ protein 


\section{CHAPTER 5. CONCLUSION AND FUTURE DIRECTION}

\subsection{CONCLUSION AND RECOMMENDATION FOR FUTURE WORK}

The phoslactomycin gene cluster consists of 29 ORFs encoding seven modular type 1 polyketide designated (plm1 through plm 7) and tailoring enzymes ${ }^{28}$. Structurally, the natural phoslactomycin has varying functionalities that are absent from the molecule generated from PKS, including three hydroxyl groups at $\mathrm{C}-8$ and $\mathrm{C}-18$ positions, a phosphoryl group at C-9, an amine group at C-25 and an unsaturated bond at the $\mathrm{C} 2-\mathrm{C} 3$ site. After PKS elongation and liberation from PKS by the TE enzyme, the nascent PKS chain undergoes some or all of the normal post-polyketide synthase tailoring steps that are typically associated with phoslactomycin natural product such as hydroxylation, phosphorylation and others. The work presented in this thesis describes the initial postPKS tailoring steps in the biosynthesis of phoslactomycin. It also provides valuable insights into the in vivo roles of key enzymes involved in the biosynthesis of phoslactomycin.

The first steps of the post-PKS tailoring steps in the phoslactomycin pathway were analyzed using in vivo or in vitro analyses of selected genes by targeted gene replacement and enzyme activity assays. The observation of M-PLM 1 and M-PLM 2 from the plmT4 and plmT8 deletion mutants suggest that the malonic acid is linked to the PKS chain at the last module of plm cluster (module 7) during PKS elongation, most likely it precedes the release of the full length polyketide intermediate from PLM-PKS. The observation of malonylated products also suggests that modification steps can occur on an intermediate 
with a C-3 malonyl group on it, suggesting that decarboxylation elimination by $\mathrm{PlmT}_{2}$ is likely to occur later in the post-PKS modification steps of phoslactomycin. The cis- $\Delta^{2,3}$ double bond formation might even be the last step in the post-PKS tailoring of phoslactomycin biosynthesis to yield phoslactomycin. At this point, when or how the malonylation occurs in the PLM biosynthetic process remains a mystery. Future work is required to unveil this mystery.

The isolation of PLM 1 from the plmT4 mutant strain indicates that PLM 1 is likely to be the first intermediate and a substrate of $\mathrm{PlmT}_{4}$ enzyme. This enzyme is the only other $\mathrm{P} 450$ monooxygenase encoded by the phoslactomycin biosynthetic gene cluster. Based on gene replacement and in vitro enzyme activity assay, $\mathrm{Plm} \mathrm{T}_{4}$ is likely to be responsible for $\mathrm{C}-8$ and C-25 hydroxylation of the PLM-PKS product. Further characterization of the isolated intermediate is needed using spectroscopic analyses such as 2D NMR to further confirm the linking of carbon to carbon bonds and carbon to protons bonds. For example the 2D HSQCED spectra of PLM 1 will confirm how the protons are attached to carbons. PLMs were first identified based on their potent antifungal activity against a range of phytopathogenic fun. The potent activity of the isolated intermediate PLM 1 can also be tested. Activities against Aspergillus oryzae, Pyricularia oryzaei and Aspergillus fumigatus is worth reporting in future.

The accumulation of the several PLM 2 products in the $p \operatorname{lm} T 8$ mutant strain suggested that plmT8 gene is likely to be responsible for the oxidation of the C-25 hydroxyl group to the 
corresponding aldehyde. Further work includes isolating the observed intermediates and characterization using NMR and carrying out in vitro enzyme assays.

The observation of phosphorylated products in the plmT8 mutant strain suggests that the proposed phosphorylation catalyzed by $\mathrm{PlmT}_{5}$ kinase can occur early in the step in the phoslactomycin pathway. Future work includes studying and analyzing the product profile of the plmT5 mutant strain to further analyze the stage at which phosphorylation occur in the pathway.

The tailoring enzymes expressed and purified in this study also sets the stage for determining the ordering steps of the post-PKS tailoring steps. The enzyme are used for characterization of the pathway by carrying out detailed in vitro enzyme assays, like determining reaction rates of isolated intermediate with proposed substrates, understanding and analyzing substrate specificity as well. Other studies that can be done using the enzymes if necessary is carrying out x-ray crystallography. This will provide a more comprehensive understanding of the interaction of proteins with the substrates. Tailoring enzymes also presents another variable that can impact structural diversity in modular PKS. So studying the enzymes may offer an opportunity to modify the structure of existing natural product based drugs to improve their activity, stability and pharmacokinetic properties.

The results obtained in this study pave the way for the complete elucidation of the postPKS tailoring steps in the phoslactomycin biosynthesis pathway. It is worth mentioning that the ordering steps may not be absolute, there may be parallel pathways, and for 
example phosphorylation and decarboxylation elimination may occur on several intermediates. The data obtained in this study sets the stage for understanding the mechanisms that build these structurally unique and pharmaceutically important agents and contributes to the general field of combinatorial biosynthesis. 


\subsection{REFERENCES}

1. Davies, J.; Davies, D., Origins and evolution of antibiotic resistance. In Microbiol Mol Biol Rev, United States, 2010; Vol. 74, pp 417-33.

2. Sevillano, L.; Díaz, M.; Santamaría, R. I., Stable expression plasmids for Streptomyces based on a toxin-antitoxin system. Microb Cell Fact 2013, 12, 39.

3. Drews, J., Drug Discovery: A Historical Perspective. Science 2000, 287 (5460), 1960-1964.

4. D, B. A.; S, B. M., Natural product Chemistry for Drug Discovery. 2010.

5. de Lima Procópio, R. E.; da Silva, I. R.; Martins, M. K.; de Azevedo, J. L.; de Araújo, J. M., Antibiotics produced by Streptomyces. The Brazilian Journal of Infectious Diseases 2012, 16 (5), 466-471.

6. Waugh, A. C.; Long, P. F., Prospects for generating new antibiotics. Sci Prog 2002, 85 (Pt 1), 73-88.

7. Matseliukh, A. B., [Streptomycetes--producers of polyketide antibiotics]. Mikrobiol Z 2003, 65 (1-2), 168-81.

8. Weissman, K. J., Polyketide biosynthesis: understanding and exploiting modularity. Philos Transact A Math Phys Eng Sci 2004, 362 (1825), 2671-90.

9. Mo, S.; Kim, D. H.; Lee, J. H.; Park, J. W.; Basnet, D. B.; Ban, Y. H.; Yoo, Y. J.; Chen, S. W.; Park, S. R.; Choi, E. A.; Kim, E.; Jin, Y. Y.; Lee, S. K.; Park, J. Y.; Liu, Y.; Lee, M. O.; Lee, K. S.; Kim, S. J.; Kim, D.; Park, B. C.; Lee, S. G.; Kwon, H. J.; Suh, J. W.; Moore, B. S.; Lim, S. K.; Yoon, Y. J., Biosynthesis of the allylmalonyl-CoA extender unit for the FK506 polyketide synthase proceeds through a dedicated polyketide synthase and facilitates the mutasynthesis of analogues. $\mathrm{J} \mathrm{Am}$ Chem Soc 2011, 133 (4), 976-85.

10. Amnuaykanjanasin, A.; Punya, J.; Paungmoung, P.; Rungrod, A.; Tachaleat, A.; Pongpattanakitshote, S.; Cheevadhanarak, S.; Tanticharoen, M., Diversity of type I polyketide synthase genes in the wood-decay fungus Xylaria sp. BCC 1067. FEMS Microbiol Lett 2005, 251 (1), 125-36.

11. Weber, T.; Welzel, K.; Pelzer, S.; Vente, A.; Wohlleben, W., Exploiting the genetic potential of polyketide producing streptomycetes. J Biotechnol 2003, 106 (2-3), 221-32; Menzella, H. G.; Reeves, C. D., Combinatorial biosynthesis for drug development. Curr Opin Microbiol 2007, 10 (3), 238-45.

12. Peirú, S.; Menzella, H. G.; Rodríguez, E.; Carney, J.; Gramajo, H., Production of the potent antibacterial polyketide erythromycin C in Escherichia coli. Appl Environ Microbiol 2005, 71 (5), 2539-47. 
13. Ghatge, M. S.; Palaniappan, N.; Alhamadsheh, M. M.; DiBari, J.; Reynolds, K. A., Application of a newly identified and characterized 18-o-acyltransferase in chemoenzymatic synthesis of selected natural and nonnatural bioactive derivatives of phoslactomycins. Appl Environ Microbiol 2009, 75 (11), 3469-76.

14. Van Lanen, S. G.; Shen, B., Advances in polyketide synthase structure and function. Curr Opin Drug Discov Devel 2008, 11 (2), 186-95.

15. Shen, B., Polyketide biosynthesis beyond the type I, II and III polyketide synthase paradigms. Curr Opin Chem Biol 2003, 7 (2), 285-95.

16. Moore, B. S.; Piel, J., Engineering biodiversity with type II polyketide synthase genes. Antonie Van Leeuwenhoek 2000, 78 (3-4), 391-8.

17. Shen, B., Polyketide biosynthesis beyond the type I, II and III polyketide synthase paradigms. Current Opinion in Chemical Biology 2003, 7 (2), 285-295.

18. Donadio, S.; Sosio, M., Strategies for combinatorial biosynthesis with modular polyketide synthases. Comb Chem High Throughput Screen 2003, 6 (6), 489-500.

19. Staunton, J.; Weissman, K. J., Polyketide biosynthesis: a millennium review. Nat Prod Rep 2001, 18 (4), 380-416.

20. Anand, S.; Prasad, M. V.; Yadav, G.; Kumar, N.; Shehara, J.; Ansari, M. Z.; Mohanty, D., SBSPKS: structure based sequence analysis of polyketide synthases. Nucleic Acids Res 2010, 38 (Web Server issue), W487-96.

21. Palaniappan, N.; Alhamadsheh, M. M.; Reynolds, K. A., cis-Delta(2,3)-double bond of phoslactomycins is generated by a post-PKS tailoring enzyme. J Am Chem Soc 2008, 130 (37), 12236-7.

22. Liu, X.-j.; Kong, R.-x.; Niu, M.-s.; Qiu, R.-g.; Tang, L., Identification of the Post-Polyketide Synthase Modification Enzymes for Fostriecin Biosynthesis in Streptomyces pulveraceus. Journal of Natural Products 2013, 76 (4), 524-529.

23. Olano, C.; Méndez, C.; Salas, J. A., Post-PKS tailoring steps in natural product-producing actinomycetes from the perspective of combinatorial biosynthesis. Nat Prod Rep 2010, 27 (4), 571-616.

24. Wohlleben, W.; Spellig, T.; M*ller-Tiemann, B., Biocombinatorial approaches for drug finding. Springer: Berlin ; New York, 2005; p xviii, 284 p.

25. Kong, R.; Liu, X.; Su, C.; Ma, C.; Qiu, R.; Tang, L., Elucidation of the Biosynthetic Gene Cluster and the Post-PKS Modification Mechanism for Fostriecin in Streptomyces pulveraceus. Chemistry \& Biology 20 (1), 45-54. 
26. Ghatge, M.; Palaniappan, N.; Das Choudhuri, S.; Reynolds, K., Genetic manipulation of the biosynthetic process leading to phoslactomycins, potent protein phosphatase 2A inhibitors. $J$ Ind Microbiol Biotechnol 2006, 33 (7), 589-99.

27. Sekiyama, Y.; Palaniappan, N.; Reynolds, K. A.; Osada, H., Biosynthesis of phoslactomycins: cyclohexanecarboxylic acid as the starter unit. Tetrahedron 2003, 59 (38), 7465-7471.

28. Palaniappan, N.; Kim, B. S.; Sekiyama, Y.; Osada, H.; Reynolds, K. A., Enhancement and selective production of phoslactomycin $\mathrm{B}$, a protein phosphatase lla inhibitor, through identification and engineering of the corresponding biosynthetic gene cluster. J Biol Chem 2003, 278 (37), 35552-7.

29. Ghatge, M. S.; Reynolds, K. A., The plmS2-encoded cytochrome P450 monooxygenase mediates hydroxylation of phoslactomycin B in Streptomyces sp. strain HK803. J Bacteriol 2005, $187(23), 7970-6$.

30. Kotowska, M., [Application of molecular biology for the discovery of biosynthetic genes of polyketide and peptide antibiotics produced by actinomycetes]. Postepy Biochem 2005, 51 (3), 345-52.

31. Julien, B.; Shah, S.; Ziermann, R.; Goldman, R.; Katz, L.; Khosla, C., Isolation and characterization of the epothilone biosynthetic gene cluster from Sorangium cellulosum. Gene 2000, 249 (1-2), 153-160.

32. Salas, J. A.; Méndez, C., Engineering the glycosylation of natural products in actinomycetes. Trends in Microbiology 2007, 15 (5), 219-232; Prado, L.; Fernandez, E.; Weissbach, U.; Blanco, G.; Quiros, L. M.; Brana, A. F.; Mendez, C.; Rohr, J.; Salas, J. A., Oxidative cleavage of premithramycin $B$ is one of the last steps in the biosynthesis of the antitumor drug mithramycin. In Chem Biol, England, 1999; Vol. 6, pp 19-30.

33. Silakowski, B.; Schairer, H. U.; Ehret, H.; Kunze, B.; Weinig, S.; Nordsiek, G.; Brandt, P.; Blöcker, H.; Höfle, G.; Beyer, S.; Müller, R., New lessons for combinatorial biosynthesis from myxobacteria. The myxothiazol biosynthetic gene cluster of Stigmatella aurantiaca DW4/3-1. J Biol Chem 1999, 274 (52), 37391-9.

34. Roman, G. G.; Kathrin, B.; Thorsten, W., Site-Directed Mutagenesis Using Oligonucleotide-Based Recombineering. 2013.

35. Gust, B.; Challis, G. L.; Fowler, K.; Kieser, T.; Chater, K. F., PCR-targeted Streptomyces gene replacement identifies a protein domain needed for biosynthesis of the sesquiterpene soil odor geosmin. Proceedings of the National Academy of Sciences of the United States of America 2003, 100 (4), 1541-1546.

36. Rix, U.; Fischer, C.; Remsing, L. L.; Rohr, J., Modification of post-PKS tailoring steps through combinatorial biosynthesis. Nat Prod Rep 2002, 19 (5), 542-80. 
37. Madduri, K.; Torti, F.; Colombo, A. L.; Hutchinson, C. R., Cloning and sequencing of a gene encoding carminomycin 4-O-methyltransferase from Streptomyces peucetius and its expression in Escherichia coli. J Bacteriol 1993, 175 (12), 3900-4.

38. Scheich, C.; Kümmel, D.; Soumailakakis, D.; Heinemann, U.; Büssow, K., Vectors for coexpression of an unrestricted number of proteins. Nucleic Acids Research 2007, 35 (6), e43.

39. Esposito, D.; Chatterjee, D. K., Enhancement of soluble protein expression through the use of fusion tags. Curr Opin Biotechnol 2006, 17 (4), 353-8.

40. Baneyx, F., Recombinant protein expression in Escherichia coli. Current Opinion in Biotechnology 1999, 10 (5), 411-421.

41. Hannig, G.; Makrides, S. C., Strategies for optimizing heterologous protein expression in Escherichia coli. Trends in Biotechnology 1998, 16 (2), 54-60.

42. Sassenfeld, H. M., Engineering proteins for purification. Trends Biotechnol 1990, 8 (4), 88-93.

43. Waugh, D. S., Reprint of: Making the most of affinity tags. Protein Expr Purif 2011.

44. Falke, J. J.; Corbin, J. A., Affinity Tags for Protein Purification. In Encyclopedia of Biological Chemistry, Lane, W. J. L. D., Ed. Academic Press: Waltham, 2013; pp 61-65.

45. Duong-Ly, K. C.; Gabelli, S. B., Affinity Purification of a Recombinant Protein Expressed as a Fusion with the Maltose-Binding Protein (MBP) Tag. In Methods in Enzymology, Academic Press.

46. An, Y. D.; Du, Q. Z.; Tong, L. Y.; Yu, Z. W.; Gong, X. W., Cloning, expression and purification of penicillin-binding protein 3 from Pseudomonas aeruginosa CMCC 10104. Protein Expression and Purification 2015, 110 (0), 37-42.

47. Meunier, B.; de Visser, S. P.; Shaik, S., Mechanism of oxidation reactions catalyzed by cytochrome p450 enzymes. Chem Rev 2004, 104 (9), 3947-80.

48. Mansuy, D., The great diversity of reactions catalyzed by cytochromes P450. Comp Biochem Physiol C Pharmacol Toxicol Endocrinol 1998, 121 (1-3), 5-14.

49. Betlach, M. C.; Kealey, J. T.; Ashley, G. W.; McDaniel, R., Characterization of the macrolide P-450 hydroxylase from Streptomyces venezuelae which converts narbomycin to picromycin. Biochemistry 1998, 37 (42), 14937-42.

50. Xue, Y.; Sherman, D. H., Biosynthesis and combinatorial biosynthesis of pikromycinrelated macrolides in Streptomyces venezuelae. Metab Eng 2001, 3 (1), 15-26.

51. Cole, T. R.; Igumenova, T. I., Expression and purification of the N-terminal regulatory domain of Protein Kinase C for biophysical studies. Protein Expression and Purification 2015, 110 (0), 14-21. 
52. Lewy, D. S.; Gauss, C. M.; Soenen, D. R.; Boger, D. L., Fostriecin: chemistry and biology. Curr Med Chem 2002, 9 (22), 2005-32.

53. Chen, Y. L.; Zhao, J.; Liu, W.; Gao, J. F.; Tao, L. M.; Pan, H. X.; Tang, G. L., Identification of phoslactomycin biosynthetic gene clusters from Streptomyces platensis SAM-0654 and characterization of PnR1 and PnR2 as positive transcriptional regulators. Gene 2012, 509 (2), 195-200. 


\subsection{APPENDIX}

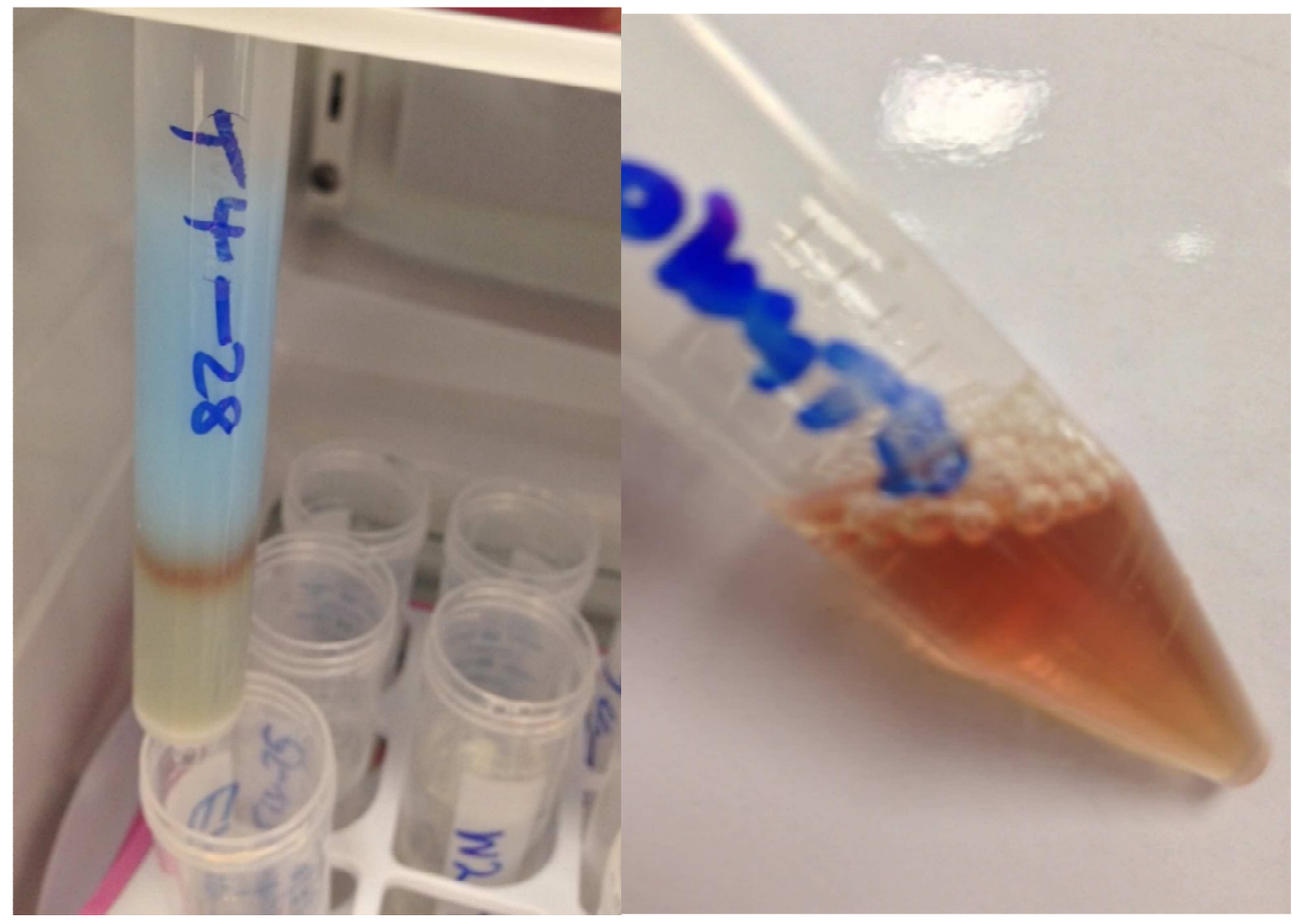

Figure 34 A. Purified $\mathrm{PlmT}_{4}$ protein 